The Poetics of Action:

LearningToLoveYouMore.com and Participatory Art-making Practices

\author{
by \\ Katherine McIntyre, B.Hum. \\ A thesis submitted to the Faculty of Graduate Studies and Research \\ in partial fulfilment of the requirements for the degree of \\ Master of Arts \\ in Art History: Art and Its Institutions
}

Carleton University

Ottawa, Ontario

December 1, 2009

(C) 2009 Katherine McIntyre 

Library and Archives
Canada

\section{Published Heritage} Branch

395 Wellington Street Ottawa ON K1A ON4 Canada
Bibliothèque et

Archives Canada

Direction du

Patrimoine de l'édition

395 , rue Wellington

Ottawa ON K1A 0N4

Canada
Your file Votre référence
ISBN: $978-0-494-64456-0$
Our file Notre référence
ISBN: $978-0-494-64456-0$
NOTICE:

The author has granted a nonexclusive license allowing Library and Archives Canada to reproduce, publish, archive, preserve, conserve, communicate to the public by telecommunication or on the Internet, loan, distribute and sell theses worldwide, for commercial or noncommercial purposes, in microform, paper, electronic and/or any other formats.

The author retains copyright ownership and moral rights in this thesis. Neither the thesis nor substantial extracts from it may be printed or otherwise reproduced without the author's permission.
AVIS:

L'auteur a accordé une licence non exclusive permettant à la Bibliothèque et Archives Canada de reproduire, publier, archiver, sauvegarder, conserver, transmettre au public par télécommunication ou par l'Internet, prêter, distribuer et vendre des thèses partout dans le monde, à des fins commerciales ou autres, sur support microforme, papier, électronique etlou autres formats.

L'auteur conserve la propriété du droit d'auteur et des droits moraux qui protège cette thèse. $\mathrm{Ni}$ la thèse ni des extraits substantiels de celle-ci ne doivent être imprimés ou autrement reproduits sans son autorisation.
In compliance with the Canadian Privacy Act some supporting forms may have been removed from this thesis.

While these forms may be included in the document page count, their removal does not represent any loss of content from the thesis.
Conformément à la loi canadienne sur la protection de la vie privée, quelques formulaires secondaires ont été enlevés de cette thèse.

Bien que ces formulaires aient inclus dans la pagination, il n'y aura aucun contenu manquant. 
Place Holder: Acceptance Page 


\begin{abstract}
Participation has become a dominant theme in both digital environments and in contemporary art. This thesis explores how the distributed network systems of the Internet affect the production, distribution and reception of participatory art. Through an examination of the website http://www.learningtoloveyoumore.com (2002), this thesis will demonstrate that vernacular art-making practices are extended by participatory frameworks and amplified by distribution on the World Wide Web. This study will be focused through the discussion of vernacular creativity movements and the use of instructions in artistic production. This thesis conducts an evaluation of the history of participatory art and how collaborative methods of art-making developed throughout the history of recent art. This study investigates how participation within the Learning To Love You More project is enriched by an ethic of sharing on the Internet. Finally, this thesis contends that the act of publishing on the Internet is a political one, and encourages public engagement with art.
\end{abstract}




\section{Acknowledgments}

Galileo Galilei reportedly said: "You cannot teach a man anything; you can only help him discover it within himself'. While this may be true, the following people helped me find pleasure in the tumultuous process of discovery. I wish to thank Carol Payne for her compassionate and insightful guidance and Josée Drouin-Brisebois for her enthusiastic advice. I would also like to acknowledge Ming Tiampo and my peers for their convivial support and friendship throughout the thesis process. I would like to express my appreciation for the financial support from SSHRC and the Faculty of Graduate Studies and Research. I am thankful for the steadfast encouragement of my friends, especially Tuesday Dejong, and for the unwavering confidence and love of David Bussell. My sincere gratitude goes to my family, Peter, Anne and Dan McIntyre, who taught me to love art-making in the first place. Finally, I am grateful to Miranda July, Harrell Fletcher and every person who participated in the Learning To Love You More project because they helped me discover what art is truly about. 


\section{List of Illustrations}

Figure 1: Katrina and Ulf (London, UK). Report for Assignment 39, photograph

Figure 2: Mark and Joan (Columbus, Obio, USA). Report for Assignment 39, photograph

Figure 3: Sherry and Steve (Orlando, Florida USA). Report for Assignment 39, photograph

Figure 4: Steve and Sharon (Oakland, California USA). Report for Assignment 39, photograph

Figure 5: Home Page: Learning To Love You More.com, screenshot

Figure 6: Daniel Jaffe's Report for Assignment 21: Spend time with a dying person, photograph and instruction set

Figure 7: Instructions for Assignment 17, screenshot

Figure 8: Dan Green Protesting to stop protesting (Vancouver, Washington USA) Report for Assignment 34, photograph

Figure 9: R.P. Frampton's. Cut a bole into an object (North Delta, British Columbia CANADA)

Report for Assignment 44, photograph and instruction set

Figure 10: Mark Glasgow's Claire's bairdressing doll that she cut all of the bair off of (Donaghadee, IRELAND) Report for Assignment 5, photograph and instruction set

Figure 11: Trish Mau's. Make a field guide of your yard (Vancouver, British Columbia CANADA) Report for Assignment 66, digital photograph collage and instruction set

Figure 12: Tacoma Students for a Democratic Society's Protesting for a democratic society (Tacoma, Washington USA) Report for Assignment 34, photograph

Figure 13: The Oliver Family, photograph

Figure 14.1, Figure 14.2 Carol Candeloro's Make a paper replica of your bed (Chicago, Illinois US A) Report for Assignment 16, photographs

Figure 15: Jean Crotti or Suzanne Duchamp. Readymade Malbeureux, photograph

Figure 16: Suzanne Duchamp. Readymade Malbeureux, painting

Figure 17: Homepage: Instructables.com, screenshot 
Figure 18: Yoko Ono, Shadow Piece, photograph of instruction painting

Figure 19: Yoko Ono, Walking Piece, photograph of instruction painting

Figure 20: Lygia Clark. Lygia Clark using Rede de Elástico, photograph

Figure 21: Lygia Clark. Mask with Mirrors, photograph

Figure 22.1, Figure 22.2 Roy Agam. Holy Light, lenticular Agamograph

Figure 23: The NAMES Project Foundation. The 1996 display of the entire AIDS Memorial Quilt on the Mall in Washington, D.C., photograph 


\section{Introduction}

\section{Screenshots: LearningToLoveYouMore.com}

On the website LearningToLoveYouMore.com, the drop-down menu bar for Assignment 39 aggregates over a hundred photographs that serve as completed reports for the assignment. There is a photograph of Katrina and Ulf taken by their daughter Marika, in London, UK (figure 1). In it, Katrina and Ulf are mid-kiss, locked in embrace in front of a rolling pastoral landscape. Another photograph is of Mark and Joan taken by their daughter Kayla of Columbus, Ohio (figure 2). The photograph captures them in the midst of an epic kiss in front of an ornate carved stone fountain in full spray. In both photographs, clever composition effectively obscures faces, yet in each image the kiss is presented as the central theme in the foremost picture plane. Casey Szot's photograph captures her parents Sherry and Steve kissing underwater in a backyard swimming pool (figure 3). Sherry is wearing a striped bikini and her hair is floating up towards the surface of the water while Steve reaches out to grab Sherry's hand. The photograph is an artless snapshot where the swimmers are off-centre and Steve's legs blocked at the bottom right-hand corner of the image by an opaque ring. However, the bubbles between the mouths of the kissers, and additional swimmers visible in the background present this image as a stolen moment that otherwise would have passed unnoticed. A fourth photograph by Reese Ornellas of Oakland, California portrays his parents Steve and Sharon in a playful embrace (figure 4). Steve, in sport sunglasses and a black T-shirt, embraces Sharon, putting his hand in her hair and 
licking her in the centre of her forehead. Sharon's arms are wrapped around Steve and, seemingly used to this behaviour, she grimaces gleefully in response.

So what are these photographs reporting? They present completed responses for Assignment 39: Take a picture of your parents kissing. These photographs were selected from the submitted assignment reports showcased in aggregate on the website http://www.LearningToLoveYouMore.com (2002, figure 5). The project is spearheaded by the artists Miranda July and Harrell Fletcher. ${ }^{1}$ Visitors to the site voluntarily commit to the assignments, complete them on their own schedules and in their own specific environments. The full instructions explicitly state what is required of participants: "Take a picture of your parents kissing (or at least hugging). Do not send us an older picture of your parents, we are looking for a new picture taken specifically for this assignment."2 The participants later submit a report of their activity to the website.

Assignment 39 is one of the most popular assignments on the site. A completed report for this assignment is even featured as the cover of the book Learning To Love You More (2007), which serves as the printed record for this project. I want to look at why this assignment, like so many others formulated by the website, is so popular: why have over 100

\footnotetext{
${ }^{1}$ Harrell Fletcher (b. 1967) is a Portland-based artist who individually and collaboratively creates sociallyengaged interdisciplinary projects. He is also the Professor of Art and Social Practice at Portland State University. His artwork is featured in the collections of the Museum of Modern Art, The Whitney Museum, The New Museum, and the San Francisco Museum of Modern Art. Working out of Los Angeles, Miranda July (b. 1974) is an award-winning performance artist, filmmaker and author. Her artwork and videos have been featured in the Museum of Modern Art, the Guggenheim Museum, and most recently at the 2009 Venice Biennale. The two artists have been working together on Learning To Love You More since 2002. My decision not to interview Fletcher or July was purposeful because doing so would implicitly privileges their role as makers over that of the other participants. Instead, the emphasis of this thesis study lies on the project itself and the participatory practices it stimulates.

2 "Assignment \#39: Take a picture of your parents kissing (instructions)." Learning To Love You More, $<$ http://www.learningtoloveyoumore.com>.
} 
people submitted their photos to this project? Who are the participants? And why do they participate in such an abstract web project? What are the social or political implications of their participation?

This thesis investigates the actual actions and behaviours this project stimulates in order to gain a better understanding of participatory practices in contemporary art. Learning To Love You More provides a telling case study of the innovative ways contemporary artists are using networked technologies to support artistic practice. By examining the website Learning ToLoneYouMore.com I will determine what kind of art it engenders, how it functions and why its audience of active participants should be of interest to art historians today.

Key to Learning To Love You More is the critique of authorship. Without question, Miranda July and Harrell Fletcher play central roles in the enterprise; however, neither exclusively consider Learning to Love You More as part of their own individual art practices, rather they identify it as a participatory website. As a website, the art project is a space for contributions from an ever changing and fluid group of participants. Accordingly, this thesis does not present a conventional biographical portrait of Fletcher and July; doing so would privilege their artistic practices over a discussion of participatory art-making. While the two artists are essential to Learning To Love You More, this study is centrally interested in the artistic activity of a plurality of participants. Therefore, this thesis is not organized around the work of Fletcher and July though it addresses their leadership role within the project.

In this study, I consider how participatory art functions within the framework of contemporary art-making. This is a study more engaged with questions of arts participation than individual artistic performance or online performativity. It addresses the methods and 
techniques that encourage audiences to actively engage in art-making projects, including instruction, collaboration and discovery processes. This study raises questions about how people play with and perform identity through discussions of art-making, anonymity, and acts of publishing. Moreover, this study will address the impact that distributed computing has had upon artistic practice today. Spurred on by advances in science and technology, there has undoubtedly been a shift in the production, presentation and distribution of art. This has led to new ways of defining art and has necessitated a re-examination of the way we identify and discuss artistic activity. In his much discussed essay "The Work of Art in the Age of Mechanical Reproducibility" (1939), Walter Benjamin argued that, as a result of innovations in reproductive technologies (like the film camera), the status and role of artworks fundamentally changed. Revisiting the theoretical tradition established by Walter Benjamin, Bill Nichols's essay, "The Work of Culture in the Age of Cybernetic Systems" (1988) re-examined how our presuppositions regarding the divide between art and life have collapsed and ontologically transformed within distributed network systems in the digital age. Because of the ease and accessibility of reproductive technologies in a digital age, the nature of art, according to Nichols, is becoming increasingly interactive, in reflection of interactive computer network technologies. Further, he argued that social and cultural realities are shaped by our interaction with art, claiming that the reproduction of art by means of electronic communication technology had altered both how a society engages with art, and consequently the structure of society at large.

Along the same line, I suggest in this thesis that creative practice has a different character as a result of the use of distributed network technologies. Art history frequently 
presents us with the image of the 'artist' as a solitary genius, achieving creative mastery in the confines of the studio: Michelangelo in his Florence workshop, Jackson Pollock in his Long Island house, Louise Bourgeois in her Brooklyn warehouse. But, as technology changes and tools that support making and distributing art become more accessible, it is clear that we need to revise our perception of what an artist is and what they do. I believe this thesis demonstrates that in today's cultural context, one heavily dependent upon digital tools and computer networks, that anyone can be an artist, and that art-making is something we all should participate in.

Vernacular or everyday art-making is quickly becoming a dominant mode of creative activity in the twenty-first century. Just like the colloquial character of vernacular language, vernacular art practices describe ways of making art using accessible, ordinary and often mainstream techniques and materials. Vernacular creativity includes a wide range of everyday creative acts occurring outside the cultural value systems of commercial creativity and high art practice. Further, the makers of vernacular 'art' typically do not conceive of themselves self-consciously as artists. Finally, their actions, like vernacular language use, draw attention to the local or temporal specificity of their creation and remain open to exchange or elaboration. ${ }^{4}$ Supported by the distributed networks of the Internet and low-cost, userfriendly media tools like camera phones and digital video recorders, an increasing number of people are completing art activities everyday and broadcasting the results worldwide. This

\footnotetext{
${ }^{3}$ Approaching Learning To Love You More as a work of vernacular creativity draws attention to the project as something greater than an archive of completed assignments. By identifying it as a work of vernacular creativity, the participants are honoured as cultural creators, beyond participants in an arts project. Vernacular creativity will be discussed in greater detail in Chapter 2.

4 Jean Burgess, "Mapping Vernacular Creativity V.1.0" (2005),

$<$ http://creativitymachine.net/2005/03/26/mappingvernacularcreativity-v-01/>
} 
becomes more important as art-making has been redefined in recent years as a wide spectrum of art activities created with disparate media types, ranging from painting to performance, and by a varied supply of creative agents, both professional and untraincd.

Trained perception is fundamental to understanding the arts. Aesthetic understanding is not about cultural context, but rather, according to theorist Dennis Dutton, about "gaining cultural knowledge in order to see aesthetic qualities which have intentionally becn placed in objects to be seen". This considered, LeamingToLoveYouMore.com will be more easily recognized as an art project when we have investigated the formal, narrative and communicative qualities intentional in the project.

\section{Outline of Thesis Study}

This thesis is centred on an interdisciplinary investigation of participatory art practices and how they function alongside the networked environment of the Internet. Because of the broad scope of such an investigation, this thesis is focused through a case study. $\mathrm{http}: / /$ www.learningtoloveyoumore.com, is an ongoing participatory art project run by the artists Miranda July and Harrell Fletcher. Intermittently, the artists posted 'assignments' or instructions for artistic actions on the website. Participation in the project is a two part process: completing an art action and uploading a report to the website. The completed reports serve to document the art events through a range of media, including text, photography, video and audio documents.

In this thesis, I make three main propositions: first, I claim that heuristic or discovery-based methods of art-making promote self-directed aesthetic experience; second, I

\footnotetext{
${ }^{5}$ Dennis Dutton, The Art Instinct (New York: Bloomsbury US, 2008), 84.
} 
claim that the development of participatory practices in recent art history have stimulated the current emphasis on collaborative protocols in creative activity; third, I claim that distributed networks enhance the political dimension of art-making because they amplify how art can be shared with an audience. Through the application of my research findings on the case study, I argue that vernacular art-making practices, especially those advocated by Learning To Love You More, are supported by participatory frameworks and amplified by distribution on the World Wide Web.

In Chapter 1, I will formally introduce the case study LearningToLoveYoumore.com as representative of a subculture of participatory art within the scope of contemporary art practice. First, I will outline the history of the art project and evaluate its aesthetic character. In this section, I discuss how Learning To Love You More typifies a new media arts project and consider the character of the assignments posted on the website. I also describe how the participants identify themselves and problematize the effect of anonymity on the project. The curatorial role that Fletcher and July fulfil will be investigated in this first section as well. Second, I will argue that instructions are valuable as a heuristic mode of creative practice. I analyze instruction sets from LearningToLoveYouMore.com and provide context for instruction-based art-making in art history. I then theorize that instructions stimulate heuristics in art-making, encouraging art activity focused on discovery and self-directed aesthetic experience. Third, I illustrate the quotidian nature of Learning To Love You More and how it democratizes art-making. I outline the values of 'vernacular creativity' and explain how LearningToLoveYouMore.com is related to the movement. I also probe the relations between the online state of the art project and how it manifests in the real world. 
In Chapter 2, I historicize participatory art to explain the precedents of LearningToLoveYouMore.com. In this chapter, I will first assess how participatory art activates its audience. I will take a historical look at participatory aesthetic experiences such as Happenings and Event Scores. I will highlight the pioneering artists who developed the principle of participation in art-making during the 1950 s and 1960 s. I will briefly trace the history of participatory-art related exhibitions and conclude by commenting on the political and conversational tone of these art displays. The second part of this chapter will engage with the work of two leading theorists of participatory art-making, Umberto Eco and Nicolas Bourriaud. I will provide a discussion of Eco's "Theory of the Open Work" and Bourriaud's "Relational Aesthetics" and investigate the implications of their theoretical texts. I will examine how the practices they describe change the structure of art-works, and how art-making adopts an experimental character. Before concluding this section, I will also present criticism of Bourriaud's theory by the critic Claire Bishop. The third section of Chapter 2 will begin by addressing the increasing importance of collaboration (beyond participation) in art-making practices. Participation describes the action of taking part in an activity, whereas collaboration describes the process where individuals work together to achieve a goal or produce an object. I will consider collaborative models of production in art history and compare the collaborative methods of contemporary artists. I will consider how meaning is created and end with a discussion of collaborative protocols on the Internet.

In Chapter 3, I argue that sharing practices, especially publishing, are amplified by distributed network systems like the Internet. In this section, I first define what distributed networks are and determine how they can serve as a metaphor for understanding Learning To 
Love You More. I briefly outline the development of communications technologies and introduce the key principles that relate to the project. I also explore the role of documentary perspective on LearningToLoveYouMore.com and focus on how it helps solve the problem of documenting ephemeral art-works. The second part of this chapter will centre on a discussion of Web 2.0 protocols and how they led to the rise of participatory publishing economies. I consider the impact of the practices of citizen journalism on the practice of participatory art-making. I interrogate the relation between freedom of expression and the act of publishing. This part concludes by identifying how digital tools have amplified the effect of creative projects. The final section of Chapter 3 will argue that sharing is a political act and that LearningToLoveYouMore.com serves as a legitimate platform for aesthetic expression. I explain how website architecture imbues meaning for interactive projects and demonstrate how the project title, Learning To Love You More, suggests an ethic of sharing. I discuss the political dimension of the project employing etymological poetics to explain the Greek polis. This section ends by revealing the power dynamics of the audience as a community of remembrance.

Finally, I will recapitulate the main themes explored in the study to prove that the model of LearningToLoveYouMore.com is an effective means for stimulating vernacular artmaking. Additionally, I will indicate how this thesis affects further study in the field. This thesis concludes by arguing that active aesthetic participation is integral to cultural engagement. 


\section{Chapter One: The Leaming To Love You More Project}

Using the lens of the Learning To Love You More project, I will consider how the creation of artworks in a digital environment differs from other modes of art creation. We must reevaluate the relationship between an artist and his or her audience in extended art practices, which include the creation of instructive, performative and interactive artworks. I will examine how the case study functions, specifically how it integrates real-world art practices within a web-based platform. In this first chapter, I examine the Learning To Love You More project as a participatory art project facilitated by the distributed networks of the Internet. I also interrogate how the project functions, and consider what implications it has for creative practice in the twenty-first century. First, I will trace the history of Learning To Love You More and discuss how it is structured. In this chapter, I perform an aesthetic assessment of the project and consider the tenacity of the art actions and events it provokes. Second, I will investigate the heuristic dimension of the project to demonstrate the participant-directed experience of Learning To Love You More. Finally, this section concludes with a consideration of how this project aligns with popular vernacular creativity movements which are supported by digital tools.

\subsection{Evaluating Learning To Love You More}

Learning To Love You More is a web-based art project launched by Harrell Fletcher and Miranda July in 2002. Participants in the project visit the website LearningToLoveYouMore.com, accept an assignment and complete it by following the instructions given. Their final creation is then documented by an appropriate media (often specified in the assignment directions) and a final report of their efforts is submitted electronically or by post mail to Yuri Ono, the 
domain master of the website. The site is built using PHP scripting language, free software that produces dynamic web pages with minimal coding. ${ }^{6}$ The reports are then uploaded to the website and aggregated by assignment number for public view.

The project began as a training exercise with a trial run at the Maine College of Arts Summer Program in 2002 for the exhibition Playground (7 Mar 2003 - 19 Apr 2003, Institute of Contemporary Art, Portland, Maine). 'Twenty students accepted the first five Learning To Love You More assignments. Because of the project's success, Learning To Love You More was then expanded to ten assignments and made public after the conclusion of the summer program trial. ${ }^{7}$ The website began to grow as a result of word-of-mouth promotion and through blogs that linked to the project website. ${ }^{8}$

The assignments were intermittently evaluated and expanded by the creators. New assignments were added to the site every five to six months. As of May 1, 2009, the project had reached a tentative conclusion with a total of over 8000 reported participants in the seven years of its operation. The final assignment posted, Assignment 70: Say Goodbye, heralded a playful conclusion to the project. The final message on the website's main page notified participants of the project's conclusion, permitted them an opportunity to withdraw

\footnotetext{
"Dustin Luke Nelson. "InDigest InDialogue: Yuri Ono" (web interview)

.<http://www.indigestmag.com/ono1.htm.>

${ }^{7}$ Nelson. "InDigest InDialogue: Yuri Ono" (web interview).

${ }^{8}$ Blogs which featured posts about the Learning To Love You More project include Notes from Underdog on June 17, 2005 [http://underdog.typepad.com/wandering_outloud_/2005/06/favorite_book_f.html], Technology and the Body on December 2, 2005 [http://technologyand thebody.blogspot.com $/ 2005 / 12 /$ response-to-learning-tolove-you-more.html], and girlprinter on July 27, 2005 [http://girlprinter.blogspot.com/2005/07/assignments.html].

Also, several blogs act as showcases for individuals who complete Learning To Love You More assignments outside the project's framework, including the Oliver family blog [http://oliverlove.blogspot.com], a blog run by a 'learning to love you more collective' [http://learningtoloveus.wordpress.com] and an anonymous blog published under the screen name $=^{\wedge} .{ }^{\wedge}=[\mathrm{http}: / /$ keepkeepinghappy.blogspot.com] $]$. Also, exterior to the project, there are also over 500 photos on Flickr.com tagged as LTLYM or learningtoloveyoumore in response to the project.
} 
submissions from the permanent archive, and invited visitors to continue doing the assignments and sharing the events where assignment results were publicly displayed. The resultant web archive will continue to exist but it will not be continuously updated. This decision is motivated by financial and time constraints, as the project has not ceased in its popularity and there has not been a decline in the number of submitted reports. Nonetheless, the project will continue indefinitely as a corpus of instruction sets on the website and in the published book.

How 'new media' is Learning To Love You More? The theorists Randall Packer and Ken Jordan delineate the key characteristics of new media: integration, interactivity, hypermedia, immersion and narrativity. ${ }^{10}$ New media integrates disparate media forms. Interactivity describes the capacity of a user to alter the media he or she encounters either as an individual or in a collaborative role within a group. New media offers audiences an opportunity for participation because most new media operates on interactive platforms. Hypermedia can be considered an aesthetic experience that permits links between media objects - text, image, sound - to develop personal paths of emphasis between the associative content. Immersion is the quality that describes the use of spatial metaphors to organize and arrange information. It relates more to navigation than it does to organization. Finally, new media is conducive to new methods of narrative construction, often non-linear and self-directed. Considering these characteristics, it is clear that Learning To Love You More is a strong example of a new media art project. The website integrates different media forms including text, video and $\mathrm{mp} 3$ files. It is interactive in its structure, but the site navigation is also totally interactive allowing the

\footnotetext{
9 Nelson. "InDigest InDialogue: Yuri Ono" (web interview).

${ }^{10}$ Randall Packer and Ken Jordan, eds. Multimedia (New York: Norton, 2002), xxxv.
} 
visitor to browse reports by title, artist name or assignment number. The hypermedia quality of the cite is evident in the freedom the visitor has to select and view assignments, some of which link to contact information, like e-mail addresses, or additional artwork on exterior sites. The website is immersive, notably because the reports are presented in aggregate and can best be explored by the immersive experience of scrolling and searching. Finally, the site permits flexible narrative construction, letting the visitor shape their own natrative of the project, ${ }^{11}$ as well as explore narrative strains in the artworks themselves, by assignment number or by artist.

The visual characteristics of the website are aesthetically inviting and seem to motivate engagement with the project. The home page itself does not use logos or animations, nor does it feature complex graphic design. On the contrary, the project is presented on a webpage that is remarkably bare-bones and no-nonsense. The aesthetic layout of the webpage is inviting. Rather than a stark-white or hard-black background, the website features bright-orange title-bars set upon a pale beige-pink background screen. 'The simple text script is either white or orange to match the title-bars. The script is also without serifs or cmbellishments, which helps to create a neutral tone for the webpage. The centred presentation of images highlights that the main focus of the visit is on the assignment reports. Nevertheless, the navigational toolbars remain present, framing the webpage on the top and left-hand side. 'This means that the visitor can always re-orient him or herself from any point within the webpage. Moreover, the simplicity of the site design means that the

\footnotetext{
11 The fact that the project history on the website is vague and incomplete suggests that an over-arching narrative is not necessary to the project. The website does not feature foundational information or even an 'About' page, but rather the organic development of the project is emphasized by the title page that displays a programmatically-selected image from project reports (see figure 5).
} 
website can be easily navigated by visitors with varying skill levels. The welcoming and colloquial language used to title the sections and explain the instructions ensures that the interactive experience for a visitor is clear and direct. Because of its clear, simple and warm design, the aesthetic presentation of the site both encourages participation and ensures the participatory experience is comfortable.

The thread that unites the Learning To Love You More assignments is that they are all indeed assignments. Besides this, the requests they make are varied. Sometimes participants are asked to take photographs, re-create objects using craft materials, rearrange things found in their own home, or compose text from personal wishes and desires. Many of the assignments request participants to endure particular experiences: Assignment 31 asks participants to spend time with a dying person (figure 6); Assignment 17 asks participants to record their own guided meditation (figure 7). The project also strives to inspire the exercise of the participant's individual voice, encouraging political engagement as in Assignment 34: Make a protest sign and protest (figure 8). The cause, method and type of protest are undirected, and the extended instructions simply offer the participant a range of options to choose from: "You can protest alone, with a group that you assemble, or with a pre-existing protest group". ${ }^{12}$ Many assignments require the participant to investigate his or her past: Assignment 11 asks participants to photograph a scar and write about it, Assignment 18 directs the visitor to te-create a poster they had as a teenager. Many assignments have a goal of investigating relationships, such as Assignment 33 which asks participants to braid someone's hair, or Assignment 20 which directs the visitor to compose a portrait of two separate families. The

12 "Assignment \#34: Make a protest sign and protest (instructions)." Learning To Love You More, $<$ http://www.learningtoloveyoumore.com/reports/34/34.php>. 
minute art objects created for the Learning To Love You More assignments belies the deft nature of the greater project. As curator Julia Bryan Wilson observes, "there is a tension between the relative small scale of Learning To Love You More as material outcomes - all the short paragraphs, 45 second videos and paper beds - and the possible magnitude of its intangible effects". ${ }^{13}$ The force of Learning To Love You More lies in the deluge of submitted reports, over 8000 in seven years, which more accurately reveals the power of the art project than the discreet character of the instruction sets or the modest material art objects created for the assignments.

Wilson argues that continuing interest in the project stems from its unpredictable character. She even notes that the project best succeeds when the reports "simultaneously inhabit and thwart the assignments expectations, when the limitations have been transformed to make pieces that deliver a psychological charge". ${ }^{14}$ As a result of its unpredictability, the project draws attention to the capacity art has to sustain a range of unstable interactions.

Succinctly categorizing Learning To Love You More as a specific art form is even more difficult. The project itself is a cacophony of contradictions: it is decidedly post-modern, because of its ironic, absurd and self-referential character, but not intentionally so; it is too performance-based to be considered net.art, but too dependent on computer networks to be squarely categorized as anything else. LearningToLoveYouMore.com could also be considered a conceptual art project, but the materialization of the assignments is of interest along with the

\footnotetext{
${ }^{13}$ Julia Brian Wilson, "A Modest Collective: Many People Doing Simple Things Well” in Fletcher and July's Learning to Love You More (New York: Prestel Publishing, 2007), 146.

14 Wilson, 145.
} 
instructions given. The assignment instructions constitute the conceptual vision for the project, but it is the manifestation of completed assignments that drives the continued popularity of the project.

Learning To Love You More, while in the form of a website, extends beyond the confines of its structure. In this capacity it is a kind of intermedia art. An early interest in intermedia artworks can be found in Wagner's pursuit for the Gestamkunstwerk, or a total artwork. This was rooted in his belief that the synthesis of disparate artistic forms into one common form would free the artist and ensure that he was "to be that which he has the powers to be". ${ }^{15}$ Contemporary understandings of intermedia art are strongly informed by the Canadian artist Dick Higgins. In his essays on intermedia, Higgins suggests that the art form should be viewed as an irreversible historical innovation more comparable to the development of instrumental music than, for example, the development of Romanticism. ${ }^{16}$

The artists describe this project as revealing the "freciuently wild, sometimes hilarious and quietly stunning creative lives of a few people living on earth right now" ${ }^{17}$ However, many of the assignments do not have much information about the participants who have created the reports. While it is mandatory that submissions include a name and location, the name can be a pseudonym and the location is unverified. In many cases real names are missing, and observers are left only with partial information about a participant, such as the participant's birthplace or what a wall in a participant's house looks like. These intimate details are balanced by the anonymity that often characterizes identity performance in digital

\footnotetext{
${ }^{15}$ Packard, Multimedia, 4.

${ }^{15}$ Dick Higgins. Modernism Since Postmodernism: Essays on Intermedia (San Diego: Fiction International, 1997).

${ }^{17}$ Fletcher and July, Learning To Love You More, 1.
} 
networks. Within participatory networks, users choose to interact with their peers despite the fact that they cannot confirm that the identities they present are real. Nonetheless, network users often engage in serious work with anonymous peers, ranging from program writing, to music sharing to art-making activities.

The high degree of anonymity in the project confirms that the goal of Learning To Lave You More is to provoke an exploration of the self. Several of the submissions are from anonymous creators or feature narratives about unknown protagonists. The submission guidelines demand that all reports be submitted under a name, but they do not place any further restrictions upon participation. The reports listed on the website credit participants using their first names, full names, pseudonyms, or screen names composed with Leetspeak. ${ }^{18}$ Participants in the project get to control the amount of information they submit to the site, and as such, get to choose what parts of themselves they will present to the Internet public. As well, some participants identify themselves as artists, some post their email addresses, and others use full sentences as screen-handles. As a result, there is no consistency in collecting and posting the artist information on the site. Knowing the identities of the participants is not necessary. In statistical fields, even data collected on surveys from anonymous participants is considered useful. Moreover, the frequency which reports are posted under pseudonyms or by anonymous participants suggests a correlation with the culture of anonymity that operates in many digital environments on the Internet.

\footnotetext{
${ }^{18}$ Originated by elite users of BBS (bulletin board systems) in the 1980s, Leetspeak is a form of symbolic writing used on the Internet wherein letters from the Roman alphabet are replaced with ASCII characters. Most popular Internet slang is composed of Leetspeak (i.e. LOL, 'Laughing Out Loud') which features loose grammar, intentional misspellings and the substitution of alphabetic characters with symbolic or numeric characters (i.e. K@t3 the GR8). Participants who have identified themselves on the website using Leetspeak include Mgn (Assignment 37), 13etty (Assignment 42), and bLAZay00 00 (Assignment 45).
} 
Miranda July (née Miranda Grossinger ${ }^{19}$ ) has worked under a pseudonym since her debut short film Atlanta, produced in $1996 .{ }^{20}$ What this reveals is that while the participants are central to the Learning To Love You More project, their conventional identities are not necessarily of importance.

Meaning is not derived from the events in a fiction or content of an artwork, but rather is achieved through interpretation. Point-of-view is central for understanding meaning in the arts. The author of an assignment report is a real person, even if we are unaware of their 'true' identity. The author is the prime mover of the artwork's creation. They are in control of the interpretation of the character, the actions and events that occur in the report. They are able to persuade and manipulate the audience, plant hints, play jokes or adapt the tone for a specific purpose. The experience of a story is inescapably social. It is not an imaginary social life that occurs, rather, the author's palpable presence exists. Fiction is essentially communicative, therefore it is social. 21

Learning To Love You More is a structured art project that evolves and permits manipulation. In particular, Assignment 44: Make a "LTLYM Assignment" (figure 9), asking participants to take on Fletcher and July's role, reveals the open-ended organic nature of the project. The goal of the project appears then to be an attempt to encourage art making in general and incorporate it into the daily lives of ordinary people. This self-referencing assignment offers the possibility for open participation and authentic contribution to the project at large. July and Fletcher, although they may create the other seventy assignments,

${ }^{19}$ Wesley Morris. "Putting all they know to work". The Boston Globe.

$<\mathrm{http} / /$ www.boston.com/ae/movies/articles/2005/06/26/putting_all_they_know_to_work/ > .

${ }^{20}$ Miranda July. "Atlanta". MirandaJuly.com. <http://mirandajuly.com/movies/atlanta $>$.

${ }^{21}$ Dutton, 125. 
do not attempt to restrict participants from playing with the leadership of the project. Moreover, several assignments have stemmed directly from submitted reports. Two popular reports in response to Assignment 14: Write your life story in less than a day inspired the creation of Assignment 19: Illustrate a scene or make an object from Paul Arensmeyer's life story and Assignment 22: Recreate a scene from Laura Lark's life story. Maurisa Breton's short video report to Assignment 2: Make a neigbborbood field recording inspired the creation of Assignment 57: Lipsync to sby neigbbor's Garth Brooks cover. The intimacy of the imaginary conversations resulting from Assignment 52: Write the phone call you wish you could have motivated the creation of Assignment 65: Perform the phone call someone else wished they could have. Most of the subsequent assignments invite participants to revisit an assignment theme using a different medium. Drawings and sculpture are used to respond to written stories, short videos respond to audio recordings, and people perform versions of fictional dialogues. The assignments thus have a circular character, wherein several instructions sets grow outwardly from previous assignment directives.

While Learning to Love You More asks its participants to make a variety of craft-like projects, the art-making they engage in cannot wholly be considered craft. Many scholars, specifically Collingwood as early as the 1940s, have argued that preconception is a key factor in the creation of crafts. A craftsperson knows in advance what the outcome or end product of their creative activity will be. This foreknowledge is required by the idea of craft itself. In contrast, art-making features skill and technical competence but has little foreknowledge of 
an end state at the beginning of the artistic process. Art is open to the creative process and is able to change direction and goals; the artist never fully knows what they are doing. ${ }^{22}$

The disclosure of intimate details in the reports affects their perception as beautiful. Moreover, the slow, painstaking means of production of handmade art objects can represent a drain on creative and intellectual effort: Assignment 5: Recreate an object from someone's past (figure 10); Assignment 48: Make the saddest song; Assignment 66: Make a field guide to your yard (figure 11). Most of the LearningToLoveYouMore.com teports showcase artistic endeavours achieved by hand. However, the honorific designation of handmade arts still establishes them as a superior achievement than machine-made creative goods.

To reward participants who take the project seriously, Fletcher and July offer small artist grants to select participants who have submitted reports to the websites. The funding for the grants is not continuous because it is derived from art funding grants that Fletcher and July themselves have independently pursued. Both artists apply for several grants and if they are successful they reserve a section of their grants to redirect towards the Learning To Love You More project, acknowledging that "rent can't be paid with a picture of the sun". ${ }^{23}$ The grants distributed in 2005 and 2006 were awarded in $\$ 500$ denominations to eight different participants. Fletcher and July motivate the decision to award grants, informing participants on the website that the monies are a way "to express our admiration for your reports." ${ }^{24}$ Yuri Ono, the website administrator, offers further motivation: "The grant giving,

\footnotetext{
22 See R. G. Collingwood. The Principles of Art. (Oxford: Clarendon Press, 1945), also Dutton, 226.

${ }^{23}$ Fletcher and July, "Grants". <http://www.learningtoloveyoumore.com/grants.php>.

${ }^{24}$ Ibid.
} 
for us, is a way of encouraging people to not lose hope and to keep creating things". ${ }^{25}$ The website playfully informs that all participants qualify for consideration: "The recipients are chosen by us solely on the basis of their reports; in other words, by submitting a report you automatically become a contender, no applications necessary." ${ }^{26}$ While the artists received an Emerging Fields grant from the Creative Capital Foundation in 2002, the project receives little outside financial support beyond what Fletcher and July invest in the project.

The Learning To Love You More grants highlight the work that Fletcher and July perform as administrators on the art project, however, their involvement in the project remains mostly curatorial. In contrast to the active involvement of the participants, Fletcher and July serve as instigators and aggregators: they motivate the creation of artwork, and aggregate the reported results in a centralized, accessible location. In this way, July and Fletcher appear as a conductors for an orchestrated experience, rather than artists who have made an art object. Occupying the role of a curator is a practice familiar to both Fletcher and July who have served in curatorial positions on previous creative projects. Most notably, Joanie4Jackie, a video chain letter project, was founded by Miranda July in 1995 as an alternative distribution system for women moviemakers. While still in graduate school at the California College of Arts and Crafts, Harrell Fletcher collaborated with artist John Rubin for Gallery HERE (1993-95) in Oakland, California. The artist-run centre operated out of a borrowed vacant retail building and exhibited a series of shows about people and places from the surrounding neighbourhood:

${ }^{25}$ Nelson. "InDigest InDialogue: Yuri Ono" (web interview).

${ }^{26}$ Fletcher and July, "Grants". 
One show was about a man named Albert who owned a rug store across the street from us. For another show we had people's garage sales in the gallery and put story tags on all of the stuff that was for sale. Other shows were about a man's apartment court yard garden, a huge cement boat that had been built in a vacant lot, and burritos that were available in the neighborhood. ${ }^{27}$

Fletcher's curatorial involvement in civically-oriented arts projects early in his career demonstrates a foundational interest in socially engaged interdisciplinary art practices.

It is Fletcher and July's interest and experience in socially engaged art practices which sets Learning To Love You More apart from other participatory web-based platforms. Learning To Love You More differs from the free-form expressive spaces of YouTube, MySpace and Facebook because participation in the project represents a self-consciously creative contribution to a collective effort, rather than the development of an individual ego. ${ }^{28}$ Moreover, despite the fact that the instruction sets clearly delineate the structure of the project, Learning To Love You More remains true to its foundational claim. The goal of the project is to guide people towards their own artistic experience. Much like the decision of academic institutions, such as the Massachusetts Institute of Technology, to provide 'open courseware' to the public over the Internet, Learning To Love You More operates from the perspective that, if given the right tools and a moderate framework, individuals will work towards a meaningful experience.

The Internet is an aesthetic experience. The physical character of Internet use is often overlooked, as we tend to offer greater attention to the acts completed therein. The

\footnotetext{
${ }^{27}$ Allan McCollum. Harrell Fletcher: Where I Lived, and What I Lived For (interview). Domaine de Kerguéhennec, Centre d'art contemporain (Bignan, France, 2009).

$<$ http://homepage.mac.com/allanmcnyc/harrellfletcher/mccollum_interview.html $>$.

${ }^{28}$ Wilson, 146
} 
physical activities associated with Internet use - starting technology, looking at a screen, opening a browser and navigating via mouse and keyboard use - are minute and unassuming actions. Yet, all Internet activity is rooted in corporeal reality, despite its seemingly ephemeral nature. The Internet operates through physical systems that exchange requests and responses over a transmission medium; web traffic travels through hardware servers which send signals through wires.

The participatory experience of Learning To Love You More is civic, but not necessarily community-oriented. There is little opportunity for interaction between participants in the technical framework of the project. A few of the reports published on the website include the participant's e-mail address, but most of them do not provide the opportunity for further contact. However, despite the lack of inter-project communication, the project encourages civic engagement through assignments like Assignment 4: Start a lecture series, Assignment 60: Write a press release about an everyday event and Assignment 62: Make an educational public plaque. Moreover, the assignments can be completed by individual participants taking part in the project or by a group of participants in a collaborative fashion. Several reports have been submitted by small groups (such as the Tacoma Students for a Democratic Society, who submitted a report for Assignment 34: Make a protest sign and protest, figure 12), entire art classes (such as a Performance Theory Class in Melbourne, Australia who submitted a report for Assignment \#24: Cover the song 'Don't Dream It's Over') and even whole families (most notably the Oliver Family in Seattle, ${ }^{29}$ Washington, who completed 63 assignments, figure 13). Julia Bryan Wilson observes that with these assignments "the relational aspect of the project is

${ }^{29}$ A section of the Learning To Love You More site is dedicated to showcasing assignment reports from the Oliver family: < http://www.learningtoloveyoumore.com/oliver_family/index.php $>$. In addition, the family of six tracked their 'artistic missions' on their blog: <http://oliverlove.blogspot.com>. 
less Bourriaud's realm of social interaction [discussed further in Chapter 2] than the relation of the self to the self to its own opaque desires and muted longings" ${ }^{30}$ Thus, the project appears oriented towards improving social relations, but specifically the development of the self for relations with others rather than the construction of relations with others.

\subsection{The Value of Instructions: Heuristics in Creative Practice}

Instruction, both as a form of communication and a means to structure art production, is incomplete without participation from an audience in consummation of assigned tasks. We encounter instructions in many aspects of our lives, ranging from directions on how to use a new blender or recipes for making margaritas. Instructions direct a person to complete an action or task. Instructions essentially represent a communicative exchange, wherein one person tells another person what to do. The person receiving the instructions has the liberty to decide if they wish to follow them or not.

Within the Learning to Love You More project, participation of a mass audience is considered as the corollary to the artist's instructions. The assignments are given in instruction form and come in two parts. The first part is the numbered assignment title, placing the assignment in sequence with the total project and offering a one-line summary of the assignment requirements. The first part is clear and direct, often referencing the final media form that the report will take: Assignment 21: Sculpt a bust of Steve; Assignment 29: Make an audio recording of a choir. The second part of the assignment instructions are the extended directions for completing the art assignment and details on how a report should be submitted. Often, the extended instructions offer a background story to the assignment,

30 Wilson, 146 
directions for use of materials and clear directives toward a specific outcome. For example, the instructions for Assignment 16: Make a paper replica of your bed (figure 14.1, 14.2) outline what materials to use, what dimensions are desired and what visual details are preferred:

Using paper, cardboard, colored pencils, glue and/or tape, make replicas of your sheets, blankets, comforters, pillows and anything else that comprises your bed. Then assemble them the way you assemble your bed. The completed bed should be roughly the length of a pencil. Take special care to reproduce the patterns on the fabric and any stains or other irregularities. ${ }^{31}$

Moreover, the instructions for documentation request two photographs for the report: "Take one photograph of the bedding elements laid out separately and another photograph of the assembled bed". ${ }^{32}$ The instructions given for each assignment are quite explicit, yet in many cases, they serve as a point of departure for most participants who interpret instructions for their own purposes. Wilson affirms this reading, emphasizing that the assignment directions are: "hardly marching orders, any more than the rules of a sonnet are" ${ }^{33}$ Through the means of instruction sets, Learning to Love You More presents an authentic opportunity to participate meaningfully in art-making.

The idea of generating art projects from instructions is not new. Most art produced in school settings, whether in Kindergarten classrooms or at art training colleges, is produced as a result of an assignment given to the students by an instructor. Instructions have also been a mode of aesthetic communication that artists have played with for decades. Marcel Duchamp's Readymade Malbeureux (Unhappy Readymade, 1919) was an instruction-

31 "Assignment \#16: Make a paper replica of your bed (instructions)." Learning To Love You More, $<\mathrm{http} / /$ www.leamingtoloveyoumore.com/reports/16/16.php $>$.

32 Ibid.

${ }^{33}$ Wilson, 145. 
based artwork created as a wedding gift for his sister Suzanne and her husband, the Dada painter Jean Crotti. ${ }^{34}$ While Duchamp was in Buenos Aires on a trip, he sent a letter to the newlyweds in Paris, instructing them to purchase a geometry book and hang it by strings from their balcony. Duchamp explained the Readymade as such: "The wind had to go through the book, choose its own problems, turn and tear out the pages". ${ }^{35}$ The work is known through a photograph taken by either Crotti or Suzanne Duchamp Crotti (figure 15, which Marcel Duchamp later retouched and included in his Box in a Valise, 1941) and a painting by Suzanne Duchamp of the Readymade installed outdoors (figure 16). The intended physical deterioration of the textbook indicates that the artwork is manifest through the process of fulfilling the instructions, rather than in the creation of an art object.

Alan Kaprow's Happenings and the Fluxus group's mail art centrally employed instruction sets for the actualization of artworks. Japanese-American performance-based artist Yoko Ono is also well known for using instructions in her projects to structure conversations between her and her audience. David Askevold's Projects Class at NSCAD between 1969 and 1972 initiated a direct exchange between the artists in the art-making process. Askevold invited well-known conceptual artists, including Sol Lewitt, Joseph Kosuth, Dan Graham, Lucy Lippard, Lawrence Weiner and Robert Smithson, to create proposals for art projects to be completed by students in the class. When an artist relinquishes inspiration as mandatory for creative practice, the opportunities for exploration

${ }^{34}$ Arturo Schwarz, ed., The Complete Works of Marcel Duchamp (Delano Greenidge Editions: New York 2000), 668-669.

35 Duchamp, in Cabanne, Dialogues with Marcel Duchamp, (New York: De Capo Press, 1987). 
are expanded. ${ }^{36}$ At times, a system of instruction paradoxically offered an artist more liberty because it serves as an instrument for a pre-defined creative practice.

The emphasis upon the artistic process in participatory art encourages a consideration of the heuristic dimension of Learning To Love You More. Heuristics is the 'science of discovery'. The term beuristic derives from the Greek root word beuriskein, meaning 'to find'. Roman historian Vitruvius claimed that Archimedes exclaimed 'Heurēka!', or 'T have found it!', when he solved the problem of how to assess the quality of gold in the crown of Hiero of Syracuse. Heuristics describes a method for problem solving and is concerned with arriving at solutions or judgments primarily by means of intuition. Essentially, heuristics are a means of path-finding, a way to develop strategies to discover new things.

Considering this definition of heuristics, heuristic art is seen as a type of art whose primary focus is to guide a participant towards an aesthetic experience. Yoko Ono's Grapefruit (1964) [discussed further in Chapter 2] can be seen as an early example of the deliberate use of heuristics in contemporary conceptual art. The theorists George Yudice and Osvaldo Sanchez have featured an exploration of the heuristic dimension in their research. They aim to interrogate "public experience, of what it is to come together as a public" and believe that the best way to achieve this is through heuristic processes "whereby people constitute themselves (in public), engaging in self-making". ${ }^{38}$ The heuristic method is thus a means to catalyze exchanges in the public realm between people, contexts and institutions

\footnotetext{
${ }^{36}$ Library and Archives. Proposals from Halifax (catalogue). National Gallery of Canada (Ottawa, 2000).

${ }^{37}$ George Yudice and Osvaldo Sanchez. Discerning the Heuristic Dimension of Public Art (lecture). University of Minnesota (Minneapolis: Minnesota, 1999). < http://artandcommitment.umn.edu/yudicesanchez.html >.

${ }^{38}$ Yudice and Sanchez, Discerning the Heuristic Dimension of Public Art.
} 
alike. More specifically, Yudice and Osvaldo define the heuristic, not as a subject for art, but rather as a dimension of art:

The heuristic... is not something which puts itself at the service of a practice (e.g., a method which an art practice assumes); it is rather a dimension inherent in that practice, just as the epistemic, the aesthetic or the ethical are also dimensions of any art work. ${ }^{39}$

They regard practices which integrate a heuristic dimension as enabling of artistic acts.

Yudice and Osvaldo discuss the multiple instrumentalities of heuristic games and identify that such activities create a 'range of logics', rather than a single expected outcome. Discussing how heuristic experience motivates creative activity, they state: "We are referring to experiences in which the co-participants come to sense, witness, intuit, move with and/or channel a creative energy that is not essentially or exclusively aesthetic". 40 Thus, the art experience is not limited to the discovery of aesthetic knowledge, but also reveals how art intersects with the creative forces of everyday life.

For Learning To Love You More participants, the heuristic dimension of their experience is shaped by the use of the assignment instructions which serve as the structural framework for the creative process. The use of instructions organically stimulates heuristic problem solving methods because participants must begin by interpreting an assignment. Within each assignment, individual creative agents explore the poetics of an aesthetic proposition. The project promotes self-making through assignments that provoke new social and environmental relations (Assignment 2: Make a neigbbourbood field recording), the

\footnotetext{
${ }^{39}$ Ibid.

40 Ibid.
} 
development of critical perspective and voice (Assignment 8: Curate an artist's retrospective in a public place), the rediscovery of the past (Assignment 18: Recreate a poster you had as a teenager) and the exploration of non-traditional life strategies (Assignment 40: Heal yourself). Their interrogation occurs in the sphere of everyday life, deliberately outside of institutional settings like art training schools or formal art galleries. However, each recipient also engages a public sphere through the publication of their assignment reports on the website.

Let us now turn to a discussion of the impact of creative acts in everyday life and how they intersect with our popular digital technology. Through a consideration of vernacular creativity movements centered online, it can be better understood how the networked character of Learning To Love You More supports open participation.

\subsection{Vernacular Creativity}

The rise in creative acts by and for people who do not usually identify themselves as artists has been termed 'vernacular creativity' by scholars and new media analysts. ${ }^{41}$ Recently, text panels for the exhibition "Folk Archive: Contemporary Popular Art from the UK" (2006, Barbican Centre, London), curated by Allan Kane and Turner Prize winner Jeremy Deller, used the nomenclature of vernacular creativity to draw attention to the every-day quality of the artistic projects showcased. In addition, scholars of geography and urban life have been investigating vernacular creativity as a way of understanding the local creative production of

\footnotetext{
${ }^{41}$ Due to similar topic matter, the following section relies heavily upon the notion of vernacular creativity as articulated by scholar Jean Burgess. Her work specifically addresses how the common or every-day character of vernacular creativity intersects with digital culture. However, scholars in several fields have begun to use the term 'vernacular' to discuss the ubiquitous and wide-ranging forms of every-day creative work. For example, reference Roger D. Abrahams, Everyday Life: A Poetics of Vernacular Practices (Philadelphia: University of Pennsylvania Press, 2005), R. W. Brunskill Vernacular Architecture: An Illustrated Handbook. (London: Faber, 2000), Michel De Certeau, The Practice of Everyday Life. Trans. Steven F. Rendal (Berkeley: University of California Press, 1984), and Gary Alan Fine, Everyday Genius: Self-Taught Art and the Culture of Authenticity. (Chicago: Chicago University Press, 2004).
} 
every-day people. ${ }^{42}$ The word vernacular has roots in Latin, where it can be understood figuratively to mean 'native' or 'domestic', even 'folksy'. I will use the term 'vernacular creativity' to describe the Learning to Love You More project because it draws attention to everyday creativity outside cultural value systems or high art production. Because of this, my use of the term 'vernacular' is similar to Geoffrey Batchen's employment of the term in his discussion of 'vernacular photography'. For Batchen, the term is "both a provocation and a challenge". ${ }^{43}$ Using vernacular creativity as a way of understanding the Learning To Love You More project is most appropriate because the kind of art that the assignments ask a participant to accomplish could be made in any national setting, and in any home: Assignment 6: Make a poster of shadows; Assignment 33: Braid someone's bair; Assignment 53: Give advice to yourself in the past; Assignment 67: Repair Something. The assignments need only commonplace skills and everyday resources to perform required tasks. It is easy and interesting to participate in these creative projects.

In a similar fashion, art theorist Denis Dutton approaches the arts as a field of activities, objects and experiences that appear naturally in human life. ${ }^{44}$ The arts are not biologically driven (although biology is relevant to their development), but rather they depend on persistent, cross-culturally identified patterns of behaviour and discourse. The making, experiencing and assessing of works occurs without the influence or help from theorists, critics or institutions. The arts have been enjoyed previous to contemporary

\footnotetext{
${ }^{42}$ See Tim Edensor, Deborah Leslie, Steve Millington, and Norma Rantisi in Spaces of Vernacular Creativity: Rethinking the Cultural Economy (New York: Routledge, 2009).

${ }^{43}$ Batchen, Geoffrey. "On the History of Photography: A Talk With Geoffrey Batchen" (Interview). Folio. Retrieved 23 May 2005 from <http://www.gc.cuny.edu/faculty/folio/fall2002/Batchen.htm>.

44 Dutton, 51.
} 
theoretical rumination. The arts are rich, scattered, variegated realms of human practice and experience that have long existed in human history. ${ }^{45}$

The work of post-doctoral research fellow Jean Burgess can be used to evaluate how new media has 'democratized' artistic production in the twenty-first century. Her work suggests that the engagement of everyday people with art-making practices within contemporary society differs from historical folk-art practices because of its inclusive character, its dependence on networks to share results and the mediation of these creative practices by user-friendly digital technologies. Burgess defines vernacular creativity as:

...creative practices that emerge from highly particular and non-elite social contexts and communicative conventions, mediated and transformed when brought into relationship with digital distribution, consumption and network technologies. ${ }^{46}$

Vernacular creativity includes everything from making a scrapbook, to sharing digital photographs, to making crafts on a weekend. A website that typifies this kind of activity is Instructables.com (figure 17), a web-based documentation platform that allows makers to share instructions for a range of projects, including crafts, outdoor construction, food recipes, DIY machines, costumes and pranks. While final products of vernacular creativity may be put up for sale, participants in these communities emphasize the sharing component of their projects. Using digital photographs, chat forums and software to distribute ideas, advice and reports of finished creative projects, vernacular creativity communities seek to connect people who do creative acts. As a movement, vernacular creativity challenges the

\footnotetext{
${ }^{45}$ Ibid., 63.

${ }^{46}$ Jean Burgess, "Mapping Vernacular Creativity V.1.0" (2005), $<$ http://creativitymachine.net/2005/03/26/mappingvernacularcreativity-v-01/> and "Cultural Participation and New Media Literacy: Photography and the Flickr Network" (IR7.0: Internet Convergences, Brisbane, September 2006).
} 
fixed borders of the creative process, re-defines display, and works to dissolve the separation between the museum interior and its surrounding creative community.

However, the interface architecture of LearningToLoveYouMore.com establishes it as a different project than vernacular creativity ventures which emphasize timeliness, objectivity and expanded narrative as central tenants. Although the website encourages navigation via assignment number and report number, you can also view the reports chronologically by post date. The time the reports are posted may not relate to their creation: days or months may pass between the acceptance of an assignment and the posting of a final report on the website. As such, time is disregarded entirely through categorical navigation of content, which is privileged as the default navigation on the website. The assignments themselves also have a flexible and interrogative petspective of time, asking participants to capture current moments, or to reflect on past events and future possibilities. Objectivity is also not stressed on LearningToLoveYouMore.com, as websites are recognized as an inherently subjective media that encourages the sharing of personal opinion through public expression. Lastly, composed narrative is not a key concern as the images and reports are meant to stand for themselves as contributions to an evolving project.

Nonetheless, the rise of vernacular creativity exemplifies the shift in art-making worldwide towards a model that relies on digital technology to support daily creative acts. Flickr.com, a photo-sharing community network provides opportunity for the average person to share amateur creative content. In December of 2004, Flickr.com had an average of 30,000 uploaded photographs a day. ${ }^{47}$ In December 2009, there were on average 3,000

\footnotetext{
${ }^{47}$ Katharine Mieszkowski. The Friendster of photo sites. (Salon.com, 2004).
} 
uploaded images a minute, resulting in an average total of around 4,320,000 new photographs added to the website daily. ${ }^{48}$ The steady pace of creative content uploads on the website reveal that participation in vernacular creativity is growing exponentially.

As digital culture develops at a steady pace, it is important to remind ourselves that participation in the World Wide Web is a voluntary action. While interaction with the Internet is often passive, such as when one reads an article or consumes an image, vernacular creativity projects offer an entry point for a non-traditional participant to become engaged with art-making. Moreover, many involved in vernacular creativity communities online simultaneously participate in activities such as local 'meet-ups' in nearby coffee shops. Similarly, Learning To Love You More has manifested as a physical exhibition in several different cities and venues including a high school in San Mateo, California, a movie theatre in Houston, Texas, and a clothing store in Portland, Oregon. This suggests that Learning To Love You More offers more than a connection with a website: it celebrates acts of local creativity by the everyday person, and shares them on a global scale through the website. Aided by user-friendly technology, people are beginning to incorporate acts of creativity into their daily lives. Encouraged by accessible tools and democratic forums for exchanging creative content, people participate both locally and globally in acts of vernacular creativity.

${ }^{48}$ Home page, Flickr.com, 2009. 


\section{Chapter Two: Participatory Art-making}

In this chapter, I consider how art production has changed within a networked age to support participatory art practices. Participation in art activities affirms social bonds, promotes heuristic learning and opens poetic space for creative group play. In this section, I will first examine the history of participatory art, relying on Umberto Eco's theory of the 'open work' to discuss the development of participatory strategies in art-making. We will then consider how participatory art affects social bonding practices, drawing on Nicholas Bourriaud's essays on relational aesthetics. Finally, we will consider how the collaborative processes inherent in participatory art projects encourage the creation of poetic spaces wherein philosophical and aesthetic play can occur.

Participation emerged as a dominant theme within the art of the twentieth century, wherein artists worked to emancipate their audiences from their roles as passive viewers of art works. This culminated in many contemporary art projects which depended on an interactive relationship between artist, viewer and art work. A theoretical framework for participatory att practices has been addressed by theorists Umberto Eco, Nicolas Bourriaud, and Jacques Rancière, as well as artists and curators whose work is chiefly concerned with participation, including Joseph Beuys, Félix González-Torres, Lygia Clark and Hélio Oiticica. Recent investigations center on relational aesthetics wherein viewers serve as producers of new art works and new social relations.

Art production in which the viewer has an active role as a participant can be considered 'open' art. Art historians point to several terms and movements to discuss works of art which have an open and participatory character: the extended art practices of the 
1970's, open or systems-based art works, interactive art, kinetic art, the Fluxus international art events, and art in digital environments. LearningToLoveYouMore.com, the website that is the focus of this study, is a great example of an 'open' art project because it permits chance, discovery and difference. When art becomes more open, the meaning of the artwork often resides, not in the art object, but in what the art object provokes. Art historian Frank Popper observes:

The work loses its materiality, and becomes simply an effect or an event: the artist loses his halo and becomes a researcher; the spectator leaves the domain of cultural conditioning and himself becomes active and creative. ${ }^{49}$

The active creative experience that participatory art provokes will be the key concern of this chapter.

\subsection{Historicizing Participatory Art}

This section of the study will trace the precedents in art history that have contributed to the development of a participatory art-making practice as seen in Learning To Love You More. This historical overview will situate the project within an artistic tradition of extended art, and establish a historical grounding for participatory art works. We will examine the artists, artworks and movements that have laid the foundation for participatory art practice today.

Critic Clare Bishop delineates the two approaches common in participatory art: "an authored tradition that seeks to provoke participants, and a de-authored lineage that aims to embrace collective creativity; one is disruptive and interventionist, the other constructive and

49 Frank Popper, Art, Action and Participation. (London: Studio Vista, 1975), 8. 
ameliorative." 50 In both trajectories, the issue of participation becomes "increasingly inextricable from the question of political commitment". ${ }^{51}$ Bishop outlines three main concerns for contemporary participatory practice: activation, authorship, and community. These are different themes from the early participatory works from the 1960 s. Today, there is a demonstrated concern for the active subject, continued questioning of the tenacity of authorship, and a perception that chaotic social bonds can be restored through collective elaboration of meaning. ${ }^{52}$ However, in order to fully comprehend how these concerns have become central to contemporary participatory art, it is important to examine the roots of participatory praxis within art history.

In the twentieth century, several artists' groups and movements worked towards the activation and engagement of the audience. In the early twentieth-century, the Italian Futurists and the Zürich Dadaists directly 'activated' their spectators by attacking or scandalizing members of their audiences. The Surrealists in Paris in the 1920 s, under the leadership of André Breton, gave up conscious control over art. Popular methods of art making for the Surrealists included automatic drawing and the cadavre exquis, or exquisite corpse, a collaborative group drawing game where participants add to an image on a folded piece of paper without knowledge of the previous contributions. The Russian avant-garde in the 1920s and 1930s worked against the solitary creative artist, reframing the artist as a collectively engaged agent. Similarly in the 1950s and 1960s, the International Fluxus movement, Guy Debord's Situationist International, and Andy Warhol's Factory all encouraged the collaboration of artists, as well as a synthetic approach to artistic media.

50) Claire Bishop. Participation. (Cambridge, MA: Whitechapel MIT Press, 2006), 11.

51 Ibid., 11.

52 Ibid., 12. 
Each of the movements attempted to reframe the conception of the artist's position as an isolated and elevated creator of an art object. The Fluxus artists, for example, presented themselves as event managers and entertainers. Warhol's philosophy led him to approach art as business and business as art. ${ }^{53}$ Each of these artists and artists' groups faced what curator Rudolf Frieling claims is the key paradox in contemporary art making: "how to do away with art by making art??. ${ }^{54}$

Other strategies that attempted to negate or question the structure of art were Event Scores, Happenings, and Instructive Artworks. Event Scores are an att form whose creation is credited to the artist George Brecht. Brecht developed the concept at John Cage's Experimental Music Composition classes at the New School for Social Research in New York in the 1960s. Composed of simple actions, ideas and objects, 'Event Scores' recontextualize everyday life as performance. They often appear as instruction sets that direct action or a proposed action yet remain open to interpretation and change. Event scores, like musical performances, can be preformed by either the creator or another performer. Georges Brecht distributed 'event cards' in the Fluxus mail editions Water Yam (1963) and Fluxkit (1965). The event cards featured instructions for events, such as \#2 Proposition: Make a salad (1962), as well as for the creation of objects and tableaux. The event cards point to art "on the brink of vanishing into invisibility" 55 because they emphasized the ephemeral character of the instructions and thereby reanimate the quotidian.

\footnotetext{
${ }^{53}$ Boris Groys, "A Genealogy of Participatory Art" in The Art of Participation, 1950 to Now. SFMOMA

Publication (New York: Thames \& Hudson, 2008), 27.

${ }^{54}$ Rudolph Frieling, "Toward Participation in Art" in The Art of Participation, 1950 to Now. SFMOMA

Publication (New York: Thames \& Hudson, 2008), 34.

${ }^{55}$ Ibid., 4.
} 
The 'Happening' was the culminating aesthetic experience in artist Allan Kaprow's search for an active art form. Also a prominent Fluxus artist, Kaprow coined the term 'Happenings' to categorize his series of set-up art events. Kaprow's seminal Happening event was his 18 Happenings in 16 Parts (1959). The Happening was hosted by the Reuben Gallery in New York and featured disparate events, including action painting and flute playing, taking place simultaneously in multiple gallery rooms. Drawing on assemblage and environmental art practices, the Happening occurred "outside the context of existing architectural and social forms". ${ }^{56}$ Historian of participatory art Frank Popper describes how the Happening gently stirs creative response:

Although the early happening, in particular, appear at first sign to have followed a very strict code of participation, and consequently to have been limited in time and influence, they succeeded in initiating various forms of activity in which the difficult process of transferring responsibility from the artist to the public occupied the centre of the stage. The description of the process in 'moral' terms can of course be seen in a more neutral way as the passage from contemplative behavior to active participation, ludic activity, autonomous behavior and finally true creativity. ${ }^{57}$

As such, the Happening changed the mode of artistic production, announcing that the end result was not an art object or effect, but rather the stimulation of further artistic creativity.

Yoko Ono, the celebrated Japanese-American artist, musician and widow of John Lennon, was also involved in the International Fluxus movement, both in Japan and in New York. Her publication of Grapefruit (1964), a conceptual art book of creative instructions, was an early invitation for the audience to become directly involved in the art-making process. The artist's book contains semi-abstract instructions for experiential events that the reader

\footnotetext{
${ }^{56}$ Popper, 22.

57 Ibid., 26.
} 
completes in his or her mind. Many of the Grapefruit pieces are well known within the oeuvre of Yoko Ono and have served as the basis for several performance events. Like the Learning To Love You More project, Grapefruit has also manifested as an art exhibition.

Ono's creative practice is an important precedent in the consideration of Learning To Love You More, especially because of her experience with instruction-based events. In contrast to Allan Kaprow's conception of Happenings as an assimilation of arts events, Ono instead defined her event-based work as being drawn from sensory perception. ${ }^{58}$ In a lecture at Wesleyan University in January 1966, Ono identified where her event practice differs from that of the New York Fluxus artists: "It is not a get togetherness as most Happenings are, but a dealing with oneself. Also it has no script as Happenings do, though it has something

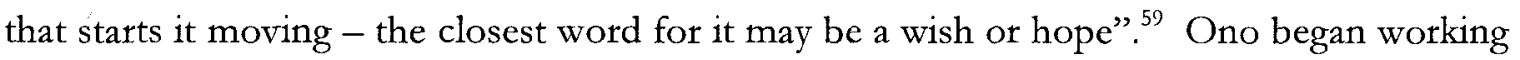
overtly with instructions as a form for art production in 1962 when her Instruction Paintings were exhibited at the Sogetsu Art Center in Tokyo. The previous year she had exhibited canvases with instructions attached to them at the AG Gallery in New York, but the Tokyo exhibition presented a set of typed instructions as paintings in her attempt to push visual art to its most conceptual extreme. The abstract character of the instructions provokes a range of possible ways to realize the artwork (or not). Two examples are SHADOW PIECE (1963, figure 18):

Put your shadows together until they become one.

\footnotetext{
${ }^{58}$ Yoko Ono, To the Wesleyan people (lecture transcript). (Wesleyan University, Connecticut, 1966) $<$ http://imaginepeace.com/news/archives/2526>.

${ }^{59}$ Ibid.
} 
And WALKING PIECE (1964, figure 19):

Walk in the footsteps of the person in front.

1. on the ground

2. in mud

3. in snow

4. on ice

5. in water

Try not to make sounds.

The Instruction Paintings aim at exploring time, space and possibility as invisible elements in an artwork, rather than focusing on the typed instructions as visible elements.

Fluxus artists obtusely indicated to their audiences that their participation was desired, yet several other artist groups were directly invoking spectator participation. An early artist network that encouraged participatory art practice was the Nouvelle Tendance, a group of art exhibitions throughout Europe in the 1960s. The movement's greatest achievement was how it articulated the relations between young contemporary artists working in Constructivist traditions in Eastern and Western Europe. The movement represented arguably the first time since the 1920s that artists from different nation states were working together to address romantic and individualistic notions of art practice, in order to support research and exploration in the artistic process. The Swiss artist and designer Karl Gerstner wrote the preface to a group exhibition in 1964, which stated:

Our aim is to make you a partner. Our art is based on reciprocity. It does not aspire to perfection. It is not definitive, always leaves the field open between you and the work. More precisely our art depends on your active participation. What we are trying to achieve is for your joy before the work of art to be no longer that of an admirer but of a partner. ${ }^{60}$

${ }_{60}$ Popper, 15. 
These avant-garde artists were interested in the way art functions in society, and the ways in which participatory structures could stimulate greater aesthetic pleasure.

Three independent artists who are considered as some of the most influential early practitioners of the principle of participation are Lygia Clark from Brazil, Roy Ascott from Britain and Yaacov Agam from Israel. In the 1960s, Lygia Clark created 'relational objects', art objects that would produce or point to relations between the people who used them. Examples include her Rede de Elástico (1973, figure 20), nets woven from elastic bands that would be used to cover people or her Mask with Mirrors (1967, figure 21), double-wearer spectacles with spinning mirrors that skewed each viewer's perspective of their partner. The invention of these 'relational objects' reveals how the status of the object shifted in participatory art practices: "Objects proposed by the artist [took] on a merely intermediary role (like that of the artist himself), and thus [lost] their separate, fetishistic status as objects of veneration and speculation". ${ }^{61}$ Throughout the 1960 s, Brazilian artists including Lygia Clark and Helio Oiticica were considered the most active and creative artists who were directly addressing art's relation to participants. ${ }^{62}$

Another early pioneer of spectator activation was the experimental artist Yaacov Agam. Agam worked from the 1950 s to the 1980 s and was considered a leader in optical and kinetic art fields. His aesthetic practice featured a concern for change and thus created transformable structures which were the equivalent of paintings and reliefs. He created 'Agamographs' (figure 22.1, 22.2), which were prints made using lenticular lenses that would physically engage the viewer. The lenticular printing methods used to create the artworks

\footnotetext{
${ }_{61}$ Popper, 14.
}

${ }^{62}$ Frieling, 42. 
provided an illusion of depth in the produced image, which morph when tilted, similar to holographic hockey cards. Lenticular effects cause the viewer to see radically different images depending on their physical relation to the work of art. ${ }^{63}$

Roy Ascott is a British artist whose work since the 1960s has focused on cybernetic systems and telematic art. The exploration of cybernetics is integral to the development of participatory art practices, especially those located online. Cybernetics (from the Greek kubernān meaning 'to govern') describes the theoretical study of communication and regulatory systems, especially their structure and control processes. Cybernetics is essentially the study of self-governance, an important principle in participatory art-making. Ascott assumes a 'cybernetic stance' in his art practice because he views dialogue and feedback as essential factors to the success of his artworks. Ascott's telematic art project La Plissure du Texte (The Pleating of the Text, 1983) was first theorized by the artist in 1966. Eleven 'authorship' nodes located in Canada, the U.S., Europe and Australia collaborated on the construction of a narrative. The collaborators "participated in collectively creating and contributing texts and ASCII-based images to the interactive unfolding, or distributed authorship, of the emerging story". ${ }^{64}$ This kind of art bears a 'cybernetic purpose', wherein the spectator becomes a participant because there is a need for active agents to sustain a system. When the viewer must participate in the creation of an artwork in order for there to be an artwork, it is evident that artists have changed the regulatory process of aesthetic experience. Traditionally, the viewer's relationship to paintings was cardinal: the artwork fundamentally was seen as an expression of the artist while the audience passively viewed it

\footnotetext{
${ }^{63}$ Popper, 14.

${ }^{64}$ Edward A. Shanken. Telematic Connections Timeline.

$<$ http://telematic.walkerart.org/timeline/timeline_shanken.html >.
} 
in a gallery. In cybernetic or telematic art, viewers become participants distributed across networks, located in different countries and active at different times. The art is not meant to be visited upon its completion, but the art element resides in the aesthetic experience of joining in networked exchange.

Major exhibitions organized in the 1960s and 1970s helped to articulate the growing interest in open and participatory art. In 1969, curator Harald Szeemann organized Live In Your Head: When Attitudes Become Form: Works, Concepts, Processes, Situations, Information at the Kunsthalle Bern, Switzerland (April - March 1969). This exhibition featured artworks representative of extended art practices by artists such as Carl Andre, Hans Haacke, Douglas Huebler, Eva Hesse, Yves Klein, Joseph Kosuth, Sol LeWitt, Robert Morris, Bruce Nauman, Dennis Oppenheim, Richard Serra, Robert Smithson, Richard Tuttle, and Lawrence Weiner. ${ }^{65}$

The convergence of extended art practices and technology was being explored in experimental New York galleries. Art historian Jack Burnham curated Software, Information Technology: Its New Meaning for Art (1970) at the Jewish Museum in Manhattan. Burnham was concerned with the underlying aesthetic principles behind art, and employed the metaphor of 'software' to discuss the conceptual structure of artworks. Contrastingly, his use of the metaphor of 'hardware' described actual art objects in aesthetic production. The layout of the exhibit was analogous to Marcel Duchamp's Large Glass (1915-22). The first two floors drew parallels between computer information technology and structuralist art theory by presenting rooms full of computers and experiments. The top floor was dedicated to

${ }^{65}$ Specific Object. I ive in Your Head (pamphlet reprint).

$<$ http:/ $/$ www.specificobject.com/objects/info.cfm?inventory_id=11107> 
conceptual art works, which to Burnham represented "the last intelligent gasp of the art impulse". ${ }^{66}$ Burnham argued that "Duchamp was trying to establish that artists, in their lust to produce art, to ravish art, are going to slowly undress [it] until there's nothing left, and then art is over." ${ }^{67}$ But Burnham's interpretation of Duchamp is not fatalistic: he doesn't believe that conceptual analysis brings the dissolution of art. Rather, he claimed that art was "dissolving into comprehension", 68 and believed in the eradication of the distinction between art and non-art.

The redefinition of the categories of art production was being addressed on an international platform in major contemporary art fairs and exhibitions worldwide. Documenta 5 (Kassel, Germany, 1972), also under the artistic direction of Harald Szeemann, had a massive cultural impact. This exhibit featured socially engaged artists who worked in process art, conceptual art and other extended art practices. Many artists attempted early institutional critique, such as Claus Oldenburg's self-organized mini-retrospective 'Mouse Museum' and Joseph Beuys's utopian 'Information Office for the Organization for Direct Democracy by Referendum'. At the Information Office, Beuys debated issues of freedom, democracy and socialism with visitors for 100 days, ending with a "Boxing Match for Direct Democracy" on the final day. ${ }^{69}$ These examples illustrate how the most notable effect of Documenta 5 was its early attempt to reframe the role of art in society. Leading critics observed the controversial effects of this redefinition on the art world, including Roberta Smith, arts editor for The New

\footnotetext{
${ }^{66}$ Edward A. Shanken. The House That Jack Built: Jack Burnbam's Concept of "Software" as a Metaphor for Art. (Duke University, 1998) < http://www.artexetra.com/House.html>.

67 Ibid.

${ }^{68}$ Ibid.

${ }^{69}$ Regina Brenner. Political Activism. Walker Art Centre

$<$ http://www.walkerart.org/archive/F/9C4309B0B50D8AA36167.htm>.
} 
York Times, who commented that "the curators' vision - to reflect social and cultural realities beyond contemporary art - riled the art world before the show even opened" 70

Recently, two major art exhibitions within the past year have put participatory and viewer-centred art in the centre of art historical and curatorial discourse: The Art of Participation: 1950 to Now (November 2008 - February 2009), organized by the San Francisco Museum of Modern Art (SFMOMA), and Caught in the Act: The Viewer as Performer (October 2008 - February 2009), held at the National Gallery of Canada. Both exhibits addressed the diverse ways artists have challenged traditional models of authorship and creative production. Moreover, the artworks presented engaged art institutions and re-examined utopian notions of political participation. ${ }^{71}$ The SFMOMA exhibit was organized as a chronological retrospective, whereas the exhibition at the National Gallery of Canada focused on the work of eleven artists and artist collectives. However, both exhibition intended to deal with the transforming condition of how works of art operate today and the new questions they provoke in their audiences. Art galleries, in their role as recognized social institutions, reposition the personal space of an artwork within the context of a social space. Participatory artworks within gallery space draw special attention to the embodied and activated experience of the spectator. The activation of the visitor in participatory art is "analogous to the viewer's engagement in the world". 72

\footnotetext{
70 Roberta Smith. "Art in Review: Documenta 5". The Newy York Times.

<http:/ www.nytimes.com/2007/09/07/arts/design/07gall.htmleex=1346904000\&en=35c6aa95c068d928\&ei

$=5124 \&$ partner $=$ permalink \&exprod $=$ permalink $>$.

${ }^{71}$ Frieling, 14.

${ }^{72}$ Bishop, 11.
} 
During the 1980 s, participatory art practice became more critically engaged. Spurned by the political crisis of cultural funding cuts under the Ronald Reagan administration in the United States, and social issues like the burgeoning AIDS epidemic, American artists once again expanded creative practice. Robert Atkins observed that at this time: "the American artist's outsider status - beholden neither to patron nor institutional sponsor - liberated twentieth-century practitioners to pursue virtually any approach, format or theme imaginable". ${ }^{73}$ This total freedom of artistic pursuit meant that non-traditional projects, especially aesthetically engaged political projects, could gain artistic clout in the public sphere. A notable example of participatory creative practice at this time was the NAMES Project AIDS Quilt (1987; now trademarked as the AIDS Memorial Quilt, figure 23). The AIDS Quilt was organized in San Francisco by the activist Cleve Jones and represented "a genuine community artwork with no initial connections to professional artists, galleries or art institutions". ${ }^{74}$ The project encouraged open creativity by participants, inviting people to submit quilted rectangle panels in the mail or at community events. Durability and size requirements (each quilt square was to measure $3^{\prime}$ by $6^{\prime}$ ) were the only factors evaluated in the submission process. The project drew thousands of entries (there are now 47,000 rectangles), was featured on the cover of People magazine in 1988 and was awarded the Nobel Peace Prize for 1989. The primarily political goal of the NAMES Project AIDS Quilt helped it to transition from a community craft network into one of the most recognizable media artworks.

\footnotetext{
${ }^{73}$ Robert Atkins, "Politics, Participation, and Meaning in the Age of Mass Media" in The Art of Participation, 1950 to Now. SFMOMA Publication (New York: Thames \& Hudson, 2008), 60.

${ }^{74}$ Atkins, 61.
} 
To find greater precedent for networked art activity, we can turn to artists such as Ant Farm, the Eventstructure Research Group and Tom Marioni. Ant Farm was a San Francisco-based alternative collective of experimental artists and architects founded by Chip Lord and Doug Michaels in 1968. Ant Farm embraced the latest technologies in the construction and documentation of their art projects, notably documenting most of their early performances and exploits with early video cameras. The group customized cars and vans and toured their inflatable 'nomadic' architectural structures to university campuses actoss the country, supported by an early network of counter-culture activists. The Eventstructure Research Group was an Amsterdam based artist group which stressed the importance of process over product. Known for their inflatable structures and alternative cinema production, the group used contemporary technology and organized public art events in opposition to 'museum art', encouraging participation in operational art activities. Tom Marioni is a San Francisco based artist who has been hosting his philosophical art salons since 1970. Held in dozens of different locations over the years, his salon, The Act of Drinking Beer with Friends is the Highest Form of Art (1970-Present), offers participants a free beer in exchange for their social engagement. Marioni's conceptual art practice sought to reify everyday events as high art activities, and re-imagine the social situation of artists. ${ }^{75}$ These examples reveal that art does not have to meet micro-utopian claims to have a meaningful aesthetic or social experience. Curator Rudolf Frieling comments on how instigated activity is sufficient for a successful participatory artwork: "When an artwork is subject to public intervention, it does not necessarily become more interesting or

75 Frieling, 46. 
aesthetically charged. What is exhibited is rather the extent to which simple communality or antagonistic forces are acted out". ${ }^{76}$

There has also been a recent focus in art historical scholarship on the effect of dialectical projects. Frieling delineates this trend, noting how Homi K. Bhabha investigates “conversational art", Tom Finkelpearl pursues "dialogue-based public art", and Grant Kester explores "dialogical art". 77 All of these critical strategies reveal that the interest in participatory art practice rests primarily upon the quality of the relations it provokes: between the artist and audience, between the artist and a network, between participants, between creators and the narrative of art history.

The instigation of conversation and dialogue are thus presented as an important responsibility of the contemporary artist. Art history has been characterized by the way artists and movements respond to the achievements of other artists and other movements. Modernist artists responded to classical nineteenth-century culture, abstract artists responded to Cubism, and Pop artists responded to Abstract Expressionism. However, Lev Manovich stresses that: "conversations between artists and movements were typically not true conversations. One artist/school produced something, another artist/school made something in response, and that was all. The first artist/school usually did not react in turn." ${ }^{78}$ However, as mass media technologies grew increasingly popular, cultural practice in the 1980 s began to engender an authentic conversational style. Music videos influenced the

\footnotetext{
${ }^{76}$ Frieling, 48.

77 Ibid., 36. See also Homi K. Bhabha, The Location of Culture (New York: Routledge, 1994), Tom Finkelpearl, Dialogues in Public Art. (Cambridge, MA: MIT Press, 2001) and Grant Kester, Conversation Pieces: Community and Communication in Modern Art. (Berkeley: University of California Press, 2004).

${ }^{78}$ Lev Manovich, "Art after Web 2.0" in The Art of Participation, 1950 to Now. SFMOMA Publication (New York: Thames \& Hudson, 2008), 76.
} 
way motion pictures were edited, and movie cinematography began to influence video game design. The conversational nature of art production will change even further and even faster in networked culture because, in a matter of hours, individuals (rather than professional cultural producers) can exchange media messages. ${ }^{79}$ That exchange is free flowing, unstructured and often collaborative, much like the participatory frameworks of contemporary art practice.

\subsection{The Influence of Theory: Umberto Eco's The Open Work (1989) and Nicolas}

\section{Bourriaud's Relational Aesthetics (2002)}

A high degree of anonymity and its flexible character defines Learning To Love You More as an art project remarkably open to chance. In his text The Open Work (1989) Umberto Eco discusses art works which are not defined by a singular order, but rather characterized by a multiplicity of possible orders. ${ }^{80}$ His theory centers on the concept of opera in movimentowork in motion - which he observes has its roots in the 'aleatory' music of Stockhausen and Pousseur, the dynamism of Alexander Calder's mobiles, and the open structure of poet Stéphane Mallarmé's Le Livre.

Open art works are not finite and fixed works that dictate a specific reproduction, but instead are artworks "brought to their conclusion by the performer at the same time as he experiences them on an aesthetic plane". 81 This conflation of performance and reception is common in open works of art, revealing new logics for interpretation. Eco comments on the importance of interpretation, stating:

\footnotetext{
${ }^{79}$ Manovich, 77.

${ }^{80}$ David Robey, ed. in Umberto Eco's The Open Work. (Harvard University Press, 1989). ix-x

${ }^{81}$ Eco, 3.
} 
... a work of art, therefore, is a complete and closed form in its uniqueness of the balanced organic whole, while at the same time constituting an open product on account of its susceptibility to countless different interpretations which do not impact on its unalterable specificity. Hence, every perception of a work of art is both an interpretation and a performance of it, because in every perception the work takes on a fresh perspective itself. ${ }^{82}$

The open work tends to encourage, in Pousseur's words, 'acts of conscious freedom' ${ }^{83}$

Art works such as traditional paintings and classical sculpture are relatively unambiguous in their very nature, directing aesthetic responses in a particular direction. ${ }^{84}$ In contrast, Eco asserts that ambiguity is produced when 'established conventions of expression $^{85}$ are contravened or denied. Eco describes how ambiguities in works of 'open' literature reveal the different degrees of openness a work of art can contain. Eco identifies Stéphane Mallarmé's Le Livre as a text having an open material form, wherein the reader can arrange the actual pages of the book into different sequences to produce varying narratives. Eco posits James Joyce's Finnegans Wake as remarkably open in its meaning and semantic content. This implies that the open art work, without formal laws or structure, can provoke new meanings:

... because in it an ordered world based on universally acknowledged laws has been replaced by a world based on ambiguity, both in the negative sense that correctional centers are missing and in a positive sense, because values and dogma are constantly being placed in question. ${ }^{86}$

$82 \mathrm{Eco}, 4$

${ }^{83}$ Ibid.

${ }^{84}$ Robey, $x$.

${ }^{85}$ Ibid., xi.

${ }^{86} \mathrm{Eco}, 9$. 
In addition, every execution of a work is distinct from the greater definition of the open work: "Every performance explains the composition but does not exhaust it. Every performance makes the work in actuality, but is itself only complementary to all possible other performances of the work" ${ }^{37}$ The open work is not a participatory free-for-all, but remains an ordered event where the performer is presented with "the opportunity for an oriented insertion into something which always remains the world intended by the author". ${ }^{8}$ In this way, an open artwork stimulates "a new cycle of relations between the artist and his audience, a new mechanics of the aesthetic perception, a different status for the artistic product in contemporary society". ${ }^{89}$ Moreover, the open work presents new questions concerning pedagogy and sociology, and provokes further questioning of the traditional schema of the Western art historical canon. In short, Eco asserts that the open work "installs a new relationship between the contemplation and the utilization of a work of art". 90

The significant feature of Learning To Love You More is its ambiguous character; this offers an opportunity to question what art is for and what one is to do with art today. This line of questioning, prominent in contemporary art discourse, has consequently led to an interest in relational aesthetics and vernacular creativity movements. Both of these movements are gaining momentum in the twenty-first century because they feature a continuing redefinition of art and the way art functions in society.

While Umberto Eco's Theory of the Open Work demonstrates the way that the character of participatory art works has developed historically, many artworks made since the

\footnotetext{
${ }^{87}$ Eco, 15.

88 Ibid., 19

${ }^{89}$ Tbid., 23.

${ }^{90}$ Ibid.
} 
1990s within the field of relational aesthetics prove to be some of the most notable applications of this theory. Defined by the French theorist Nicolas Bourriaud, relational aesthetics is "an art taking as its theoretical horizon the realm of human interactions and its social context, rather than the assertion of an independent and private symbolic space". ${ }^{91}$ By this definition, art becomes an experiment with the 'real' world, concerned with exposing and exploring the levels of relations between humans and their social context. Bourriaud's theory is pertinent to consider for this study as most of the art instructions from LearningToL LveYouMore.com promote relational aesthetics.

While the theory of relational aesthetics is in line with the continuing history of art, the emphasis on human interaction affirms its difference from other art movements that may take social context as a point of exploration. Public art, including murals or monuments, are examples of social att based on the paradigm of display. Learning To Love You More encourages a different presentation paradigm, one that is interactive, intermittent and ephemeral. Bourriaud defines the nature of art as "a human activity based on commerce", suggesting that art is a good which is intended to be exposed and considered by other humans beyond the creator. Moreover, Bourriaud continues to explain that art functions differently than other goods of commerce suggesting that an artwork's "sole function is to be exposed to this commerce". ${ }^{93}$ Art in relational aesthetics is a state of encounter before it is anything else. Rirkrit Tiravanija's projects and installations in New York, Berlin and Bangkok have investigated the social role of the artist, specifically his Thai Soup events where he makes and shares a meal of hot soup with participants in galleries or in collector's homes.

\footnotetext{
${ }^{91}$ Nicolas Bourriaud. Relational aesthetics (Les Presses du réel, 2004), 3.

${ }^{22}$ Bourriaud, 6.

${ }^{93}$ Ibid.
} 
Relational aesthetics demands the dematerialization of art. This is not to say that relational aesthetics purports that creation of art objects should not be supported or pursued, but rather implies objecthood should no longer be considered the primary condition of art. This is supported by an expansion of the traditional categories of art to include photography, performance art, video art, intervention art, kinetic art, conceptual art and many other art-making practices, alongside painting and sculpture in the twentiethcentury. As the status of art shifts, the reception of art is also altered immeasurably. Art projects that emphasize participation and aesthetic experience allow artistic communities to circumvent the dominant commercial art market. Art moments or encounters, the primary product of relational aesthetics, have no exchange value.

Although art has long been dependent upon commercial markets for patronage, increased access to art instruction and support networks have allowed artists to pursue ideas independent from the concerns of the art markets. Bourriaud asserts that "art was intended to prepare and announce a future world: today it is modelling possible universes". ${ }^{94}$ If one follows Bourriaud's encouraging perspective on the state of art, one is led to believe that the role of art has taken a considerable jump in how it functions in today's post-modern world. As relational aesthetics becomes more prominent, we see an increasing number of artworks that present an idea or an experience instead of an object. Art experiences become examples of ways of living that focus on the interactions between human beings.

As art gains a more experiential character, the creative act of making fuses with the reception of a work of art. Art in the field of relational aesthetics appears more as a

${ }^{94}$ Ibid., 2. 
continuing experiment. The iteration of an art-work will change as time progresses, offering audiences a different experience each time they encounter a specific work. Art develops a volatile nature which varies often and widely.

This volatility and change are the desired conditions for many artists working in the field of relational aesthetics. The indefinite conditions of time and space as presented in artworks like Learning To Love You More challenge an audience member's perception of reality. The scope of the project promotes a conception of human engagement that is multi-layered and based on lived experience. This scope also creates opportunity for dialogue to occur. The work lends itself to interpretation based both in phenomenological perception and in conceptual reflection.

This line of communication between artist and audience members illustrates that participation in an art-work creates opportunity for authentic dialogue to be created. The traditional hierarchy in the art world that presents the artist as privileged over the audience is deconstructed, as the artist and audience activate the total art experience together.

While relational aesthetics has been a popular mode of participatory art production, it has also drawn criticism regarding its success as a critical art practice. In her article "Antagonism and Relational Aesthetics" (2004), Claire Bishop offers a critical analysis of the theory of relational aesthetics. Her article explores implications of Bourriaud's theory in reference to contemporary socially engaged or open-ended works of art. Her criticism draws attention to Bourriaud's presentation of human relations as an end product of artworks within the relational aesthetics movement. Bishop suggests that Bourriaud's argument lacks specificity about the nature and intention of those human relations. Moreover, she claims 
that the relations and dialogue stimulated by relational art projects are not always democratic, and are not necessarily productive without an allowance for antagonism.

I agree with Bishop's assertion that Bourriaud's account of relational aesthetics privileges intersubjective telations over detached opticality. However, her contention that the quality of the relationships in relational art is never investigated is less of a concern for this thesis. Bishop's critique of relational aesthetics calls for the inclusion of antagonism in democratically-oriented projects. This demand for explicit political engagement in artmaking represents a great contribution to the ethical goals of contemporary art, but her criticisms seems more pertinent to Bourriaud's text than application to the Learning To Love You More p roject. Learning To Love You More im plicitly shares some of the qualities of relational aesthetics, but it doesn't intentionally do so. The character of the project is democratic in that it features open participation, and it does allow for antagonism in the completion of the reports. The power of the project resides both in its ability to take itself seriously in its attempt to produce meaningful social relations (between participants and their family, between participants and their community, between participants and strangers) but also its ability to include humour, irony and nonsense in the art activities.

\subsection{Collaboration in Leaming To Love You More}

Fundamentally, Learning To Love You More encourages the perspective that contemporary art engagement should be a participatory experience. Frank Popper asserts that soliciting the viewer has always been an integral practice in art-making, but observes that there has been a qualitative rupture in what is requested of the viewer within contemporary art. He notes that contemporary participatory practices desire "total response, that is to say, contemplative and 
physical at the same time". ${ }^{95}$ When the viewer is fully engaged in an art experience, he is no longer just a 'spectator' and the term becomes inadequate. Popper suggests alternative titles: executant, actor, user, collaborator, creator. The necessary revision of nomenclature points to the transitional status of the creator in participatory artworks: "the new active role of the spectator within the aesthetic process develops necessarily from the dismissal of the unique and individualistic artist, and the flourishing of group activity demands a new level of individuality in the aesthetic process". ${ }^{96}$

Beyond participation, collaboration has become increasingly important, both in art practice and for online protocol. Participation describes the action of taking part in an activity, whereas collaboration describes the process where individuals work together to achieve a goal or produce an object. Collaboration "elevates the role of the participant to cocreator". ${ }^{97}$ Collaboration was not the model social practice for old master painting workshops during the Quattrocento and Cinquecento in Italy. Vasari observes that Michelangelo had stormy relations with his workshop assistants, whereas Raphael was adept at managing his pupils, yet both accounts highlight the fact that each artist was considered a solitary creative genius. Contemporary collaborative practices divert from this historical perception. For example, Roy Lichtenstein, Claus Oldenburg and Christo each are prominent artists today who have extended the title of 'co-creator' to their wives, Dorothy Lichtenstein, Pat Muschinski and Jeanne-Claude, in recognition of their contributions on creative ventures.

95 Popper, 10.

${ }^{96}$ Ibid., 11.

${ }^{97}$ Atkins, 58. 
Moreover, the oeuvre of Christo and his late partner Jeanne-Claude presents another model for collaboration, as their large-scale environmental art projects necessitate the assistance of volunteers for success. While Christo privately funds his art projects through auctioned sales of his drawings and preparatory designs, volunteer labour is used to construct and install the artworks. Atkins considers the contract between the artist and his workers: “[Christo's] relationship with his volunteers is predicated on barter: in exchange for labor, he offers a sense of inclusion and community in a highly mediated event". ${ }^{98}$ Judy Chicago is another artist who employs collaborative labour to construct art projects. The Dinner Party (1974-1979) and the Birth Project (1980-1985) were both assembled by volunteer craftswomen, but with less conviviality than Christo's endeavours. Rather, Chicago is said to run her studio in a manner more akin to 'a Hollywood studio than an artist's atelier,, retaining complete oversight over the outcome of the project. Yet, Chicago notably offered her volunteer participants great creative freedom in completing their assumed work and credits them in the completed artwork.

Collaborative practices are again under scrutiny as new protocols for participation are delineated for online environments. While collaboration and user participation are popular modes of creative production, they are not dominant practices. It would be incorrect to assume that all visitors to Learning ToLoveYouMore.com participate in the project. Rather, it is more likely that the 8000 participants in the project represent the distilled active engagement of several thousand more visitors to the site. This can be attributed to what network theorist Geert Lovink refers to as the 'one percent rule' of participation in online environments: "if

\footnotetext{
${ }^{98}$ Atkins, 59 .

${ }^{99}$ Ibid.
} 
you get a group of 100 people online, one will create content, 10 will interact with it (commenting of offering improvements), and the other 89 will just view it". ${ }^{100}$ The challenge with collaboration, then, is to create a framework for participation that engages the viewer both as an individual and a member of the networked human condition. Atkins considers the task at hand for contemporary artists:

If art is to continue to matter, artists must not only provide alternative ways of participating, but also of cultivating critical perspectives that ensure the possibility of individual and collective engagement in an age when the meaning of both are tortuously twisted by the forces of global capital. ${ }^{101}$

The invitation to create meaning from a multilayered aesthetic experience may be unfamiliar to an audience member who is used to the linear narratives of meaning presented to them within historical art. As a result of the didactic presentation of meaning presented in gallery wall panels and text books, society establishes that contemporary art must be interpreted by an authority figure in the art world before it is presented to the public. This line of thinking has created a politics of interpretation wherein the everyday citizen avoids hermeneutic responsibility when encountering art. Instead, they relinquish direct involvement with an artwork to a curator or artist 'who knows better'. Yet, Learning To Love You More offers an opportunity for mass audiences to reclaim interpretive authority. The specifics of an experience with the Learning To Love You More will be unique to each participant, offering the individual alone the occasion to interpret their experience. Exploring the reports with cultural analogies and personal memories continues to make it 'run' in different contexts. In this way, Leaming To Love You More is not tied to a specific meaning, rather it invites multiple stake-holders to create its interpretation. While creators in

${ }^{100}$ Geert Lovink, Zero Comments: Blogging and Critical Internet Culture (Routledge, 2007), xxvii.

101 Atkins, 64. 
Learning To Love You More participate in the project, they collaborate in the articulation of its greater meaning.

This suggests that art within a post-modern society champions difference and seeks to avoid meta-narratives. The deconstruction of the fixed borders of the art historical canon occurs through specific, situated, and active encounters with art. In contrast to the apparent demise of the teleological version of modernity, lived reality is presented as a natural place of growth. ${ }^{102}$ Artists have begun to work from the outside-in, rather than from the inside-out; contemporary art-makers seem to focus on what they can add, expand or parody within the traditional canon, rather than following it as a body of laws. The art historical canon has become a point of departure for artists who endeavour to re-imagine art and the creative processes.

Recent revisions of the art historical canon include David Summer's landmark study Real Space: World Art History and the Rise of Western Modernism (2007). This text traces the development of art through the paradigms of real space and virtual space. Most historical artists' groups, especially those who employ collaborative strategies, have presupposed the principle of real space as necessary for a successful artwork. The shared environment between the creator and the public was meant to: "unite the artist and the audience at a particular location". ${ }^{103}$ However, as computer networks achieve greater scope, and individuals become more invested in online identity performance, it is less imperative that real space be shared for collaborative projects to succeed. 'Online' is now considered as much of a 'real space' as a physical building and online tools are used to host and deliver

102 Bourriaud, 2.

${ }^{103}$ Groys, 28. 
content. Before these tools existed, participation mandated the use of real space (and real physical objects). Online tools may, or can, include open destinations (web sites etc.), as well as controlled destinations (web sites which require authentication), analogous to free or paid (controlled) admission to a real space. In the public's mind, other online communities (Facebook, Twitter, etc.) have the same verity as real spaces. Even the most conservative parts of our society, including banking and government, offer extensive online presences where we can get information and services in the same way that we can using their real spaces.

The fact that digital environments do not exploit real space and corporeal experience means that mediation is more necessary in an online collaboration so that the participant does not become alienated from the project. Aggregation by means of computation can serve as a means of mediation. LearningToL ove YouMore.com aggregates the presentation of the completed assignments: reports are gathered and organized by date, assignment number, and participant name. As a result of the compilation of several hundred images, a user is denied a single 'real' place from which to observe the work or engage with the whole of it. ${ }^{104}$ Without a definitive point for departure, the experience a visitor will have in an encounter with such an artwork will necessarily be different from all other visitors. The infinite number of paths possible through an artwork supports a reading of participatory art that considers difference to be a desired condition of experience. This perspective reflects the challenges that feminist, post-colonialist and other deconstructionists critics have raised in art discourse regarding the privileging of a 'common' art experience. Through collaborative protocols, participants

\footnotetext{
${ }^{104}$ Bishop, 13.
} 
directly challenge traditional models of arts engagement and enrich art-works by sharing their individual experiences.

Marcel Duchamp once advocated that 'Art is a game between all people of all periods. ${ }^{105}$ Now, there are an increasing number of players. Learming To Love You More promotes episodes of discovery through interactivity and collaboration. The poetic space that the project addresses is between the two spheres of real life practice and online identity performance. This suggests that the project operates on an imaginative plane, but that it is grounded in a tangible reality, the discursive space of the World Wide Web.

${ }^{105}$ Quoted in Bourriaud, Relational Aesthetics, 3. 


\section{Chapter Three: Digital Networks and the Power of Sharing}

As suggested in the previous chapter, Learning To Love You More represents art-making that is socially engaged, participatory and buttressed by digital tools. This chapter examines how distributed networks and digital technology affect the distribution of art information in order to gain a better understanding of how the Internet serves as a tool for contemporary art practices. This chapter will consider the theoretical impact that computing, the Internet and new media have had on curatorial practices and the subsequent effect these impacts have had upon contemporary exhibit practice within a networked public sphere.

In the following discussion, I examine how distributed networks and digital technology affect the distribution of art information in order to gain a better understanding of how the Internet serves as a tool for contemporary art practices. I begin with an analysis of how communication networks have supported the mass amateurization of cultural production. Then I will briefly consider the rise of Web 2.0 protocols and how they enrich the digital environment of the Internet. Finally, this section will consider why the zones for exchange on the Internet are central to further development of contemporary creative practice. In attempt to delineate an 'ethic of sharing' in online environments, this section will consider how the act of publishing is related to the creative act because both are acts of witness.

LearningToLoveYouMore.com encourages art-making as a quotidian activity that will help participants to 'love' more. Artist and participant Laura Lark comments on the effects she has seen resulting from her participation: "to think that a website - something electronic and impersonal in its being - can compel a greater understanding of humanity is an 
extraordinaty thing." 106 Interactive media artworks often strive to foil the loss of intimacy that occurs within a contemporary mediascape dominated by broadcast media like radio and television. I will now turn to a discussion of art and technology in this contemporary mediascape and consider how these factors affect Learning To Love You More.

\subsection{Distributed Networks as a 'New Ecosystem' of Communication}

In chapter 1, Learning To Love You More was introduced as a participatory art project with an unpredictable nature. The second chapter delineated the history of participatory art, illustrating how the project aligns with contemporary artistic concerns. This final chapter will consider how technology helps explain and order LearningToLoveYouMore.com.

A few recent publications have addressed the complexity of online art display. The anthology Curating Immateriality (2006), edited by Joasia Krysa, engages in a discussion regarding how the work of the curator has been transformed within the age of distributed network systems. With articles from scholars, artists' collectives and contemporary curators of new media art, this text examines how the Internet has extended the exhibit space beyond the institution, as well as the socio-economic and political implications that accompany the expansion of the traditional site of display. Describing a new "operating system" for art, Curating Immateriality explores how dynamic network systems, software and multiple creative agents serve as fundamental building blocks for a new model of curatorial practice. The discourse this book introduces serves to expand the historiography of curating into the digital age and provides a critical analysis of recent examples of online curatorial projects that showcase new media art works in a network environment.

${ }^{106}$ Laura Lark, "Laura Lark" in Fletcher and July's Learning to Love You More (New York: Prestel Publishing, 2007), 147 . 
It is integral to begin with a consideration of the Internet as a distributed network and consider what that means in the context of the Learning To Love You More project. A distributed network system describes a system of computing wherein several autonomous machines are connected through a communications network so that resources can be shared among users. Software on each of the computers enables the creation of an integrated and consistent environment for the network participants. Distributed networks are useful because they easily facilitate cooperation and coordination between several users, and over great distance if necessary. The main purpose of distributed networks is to connect resources in a transparent, open, and scalable way. This is achieved on distributed networks because they follow the key theoretical principles of openness, resource sharing, concurrency, scalability, fault tolerance, and transparency. 'Openness' in a distributed network describes how the software interface of a network is often identified upfront, as well as open to developers who wish to modify and extend the network. Resources that can be shared on a distributed network include hardware, software, or data. Concurrency helps to share resources because requests for data can be sent to multiple machines at the same time to maximize the efficacy of operations. 'Scalability' describes how a distributed network that runs on a small amount of computers can increase its processing power by adding additional computers to the network. Fault tolerance helps to improve the robustness of networks as additional networked machines help to create redundancy so that faults are easily detected and then managed by the network participants. And lastly, distributed networks, have a high degree of transparency, both in the machine locations, and the general 
interface. All of these features, establish a system of communication and interaction that is to a degree - self managing, and self-sustaining. ${ }^{107}$

While not a computing system, Learning To Love You More is a system and can be described as a distributed network. Most artists have always worked with the support of networks, whether they were composed of fellow labourers in a workshop, printers in an atelier or poets and painters in a bohemian neighbourhood. Solitary contemporary artists often work under the auspices of an artist group, such as Félix González-Torres's work with Group Material. The creative networks an artist has membership in undoubtedly affects their artistic production: "In contemporary art, unlike traditional dialogical forms such as live music or theatre, discursive practices are not distinct from, but rather constitute and frame, visual practice". ${ }^{108}$ Dialogue does not always have intrinsic value in the visual arts, but rather serves to establish a social context in which an artwork can function.

While the online presence of Learning To Love You More is a hierarchically structured webpage using the PHP programming language, the project is accomplished by means of a distributed network of participants from all over the globe working on the assignments in a spectrum of different contexts. The various 'software' that facilitates its operation would be the instructions which can be obtained from the website or from the book. Even after the website is defunct and only exists as an archive, the project can live on as a set of instructions, much like Yoko Ono's Grapefruit, which was discussed in the previous chapter. As a network of artists, Learning To Love You More is centered on sharing resources and reports related to the assignments. The project is also incredibly open, allowing participants

107 Weijia Jia and Wanlei Zhou. Distributed Network Systems. (New York: Springer, 2005).

108 Frieling, 37. 
to modify assignment directions. The project runs concurrently as participants can accomplish the assignments at any time from any location, no matter how heterogeneous. Further, it is evident from the fact that while the project began as a class activity for ten students at Santa Monica College, the project is scalable, and able to accommodate a few participants or a few thousand. The project is remarkably tolerant of faults and unpredictable events, often posting rogue assignment reports alongside 'properly' completed reports. Lastly, Learning To Love You More is transparent, offering authentic opportunity for exchange and feedback within its system, as well as outside in the 'Blogosphere' and on Facebook.com.

In Learning To Love You More, as in distributed network systems in general, the most important task is organizing the interactions between network participants. The organizational framework has to be as clear and inclusive as possible in order to enable the maximum number of participants to use the system. A protocol or communication system that is easy to read and understand is very important for participatory work.

As computing has developed, a shift occurred from employing closed systems (such as CD-ROMs) to more open systems for sharing and exchange. This shift occurred in large part because of the work of Tim Berners-Lee who developed the World Wide Web between 1989 and 1993 while employed at the European Organization for Nuclear Research (CERN). ${ }^{109}$ The World Wide Web describes the system of interlinked documents, joined and made available dynamically through the use of hyperlinks, and accessed over the Internet. While a network may connect many users, it is the innovation of viewing these pages as

${ }^{109}$ Packard and Jordan, xxx. 
hypertext in a web browser that has created the dynamic and connected environment that now defines our conception of the Internet.

The Internet represents a new ecosystem of communication, not just a competitor to traditional media. ${ }^{110}$ While there are still crucial questions regarding the problem of the 'digital divide' between those who have access to technology and those who do not, there is nonetheless a demonstrated increase in use of digital technology to support participatory cultural engagement. With the advent of these new developments, the media environment is irrevocably altered. Internet theorist Lev Manovich comments that "this universe is not simply a scaled-up version of twentieth-century media culture... Instead we have moved into the new realm of social media". ${ }^{111}$ Media content traditionally operated under a 'broadcast paradigm', wherein a small number of professionals created content for a large audience. In the 1990s, the Web became a platform for publishing, yet it still operated under the broadcast paradigm. But in the early years of the twenty-first century, the Web is collaborative and communicative, supporting thousands of disparate communicative acts ranging from searching and linking to uploading and tagging. It is important to note that not all users are producers in this framework (still only between 0.5 and 1.5 percent of users contribute content to the most popular sites ${ }^{112}$ ) but user participation is growing rapidly.

As a result of communication technologies serving as the platform of a work of art, we see that the technological system itself begins to define the artwork. This provides a

\footnotetext{
110 Clay Shirky, Here Comes Everybody: The Power Of Organizing Without Organizations. (New York: Penguin Press, 2008), 60 .

111 Manovich, 67.

112 Ibid.
} 
'territory for interaction'. ${ }^{113}$ Artworks dependent upon communication technologies become inherently interactive, naturally promoting dialectic. Ted Nelson, the 'rogue philosopher"114 who coined the term byperlink in 1963, advocated that hypermedia shifted the responsibility of narrative construction from the author to the reader. ${ }^{115}$ In doing so, he formulated a dynamic environment where the work of the original creator is enhanced by additional participants. Linking is a dynamic activity which forms a web of relations within which the reader can navigate. Unlike paper-based publishing, digital content, such as text or photographs, can be created as hyperlinks which function to link a piece of online content back to its creator or its original context. While the creation of a hyperlink doesn't prove the authenticity of content, being able to view it within a variety of different contexts (including its source context) encourages the informed consideration of the veracity of the content in question. Because of this, one could even argue that the content itself in the form of a hyperlink bears an indexical quality in that it is, in the language of Roland Barthes, literally an 'emanation' from a referent. ${ }^{116}$ This contributes to a new perception of content within digital media, wherein photographs and text are considered as data to be interpreted, rather than uncontested documented facts.

On the Internet, documentary perspective is privileged. Certainly documentary photographs are the most common form that reports take on LearningToLoveYouMore.com. Photographs are considered to bear equivocal truth value to reality, replacing total belief. This equivocal nature is central to online literacy: users are aware that the veracity of an

\footnotetext{
113 Packard and Jordan, xxxi.

114 Ibid., xxviii.

115 Ibid., xxix.

${ }^{116}$ Barthes, Roland. Camera Lucida: Reflections on Photograpby (London: Flamingo, 1984).
} 
image can be contested. Heavily publicized incidents of viewer manipulation in popular Internet culture include LonelyGirl15's pre-scripted video 'diaries' on YouTube, the photomanipulated image of a British soldier in Basara, Iraq in April 2003 that cost Los Angeles Times photographer Brian Walski his job, and the removal of body fat from French President Nicolas Sarkozy in an August 2007 photograph from Paris Match magazine. The public at large now has an awareness of the image manipulation capabilities inherent within digital photography management software, including Adobe Photoshop and Google's Picasa. As a result, truth no longer is the value measure for photography; rather it is the credibility garnered from the context an image is presented in which emerges as the indicative factor for photography's realism. Questions regarding the authenticity and reality-effect of the photographic image have long been debated by photography theorists, such as Roland Barthes, Rosalind Krauss, and Alan Sekula. ${ }^{117}$ And while it's clear that this line of questioning will remain central to photographic theory discourse, the images posted to LearningToLoveYouMore.com complicate the traditional practice of documentary photography beyond questions of authenticity.

LearningToLoveYouMore.com invites visitors to participate in various art-making behaviours ranging from painting to drawing to fictional phone calls to public interventions. The problem of documenting these art actions aligns with conventional discourse regarding the problem of how to document other ephemeral art forms, such as performance art and dance. Most of the assignments are reported by means of digital photograph. The

117 See Roland Barthes, Camera Lucida: Reflections on Photography (London: Flamingo, 1984), Rosalind Krauss, L'Amour Fou: Photography \& Surrealism (New York: Aberville Press, 1985), and Allan Sekula, Photograpby Against the Grain: Essays and Photo Works 1973-1983 (Halifax, N.S: Press of the Nova Scotia College of Art and Design, 1984). 
photographs posted to LearningToLoveYouMore.com employ traditional documentary practices, like straight photography and text captions, to support a non-traditional art project. Due to its ephemeral nature, the art actions are commonly untitled, unattributed, and most often temporary (they do not exist beyond their reported state). A photograph in a report then serves, not to authenticate the art-object, but rather to document its presence in a real space, during a specific temporal period. Similar to the way that conceptual artists and land artists employ photography in service of the greater art movements, evidential details remain secondary to the aesthetic documentation of a work of art functioning in a specific context.

Most of the photographs submitted to LearningToLoveYouMorecom contain no proper names for attribution or concrete physical locations. The lack of seemingly integral evidentiary information to accompany the posted images refocuses the viewer's attention to the project of the images as a movement, and diminishes their importance as individual photographs. The photographs serve as semiotic indices that establish a common visual language from which a discussion regarding quotidian art-making can begin. Digital photography further challenges the traditional paradigm of engagement with photographic images, subverting the act of "saving unique, original artefacts" produce numerous copies and distribute them quickly and easily over a vast geographic area.

While documentary photographs are seldom overtly manipulated, they are never unmediated. Yet the mediation does not detract from the success of the photograph as a document of an art action. Rather, the participant's final act of reporting their experience captures the intended function of the art-work, often revealing the humour and interactivity

118 W.J.T. Mitchell. The Reconfigured Eye: Visual Truth in the Post-Photographic Era (Cambridge: MIT Press, 1992), 287. 
that the assignment meant to stimulate. The participant interacts with a network of actors, and directly learns about technology and art-making throughout the process. Further, the amplified distribution of website publication makes the Learning To Love You More participant into an artist, disallowing them to be an isolated audience member. They become an active participant not only in the project, but of the shape of the network. As a result, Learning To Love You More serves as a catalyst for self-making, both in one's own daily life and in the wider public sphere of the Internet, the hub of contemporary networked society.

With network technologies, the acts of individuals are amplified, creating new frameworks for information exchange in the public sphere. Moreover, that information exchange is multilayered, accessible to participants who operate on a variety of platforms and who perform a variety of roles. While traditional media represents one way communication between producer and receiver, new media offers the same platform in dialogue with other social practices, including commenting, forwarding, and tagging. Also, new media enables interaction across media platforms. Most network media platforms permit 'social bookmarking' tools like digg.com, which functions externally to further aggregate and organize popular information throughout networked culture. These practices represent an engagement with the Internet styled by 'Web 2.0 ' participation.

\subsection{Web 2.0 and the Rise of Participatory Publishing Economies}

The development of Web 2.0 protocols has supported participatory practices online. The term 'Web 2.0', coined by Tim O'Reilly in 2004, refers to a number of technical, economic and social developments that effectively changed how users interact with the Internet. Key developments include the facilitation of user-generated-content, the concept of 
network as a platform, 'folksonomy' practices (such as collaborative tagging), syndication of content via RSS (Really Simple Syndication) feeds, and digital architecture that supports mass collaboration. ${ }^{119}$ Wikipedia.com is an example of an online participatory project that typifies the Web 2.0 movement. The practical effects of the Web 2.0 movement includes a proliferation of interactive web platforms, free software, burgeoning network opportunities, and a fall in price for popular media devices.

In order to better understand the role of Web 2.0 practices in Learning To Love You More projects, it is prudent to consider network publishing and the rise of citizen journalism. A brief examination of participatory journalism will prove analogous to our exploration of participatory art-making. While the terminology fluctuates among 'citizen journalism', 'networked journalism', 'open source journalism', 'grassroots media', and 'people's media', participatory journalism describes the active role that everyday citizens have in aggregating, evaluating and disseminating news and information in online media environments. Online media environments take multiple forms and address multiple audiences. They range from blogs that follow a specific topic, to wikis which can organize a complex set of topics, to sites that aggregate popular news feeds of general interest categories. More pointedly, participatory media projects acknowledge that their participant base is composed of amateur journalists and often draw strength from the success of voluntary 'watchdogs' or 'factcheckers' of professional journalists who have repeatedly exposed bias or error within traditional media institutions. What unites all of these diverse practices under the general

119 Manovich, 67. 
practice of participatory journalism is a commitment to amateur publishing on a mass scale. $^{120}$

Publishing is no longer an activity unique to traditional media institutions: anyone with internet access and something to say or show can become a 'publisher' in under a half an hour. Citizen journalism represents a different kind of social organizing, wherein serious complex work is created without institutional action or incentive. Actualized through acts of sharing, cooperation, and collective action, citizen journalists present an alternative to the institutional paradigm that previously was not possible because of a lack of tools. Now, collective action can occur in new ways enabled by networked social tools which can connect loosely structured groups which operate without managerial direction and outside profit motivation. ${ }^{21}$ Unlike traditional news organizations, citizen journalists and photographers are self-organized. Without dictated assignments directing what to report, the citizen journalists write about whatever they like, organizing and tagging the results only as an afterthought. As communications theorist Clay Shirky points out, we adopt tools that amplify our capabilities and we modify tools to improve that amplification. ${ }^{122}$

The production of content for relatively small niche audiences can easily thrive in digital environments. The 'long tail' economics championed by Chris Anderson of Wired magazine suggest that most of this amplified content does succeed in finding an audience. For example, Manovich points out that in the mid-2000s all tracks on iTunes (Apple's online

126) Lovink, 26.

121 Shirky, 47.

122 Ibid., 187. 
music store) found at least one listener, regardless of their obscurity. ${ }^{123}$ Long tail economics remind us that we are only beginning to comprehend the actual media diets of everyday people. Academic attention to some media types (such as the youth media movement, activist media, and political 'mashup' videos) is problematic because these projects don't represent "the typical usage of hundreds of millions of people". ${ }^{124}$ However, the alternative and progressive nature of these projects will be of continued interest to scholars, as new media forms evolve from these types. For the Learning to Love You More project, its value is derived from common practices, strengthened by the mutual membership of the participants in the network. ${ }^{125}$

What these technological developments reveal is that the social function of journalism has evolved to better reflect the original purpose of legislation adopted to protect the 'freedom of the press'. Freedom of expression, as articulated in the First Amendment to the Constitution of the United States of America and in Section $2 b$ of the Canadian Charter of Rights and Freedoms, literally refers to an individual's freedom to hold and publish opinions by means of a printing press. The articles do not encourage or protect publishing as a business, but rather advocate that publishing is as an act of public expression fundamental to a free society. ${ }^{126}$ This considered, the rise of social tools is impacting the strength and authority of traditional media institutions. The notion of 'journalistic objectivity' is questioned daily by thousands of citizen journalists who demonstrate their preference for the lateral objectivity offered from the computerized aggregation of crowd-ranked news, rather

${ }^{123}$ Manovich, 68.

124 Ibid., 70.

${ }^{125}$ Groys, 20

${ }^{126}$ Mary-Rose Papandrea. "Citizen Journalism and the Reporter's Privilege" (Boston College Law School Faculty Papers) <http://lsr.nellco.org/bc/bclsfp/papers/167/>. 
than the perceived objectivity offered from a single editor within a media institution. Citizen journalists post news and images for each other in a many-to-many publishing economy that contradicts the one-to-many publishing economy represented by newspapers and broadcast television news. Yet still, new media projects are not antithetical to traditional journalism, but rather represent a different application of the traditional principles within an alternate publishing economy.

The project of Learning To Love You More is to celebrate and foster acts of everyday creativity. Networked media serves as conduit for the distribution of information about aesthetic experience in a capacity unparalleled by institutional means of publishing. This 'mass amateurization' of digital creative practice operates chiefly by the protocol of 'publishthen-filter'. This approach to content creation encourages individuals to publish rough drafts and straight images online in their germinal form so that the content can then be altered, corrected or categorized later, either by the initial publisher or other participants on a network. ${ }^{127}$ Likewise, the consequences of failure for online media projects and texts are relatively minimal. Distributed media projects have start-up costs that concern the acquisition of a domain name hosting server, rather than the rental of an office space and salaries of a full-time staff. Content is submitted or aggregated from the distributed network itself, rather than created in a centralized institution. As a result of the connectivity offered by social networking tools in peer-to-peer networks, barriers to participation are lowered.

127 Shirky, 246. 
Online media projects can be more experimental with less operating costs than traditional institutional structures. ${ }^{128}$

Yet, LearningToLoveYouMore.com does not simply present a platform for free-form self-expression. Rather, it invites participants to commit to a structured project. On websites like MySpace.com and Facebook.com, users play with and perform different identity constructions. Even other popular participatory art projects documented online, like Frank Warren's Post Secret project and the 1000 Journals Project feature an open invitation for selfexpression. In contrast, Learning To Love You More presents an opportunity for expression, but it is through the invitation to make and exchange artworks. This suggests that the project is ultimately oriented towards the activity of art-making, rather than an interest in selfexpression. Cultural critic Lee Seigel comments on this phenomenon in the digital age, stating: "The comparison of art to self-expression would make no sense if the latter had not entirely supplanted the former in the lives of self-expression's vast number of producers and consumers". ${ }^{129}$ As Seigel describes, self-expression is now manifest as a system in itself, an industry buoyed by producers and consumers. The pursuit of art, instead, is hinged upon the belief that art-making is aligned with authentic liberation, the freeing of the creative mind and spirit.

This 'artistic liberation' is made manifest though the performance of creativity in everyday life. Learning To Love You More deliberately removed obstacles to publishing, including identity disclosure. As a result, the focus of the project is realigned from an

\footnotetext{
${ }^{128}$ Shirky, 245.

${ }^{129}$ Lee Seigel, Against the Machine: Being Human in the Age of the Electronic Mob (New York: Spiegel \& Grau, 2008), 53.
} 
investigation of who is participating, to an investigation of the character of their participation. It is truly the action, and not the individual, that is the subject of the artwork. Because the objective of Learning To Love You More is to stimulate and showcase artistic activity, not artistic excellence, the project can sustain anonymous and amateur participation.

Beyond serving as a platform for this performance to occur, the Internet supports art-making by serving as a distributed archive. Our presence and interaction with mass culture is recorded in a digital age: "what was once ephemeral, transient, untraceable, and invisible has thus become permanent, mappable, and viewable". ${ }^{130}$ Not only is the attention towards creativity in everyday life growing, but the broadcasting of everyday life via blogs or social networking sites is becoming increasingly popular. With increased and varied network activity, creative practice and cultural consumption become increasingly conflated. As a result of Web 2.0 practices, content, opinion and conversation can no longer be clearly separated. $^{131}$

\subsection{The Politics of Sharing}

The final section of this chapter considers the implications of the posted images of art actions on LearningToLoveYouMore.com and how the website helps to reinforce quotidian aesthetic acts as an essential form of artistic expression. Content posted online independent of an architecture of meaning bears limitations in its ability to effectively engage a public. For example, Flickr.com provides a standard platform for individuals to share photographs, but Facebook.com allows users to post photographs that can be immediately connected to a meaningful social network through tagging practices and newsfeed announcements.

\footnotetext{
${ }^{130}$ Manovich, 74.
}

131 Ibid., 75. 
LearningToLoveYouMorecom can be explored as an archive of photographs and texts, yet it also serves as a central hub for communication about participation in the project. It is both a site of display, and a venue that facilitates participation. New media scholars, such as Yochai Benkler, stress that this architecture for sharing is the key factor that enhances an individual's capacity for public expression. ${ }^{132}$ Combined with an ideological project, website architecture can extend the effect of political and aesthetic actions.

Technology enables collective action to occur on a large scale. Deeds completed by independent actors can be easily connected to established networks. The effect of this, according to theorist Harold Rheingold, is that "every desktop has become a printing press, a broadcasting station, a community and a market place" ${ }^{133}$ But the work of scholars like Benkler and Rheingold suggests that we don't yet know enough about the basic principles of distributed sharing practices. While cooperation and sharing economies may operate primarily because of self interest, the effects produced certainly add up to a lot more. The online world enriches the amateur producer with tools, support networks a display platform and a means of distribution. This enrichment has repercussions for individual artists, but it also allows productive groups, from programmers to academics, to self-organize in order to extend their powers. The amplification of effort extends its effects.

Developing and strengthening an ethic of sharing is the most important outcome of Learning To Love You More. The locus of the project on the Internet means that it is

${ }^{132}$ Yochai Benkler. "The Wealth of Networks: How Social Production Transforms Markets and Freedom." The Wealth of Networks: Main Site.

$<\mathrm{http}$ ///www.jus.uio.no/sisu/the_wealth_of_networks.yochai_benkler/index.html.>.

${ }^{133}$ Howard Rheingold. Way new collaboration. (TED lecture, February 2008),

$<$ http://www.ted.com/index.php/talks/view/id/216>. 
surrounded by peer-to-peer media sharing networks, open source and knowledge-sharing projects and popular social media sites, like Twitter.com and Facebook.com, that encourage the sharing of feelings from the personal lives of individuals.

The title, Learning To Love You More, points to the emphasis on social relations stimulated by acts of sharing in the project. It was given to the project by the Californiabased video and media artist Emma Hedditch. Hedditch frequently collaborates with July on creative projects, including the interior book illustrations for July's short story "The Boy from Lam Kien" (2005). Hedditch is also the author of Assignment 35: Ask your family to describe what you do and had done promotional events with July in support of the project. ${ }^{134}$ The title is not explained, yet this is not problematic for the 8000 participants. The pronoun 'you' is ambiguous, being both singular and plural, and both a formal and informal means of address. Moreover, as a shift of signifier, 'you' changes according to whom is addressed. In the project title, 'you' is used generically, referring to an unspecified person. Interaction within an online environment is not analogous to communication in the real world. Cultural critic Lee Seigel characterises the nature of online communication: "Once you're online, however, you don't have to be communicating with anyone in particular. Just being online means that you are communicating with everyone in general". ${ }^{135}$ In everyday life, communication takes place between two definite parties. In an online environment, this may be the case, but it is not necessarily so. Rather than determine a precise connotation, it is reasonable to assume that the project title encompasses all possible interpretations. The

${ }^{134}$ Emma Hedditch even accompanied Miranda July to the University of Plymouth, Exeter, UK in March 2003 to facilitate a Learning To Love You More event featuring her assignment. $<$ http://www.learningtoloveyoumore.com/pdfs/emma_exeter.pdf $>$. 135 Seigel, 173. 
plural nature of the project supports layered reading of the title. The title reflects an attempt to strengthen the relations between the artists and their audience, between the participants themselves, and between the project and the greater world. Regardless of a clear understanding of the title, mass commitment to the project is affirmed each time a contributor submits a report.

The political ramification of this suggests that sharing in integral to the development of a democratic ethic, both in society and in art-making. As this is an art historical study, I am concerned with the 'political' in so far as it describes the activity of polis building. I use the term with the poetics suggested by its entymology: the Greek word politikos referred to any activities that were concerned with the care and governance of a city or a state. In this sense, we can think of the polis as pertaining to the creation, strengthening and management of social bonds between people within a community. Moreover, when I employ the term 'political' in this study, I suggest the poetics that 1960s women's rights activist Carol Hanisch implied in her essay "The Personal is Political" (1969). Explicating upon the Students for a Democratic Society slogan from 1964, Hanisch discusses the political dimension of consciousness-raising activities, concluding that such activities were more than just 'therapy sessions', asserting that interpersonal problems most frequently have roots in political power struggles. A concern for the political is integral to this study, as Learning To Love You More represents an attempt to forge a network of art-makers in support of quotidian art-making as a legitimate form of public expression. 
Art always has political implications: "if politics is defined as the relationship between the individual and society, virtually no artwork is without political meaning". ${ }^{136}$ Yet overtly political artworks often feature text-heavy installations which command viewer's time and attention. ${ }^{137}$ In contrast, participatory art encourages the political engagement of participants through a non-proscriptive framework.

The political position of Learning To Love You More benefits most from its articulation as a project on the World Wide Web. Art-making is rearticulated by those who envision the digital environment as a viable place for aesthetic expression and welcome its inherent complexities. While the affect of viewing art in real time in a gallery or in a collector's home produces a visceral experience, viewing images of art work online produces a similar, but different affect. This is because Learning To Love You More represents a network of likeminded artists whose participation conveys their desire to engage with a public aesthetic sphere. When aggregated and viewed en masse the political message of a project is concentrated. The political dimension of Learning To Love You More is strengthened by the fact that the publication of reports is participant-motivated. This is an important distinction because sharing aesthetic experience by publishing it online is an act that discloses the self to a public. Publication announces the agency of the participant in Learning To Love You More: the artist has completed an assignment and the documentary report promises this is true.

The act of art-making, however, is a different act from documenting an art-activity and sharing it online. The first is a private act, valuable in itself. The second, however, is a political act, meant to engage the public sphere and to share a perspective of the world.

\footnotetext{
136 Atkins, 56.

137 Atkins, 58.
} 
Learning To Love You More celebrates such perspectives as necessary. Seeing, and sharing what you have seen, is an act of witnessing. It is a political act to use images and texts. Influenced by the theory of Jacques Rancière, critic Claire Bishop comments that when a spectator is active as an interpreter of an art experience, the politics of participation "might best lie, not in anti-spectacular stagings of community or in the claim that mere physical activity would correspond to emancipation, but in putting to work the idea that we are all equally capable of inventing our own translations". ${ }^{138}$ And it is in that capacity for testimony and translation that participatory digital projects can inspire the exercise of real individual agency within a growing global community.

Learning To Love You More allows participants to shirk the expectation to be original and focus on creating their own translations of the assignment instructions. Fletcher and July acknowledge this in the introduction to the published book, stating: "sometimes it seems like the moment we let go of trying to be original we actually feel something new - which was the whole point of being artists in the first place" ${ }^{139}$ From this modest proposition a bevy of artistic work has been produced. Critic Julia Bryan Wilson describes the intentions of the Learning To Love You More project to be modest as a result of what the projects avoids:

[Learning To Love You More] does not attempt to corral its participants into a limited or monolithic notion of 'community'. It does not recruit for a totalizing new social movement; it does not propose itself as the singular answer to the problem of Internet isolation. ${ }^{140}$

\footnotetext{
138 Bishop, 16.

${ }^{139}$ Fletcher and July, 1.

${ }^{140}$ Wilson, 145
} 
Rather, she suggests that Learning To Love You More "runs on an economy of generosity, not coercion or exploitation". ${ }^{141}$ Learning To Love You More simply asks its participants to take themselves seriously, to commit to artistic work and to share their results with an audience.

The relationship between artist and public remains a central concern in art-making today. An artist capitalizes on the necessary role of the audience for validation and in order to facilitate their success. In this capacity, the artist can be seen as but "an impotent agent at the mercy of the public's good opinion". ${ }^{142}$ The artist is dependent upon recognition for success, as artworks - unlike science or technology - necessitate an aesthetically devoted audience to remain on display. ${ }^{143}$ In contrast to this paradigm of the impotent artist, participatory art "subscribes thematically to a sociopolitical goal" and aims to achieve it through the collectivization of core structures and means of production. ${ }^{144}$ Participatory art empowers the viewer, but moreover it benefits the artist who is no longer subject to the "cold eye of the uninvolved viewer". ${ }^{145}$

Website art projects like Learning To Love You More should be enticing to art historians because they allow a plurality of aesthetic narratives to be captured with few costs and few barriers using shared digital photographs, videos, $\mathrm{mp} 3 \mathrm{~s}$ and texts. The documentary form of the reports creates a community of memory, where the acts of art-making inspired by the website outlast their solitary performance in the real world. The participants share their art-making with the World Wide Web. In doing so, they invite an audience. Political

141 Ibid.

142 Frieling, 20.

143 Ibid.

144 Ibid., 21.

145 Ibid., 20. 
theorist Sheldon Wolin comments on the value of an audience: "audience is a metaphor for the political community whose nature is to be a community of remembrance". ${ }^{146}$ Art historians and curators are concerned with the sharing of art-works, but they are also interested in remembering the cultural context in which they were produced. Digital technology allows complex information stored in a way that is oblique, yet dynamic. The creative acts preformed for Learning To Love You More assignments are shared, but also ordered, on the website. The hyperlinked interface of a website means it is simultaneously an active platform and an archive of cultural exchange.

The participants of a participatory art project both create the art-work, and serve as its primary audience. The use of a website as the main platform for Learning to Love You More means that the published assignment reports record the aesthetic engagement of the participants and preserve them in the public sphere. The World Wide Web, as a space of appearance for art-makers, is a public sphere because the character of Internet use is explicitly a performance.

The capacity of the project participants to work together for a common purpose can be understood as a form of power. Power is best actualized when employed for communicative purposes. The philosopher and political theorist Hannah Arendt delineates the differences between communicative power and other strategic or instrumental forms of power, such as strength, force, and violence. A display of strength may accomplish a goal for an individual, but power should be the property of a plurality of actors acting in concert for a public political purpose. Force may be a phenomenon that compels action, but power is a

146 Sheldon Wolin, "Hannah Arendt and the Ordinance of Time," Social Research, vol. 44, no. 1 (1977), 97. 
product of collective engagement and thus is a human creation. Violence relies on coercion to achieve its ends, but power is based on consent and rational persuasion. ${ }^{147}$ This considered, the collective publishing of the assignment reports imbues Learning To Love You More with importance. In regards to power, images aggregated on a website can effectively serve to support an ideological project. The project of Learning To Love You More is to 'celebrate' acts of creativity, and this act of promotion is built upon the perception of artworks as acts of citizenship within the digital environment of the Internet. Networked media serves as a conduit for the distribution of information about aesthetic expression in a capacity unparalleled by institutional means of publishing. The website is a product of action and needs a plurality of agents - its art-making participants - for power to manifest.

The website LearningToLoveYouMore.com unifies a group of artists and places them in visual dialogue with one another. Because of this, the assignment questions open up a poetic space for participants to explore. A poetic space, a venue for poiesis, is a space that is not defined, but rather is coming into being. Poiesis, described by Heidegger in The Question Concerning Technology (1954), describes the activity of 'making in the world'; it is the act of 'bringing forth' new actions and describes the movement from standing as one thing to becoming another. Pointing to the moment when the butterfly emerges from a cocoon, Heidegger describes poiesis as a threshold occasion. Poiesis is the establishment of new conditions. Poetic space represents a safe environment to make acts of identity disclosure, as the space is undefined and separate from the concerns of the real world. The poetic space in

${ }^{147}$ Hannah Arendt, Crises of the Republic (New York: Harvest Books, 1972). 
Learning To Love You More is forged within the network of artist participants, a specific public delineated by active engagement in art-making. 


\section{Conclusion}

The assignment reports of Learning To Love You More display the diverse achievements of individuals, created from free will and with conscious execution. In this thesis, I have made three chief claims. First, I argued that heuristic practices of art-making result in a discoverybased, participant-led art experience. Second, I revealed that the current emphasis on collaborative art-making stemmed from the history of participatory art. Third, I demonstrated that the political dimension of art-making in Learning To Love You More was initiated by the act of sharing reports and amplified through their publication on the distributed networks of the Internet. After an examination of the website http://www.learningtoloveyoumore.com, it is clear that vernacular art-making practices are supported by participatory frameworks, and their effect is amplified by distribution on the Internet.

In Chapter 1, I introduced the case study LearningToLoveYoumore.com and outlined the history of the project. I evaluated its aesthetic character and argued that it typifies a new media arts project. I described the participants, and explained how the artist-leaders, Harrell Fletcher and Miranda July gave instructions for the project. I argued that instructions are valuable in guiding an artistic experience. I theorized that instructions stimulate heuristics in art-making wherein the participant is permitted to shape his or her own experience through discovery. I illustrated how this experience was shaped by the vernacular nature of Learning To Love You More. Finally, I outlined how the relations between the online state of the art project and its manifestation in the real world contend with each other. 
In Chapter 2, I historicized participatory art to explain the precedents of LearningToLoveYouMore.com by giving examples of thematic exhibitions, pioneering artists, influential movements and foundational theory for participatory practices. I commented on the political and aesthetic tone of these examples and argued that this kind of art-making adopts an experimental character. In the end, I discussed how this experimental character is organized by collaborative protocols in art-making and on the Internet.

In Chapter 3, I argued that sharing practices, especially publishing, are amplified by distributed network systems. I outlined the development of communications technologies and Web 2.0 to demonstrate how technology supported the rise of participatory publishing economies. I argued that publishing is authentically about freedom of expression, something of great concern in participatory systems. I showed how digital tools amplify the effect of creative projects by making them more accessible. Because of the audience the project attracts, I argued that sharing is a political act and that LearningToLoveYouMore.com serves as a vibrant platform for aesthetic expression.

This project has revealed the new conditions that resulted from an authentic engagement with art-making. Amplified by participatory structures, network technologies and digital distribution of information, contemporary art-making has a real opportunity to shift public attitudes concerning the arts.

Art can only serve to bond us to each other. Whereas speech articulates a political action, sharing art articulates the bonds between humans in a most essential way. Theorists such as Dennis Dutton and Ellen Dissanayake have argued that art production is a uniquely human activity, one that every person has an evolutionary predilection to participate in. As 
an ethologist, Dissanayake describes art-making as an inherent human behaviour of 'making special'. In evolutionary history, bright colours and interesting patterns would gratify the senses and enable ceremony, which serves to unite social circles. ${ }^{148}$

Similarly, Dutton observes that all cultures feature the arts as a way of expressive making. While not all art forms are universal, art-making is a universal behaviour that has spontaneously appeared throughout the globe and human history. ${ }^{149}$ While action-painting or bronze-casting are not natural behaviours, the human tendency to participate in art-making is a universal phenomena. We all sing songs, tell stories, play with colours and write poems. We must acknowledge the natural sources and universal characteristics of the arts. However, if we are aesthetic beings who have evolved to make art, the conditions in which we produce art today are certainly distant from our original needs or adaptation triggers. While we may have biologically roots that encouraged art-making, it is not a behaviour scripted in our genetic code. A spider is genetically programmed to weave a web, and while we may find it to be aesthetically pleasing, our artistic pursuits are initiated by other circumstances. ${ }^{150}$ Artmaking fundamentally is an act of personal expression.

I contend that the website http://learningtoloveyoumore.com is art and that its importance lies in the way it addresses expressive art activity between traditional fields of creative production. Paying attention to movements in between recognized practices and academic discourse has been the only way that art history has ever progressed. Indeed, it is

${ }^{148}$ Ellen Dissanayake. Homo Aestheticus: Where Art Comes from and Why (University of Washington Press, 1995), 59-60.

${ }^{149}$ Dutton, 56.

${ }^{150}$ Ibid., 2. 
the amateur artist, the avant-garde revolutionary and the community craftsperson who maintain the cultural drive to produce art.

This has not been a comprehensive study of participatory art, but rather it aimed to be a symptomatic one. The conditions of collaborative production seen in the case study are common to other ventures in art production at the present moment. Website art projects offer us an opportunity to shift cultural attitudes concerning art-making.

Participatory art represents an authentic opportunity for cultural citizenship. Judith A. Larocque, the Deputy Minister of Canadian Heritage, observes that "cultural participation is one of the key tools people use to build their sense of attachment and connection to each other. Cultural participation also bridges fault lines and builds common understandings where only difference existed". ${ }^{151}$ Because of this, she advocates that cultural policy has the potential to extend its effects beyond the traditional culture industries "to influence citizenship, values, tolerance, and the very construction of Canadian society".

Participation in cultural activities is motivated by the desire to investigate and establish new possibilities of social interaction. The artist Paul Klee spoke of this desire in On Modern Art (1924), where he wrote "I do not wish to represent the man as he is, but only as he might be". ${ }^{153}$ Arts researcher Dick Stanley argues that fostering a strong local culture "enables the collectivity to model a future for itself and develop consensus around its solutions and action strategies". Continuing, he states: "Culture provides a community with

\footnotetext{
${ }^{151}$ Judith LaRoque, "Foreword" in Accounting for Culture: Tbinking Through Cultural Citizenship. Caroline Andrew, Monica Gattinger, M. Sharon Jeannotte, and Will Straw, eds. (Ottawa: University of Ottawa Press, 2005), 21. 152 Ibid., 22.

153 Paul Klee, On Modern Art. Paul Findlay, trans. (New York: Faber and Faber, 1966), 28.
} 
the symbolic resources needed to debate, contest, and oppose vital directions for collective social life as they wish... [this is] virtually a definition of inclusion and participation in any democracy". ${ }^{154}$ This reveals that the practice of cultural citizenship is literally model protocol for active participation in a democracy.

Since Ancient Greece, cultural practices were supported as a means of enriching a democratic ethos in society. Political commentator Allan Gregg raises questions about the close proximity between the arts and the political sphere in human history: "Why did the ancients create amphitheatres where politicians would hold court and spectacles would be produced? Why was the public square and essential part of the architecture of the earliest cities? Why did the Medicis build grand monuments to house the works of the artists they patronized?" 155 He concludes that these societies emphasized the importance of culture in the public realm and "demanded that creator and citizen must come into contact into a common sense of community". ${ }^{156}$ Participatory art practices, especially when they are used in public forums, serve as a means for individuals to exercise creative and civic agency.

The most common place for art to appear in the public realm is still the gallery. This study has potential implications upon contemporary curatorial methods because this thesis presents a detailed profile of a website art project operating outside of, yet still in dialogue with, institutional structures. George Dickie argued in the 1970s for the central role of art institutions in the social sanctioning of what is or is not considered art. But theorists in this

${ }^{154}$ Dick Stanley, "The Three Faces of Culture: Why Culture is a Strategic Good Requiring Government Policy Attention" in Accounting for Culture: Thinking Through Cultural Citizenship. Caroline Andrew, Monica Gattinger, M. Sharon Jeannotte, and Will Straw, eds. (Ottawa: University of Ottawa Press, 2005), 29.

155 Alan Gregg, "Reframing the Case for Culture" in Accounting for Culture: Thinking Through Cultural Citizenship. Caroline Andrew, Monica Gattinger, M. Sharon Jeannotte, and Will Straw, eds. (Ottawa: University of Ottawa Press, 2005), 30.

156 Ibid. 
line of thinking seem to be arguing a different issue altogether, one focused on delineating what is and is not part of the contemporary art world of museums, art markets and international art fairs. However, even Dickie identified the necessary existence of art outside institutions which guarantees that art will be subject to "continual reinvention whenever it lapses". ${ }^{157}$ LearningToLoveYouMore.com, a relatively small-scale website on the cultural outskitts of the established art world, is an instigator of the reinvention of art.

This is a key time for art institutions, whose cultural survival will depend on their capacity to both house tradition and permit new discursive events. Curator Rudolf Frieling comments on the tenacious act of embracing institutional change: "If successful, [the museum] becomes a producer of and an arena for social and aesthetic experiences, temporarily interrupting singularities through the presentation of participatory art that actively generates a discursive space".${ }^{158}$ We're beginning to achieve mastery over a moderate terrain in contemporary art discourse. Strategies for producing art today are "influenced by institutional critique without being anti-institutional, and [embrace] network technologies without claiming a utopian notion of technology". ${ }^{159}$ Museums and galleries of the future should aim to work in partnership with vernacular creativity projects.

This thesis contributes to the growing field of new media and digital arts histories. It opens up many new questions regarding the intersection of art-making and digital culture. Specifically, it raises questions about the vernacular character of digital projects, the performativity of identity online, the social or cultural impact of a plurality of participants

157 Dutton, 41

158 Frieling, 48.

159 Ibid., 47. 
and the status of memory in archived digital projects. In future research, I plan to continue investigating ideas about the impact of art-making in digital networked environments. These questions align with the current work of new media art historians who are starting to look at similar topics and their overall impact on culture today. This study has revealed that participatory art-making has the capacity to empower individuals in acts of self-expression Further research regarding the sociological effects of the development of a personal creative practice would complement the objectives investigated in this thesis.

Participatory art has furthered our understanding how to act as a human subject in the world today, not because it tells us what to do, but rather because it asks us to embrace the responsibility for action for ourselves. In Learning To Love You More, the art-making generated by the assignments comes to represent a state of exception from rational or artworld discourse. Art-making is rearticulated by the participants who act as individual agents with a vision of a new aesthetic order. Evident by the popularity of the project, those participants envision the digital environment as a viable place for aesthetic expression and consider everyday art-making efforts to be valuable forms of cultural expression. Art now reflects the world and changes it through associated public actions, such as publishing and distributing. Through participatory practices, art-making becomes a mixture of making and speaking, of creating and sharing, of poetics and politics. 


\section{Illustrations}

Figure 1

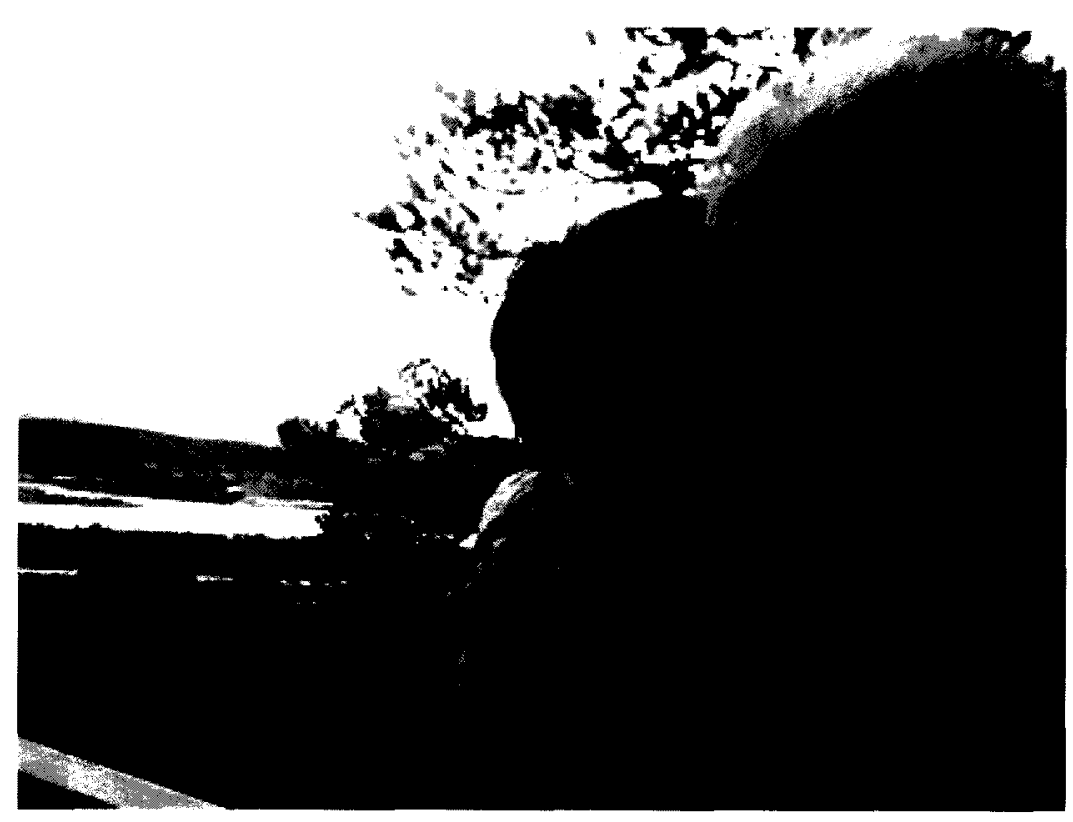

Marika. Katrina and Ulf (London, UK). Report for Assignment 39, Learning To Love You More (web). 1 Dec. 2009.

<http://www.learningtoloveyoumore.com/reports/39/marika.php>. 
Figure 2

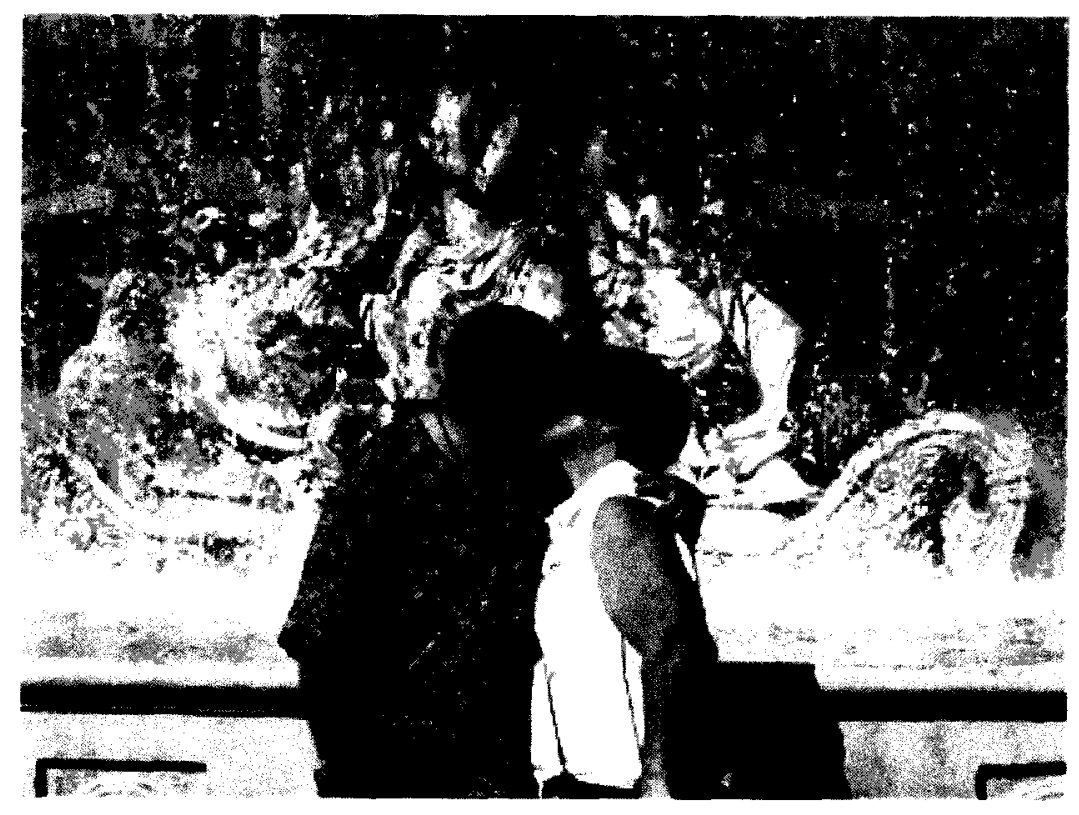

Kayla. Mark and Joan (Columbus, Obio, USA). Report for Assignment 39, Learning To Love You More (web). 1 Dec. 2009. <

http://www.learningtoloveyoumore.com/reports/39/kayla.php>. 


\section{Figure 3}

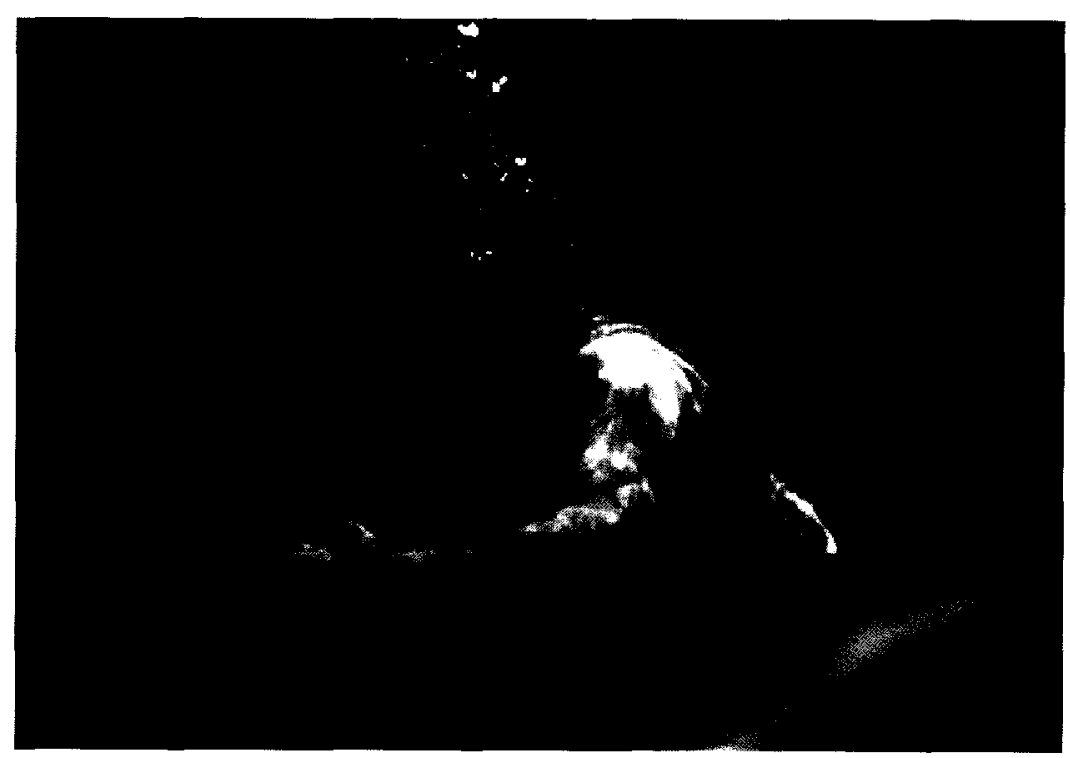

Casey Szot. Sherry and Steve (Orlando, Florida USA). Report for Assignment 39, Learning To Love You More (web). 1 Dec. 2009. <

http://www.learningtoloveyoumore.com/reports/39/szot_casey.php>. 


\section{Figure 4}

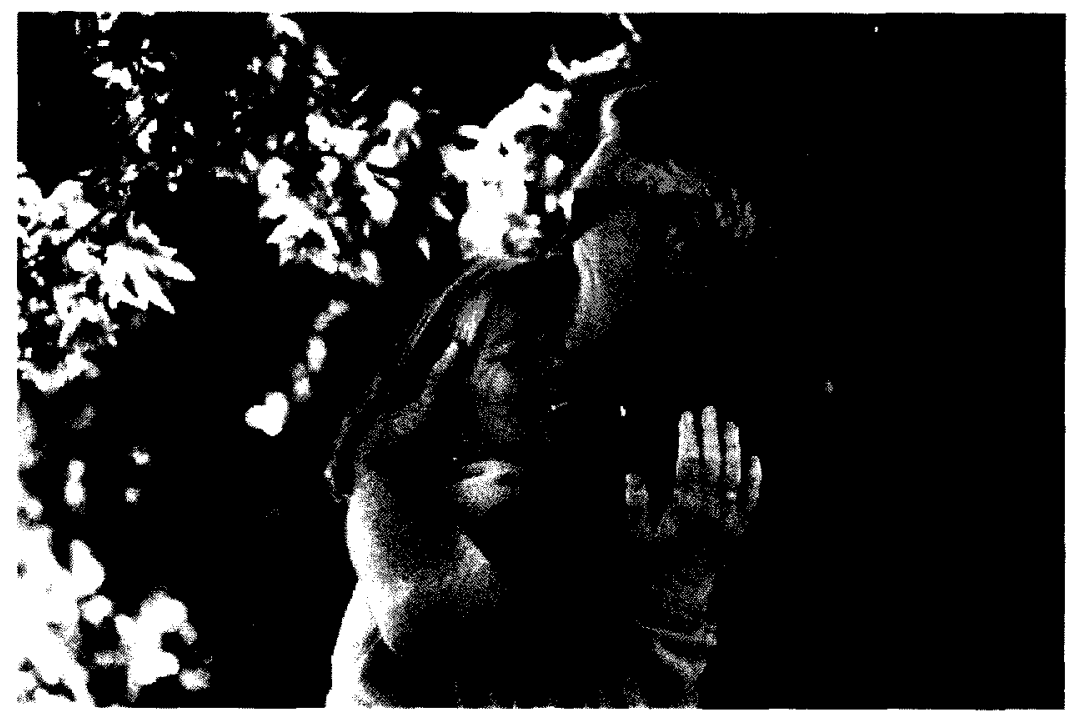

Reese Ornellas. Steve and Sharon (Oakland, California USA). Report for Assignment 39, Learning To Love You More (web). 1 Dec. 2009. <

http://www.learningtoloveyoumore.com/reports/39/ornellas_reese.php>. 
Figure 5

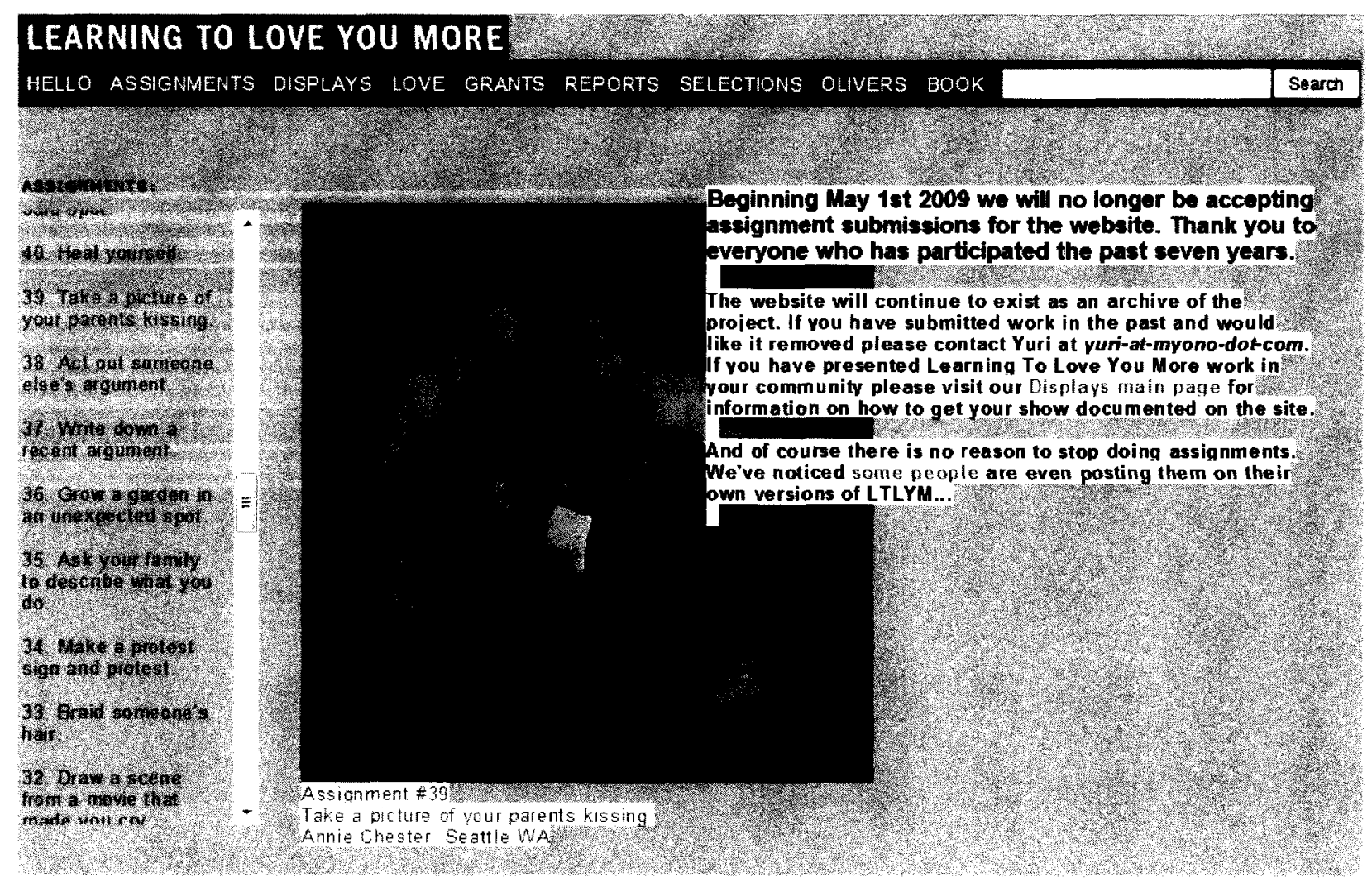

Screenshot. Home Page: Learning To Love You More. Learning To Love You More (web). 1

Dec. 2009. < http://www.learningtoloveyoumore.com>. 


\section{Figure 6}

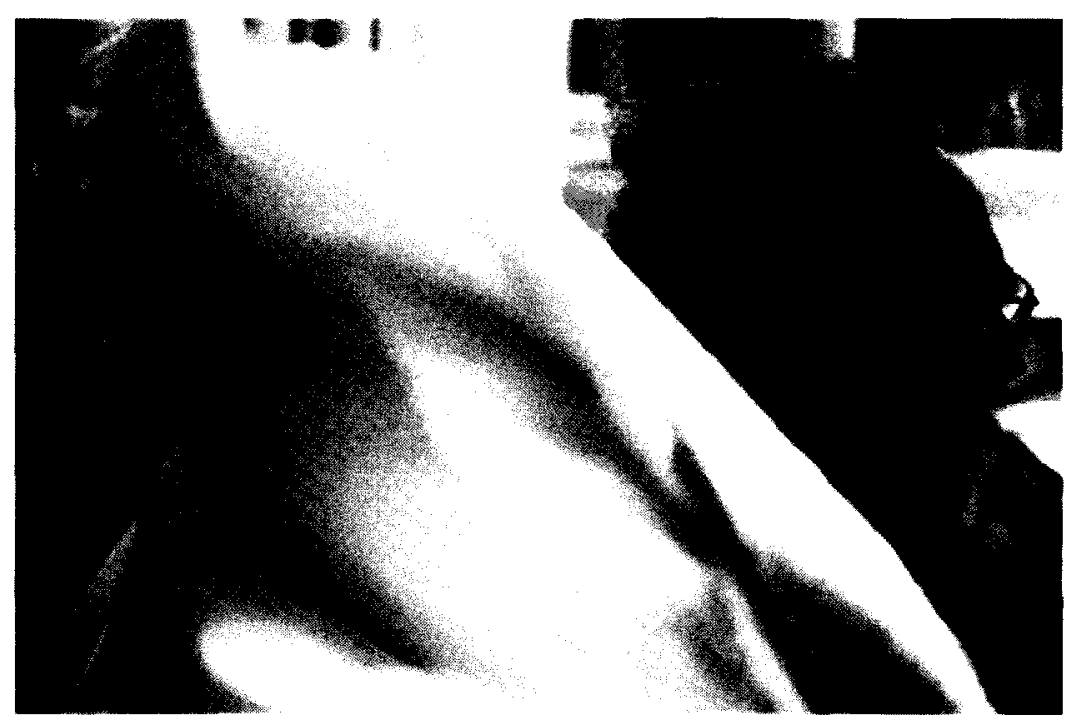

Daniel Jaffe. Report for Assignment 21: Spend time with a dying person. Learning To Love You More (web). 1 Dec. 2009. <

http://www.learningtoloveyoumore.com/reports/31/jaffe_daniel.php>.

\section{Instructions}

Assignment \#31 Spend time with a dying person.

REPORTS: Spend an hour with someone who is dying or in the advanced stages of terminal illness. This can be some one who is close to you or a complete stranger. There are huge numbers of dying people who nobody visits, so it is not hard to visit with a stranger. Just look under "hospice" in the phone book, choose one of care centers near you, and ask to speak to the volunteer coordinator. When you are bedside you must make a commitment to saying and doing as little as possible and giving this person your utmost attention. Don't take any notes when you are sitting bedside. Pay attention to what you are sceing and sensing about this person and what you are feeling within yourself.

DOCUMENTATION: For this project you are not required to report on your feelings, in fact you may want to decide ahead of time that you are not going to write a report, in order to free yourself from the reporter mentality. However, if you find that you are wanting to write about your experience when you get home, that is good too and please send this to us. If you are going to help strangers we suggest contacting your local hospice organization first and sign up for volunteer training. Hospices welcome trained volunteers to be companions to those who need it. We also highly recommend the book Grace In Dying by Kathleen Singh to anyone who would like to know more about the journey of dying.

Required documentation: Your name, the name of the person you visited, the name of the place where you visited them and the date and time of your visit. 


\section{Figure 7}

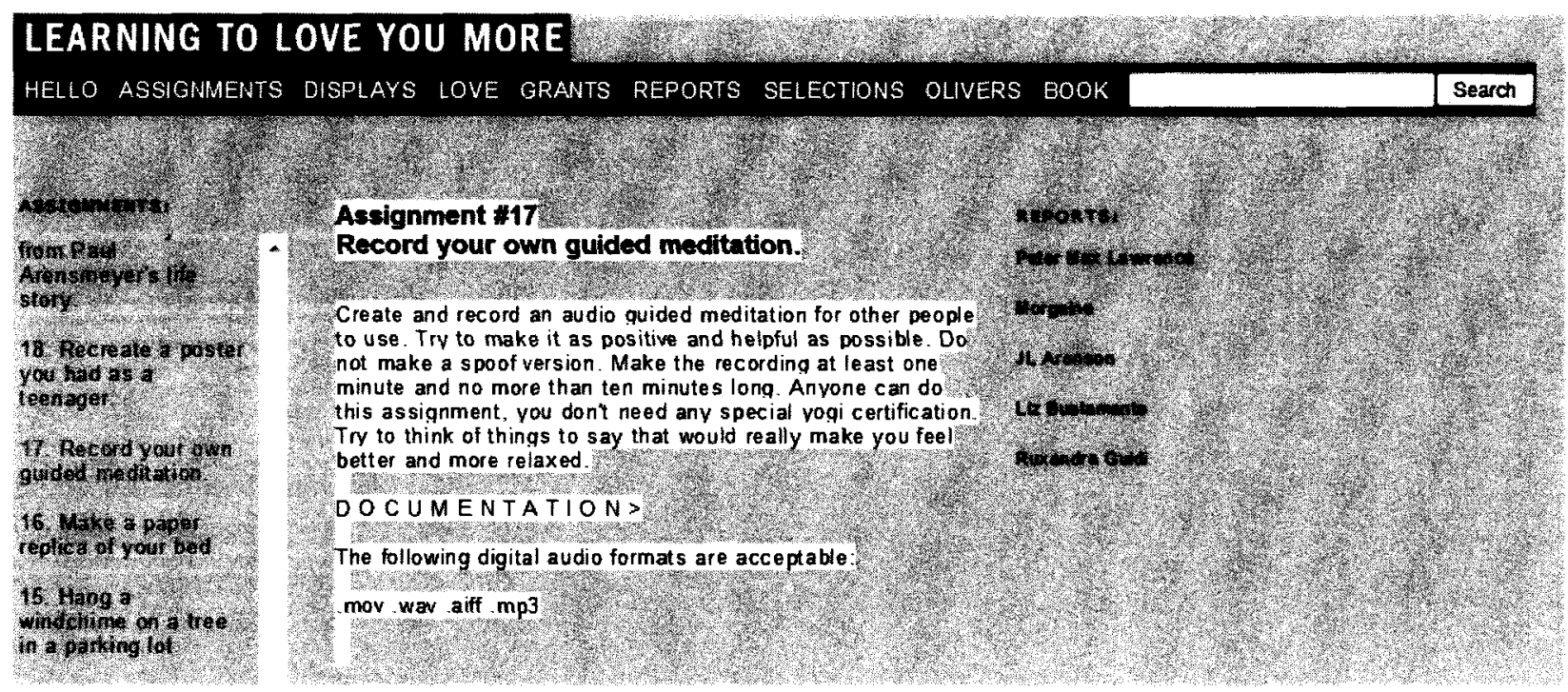

Screenshot. Instructions for Assignment 17. Learning To Love You More (web). 1 Dec. 2009. < http://www.learningtoloveyoumore.com/reports/17/17.php>. 


\section{Figure 8}

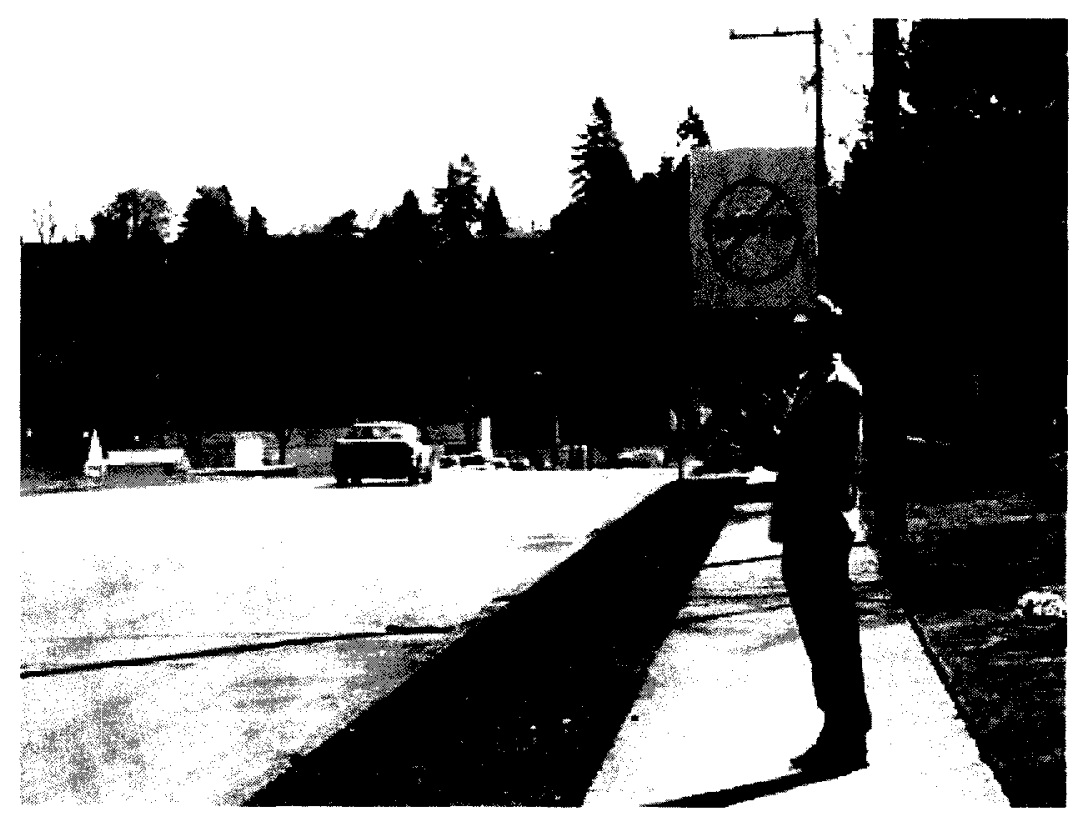

Dan Green. Protesting to stop protesting (V ancouver, Washington US A) Report for Assignment 34, Learning To Love You More (web). 1 Dec. 2009. <

http://www.learningtoloveyoumore.com/reports/34/green_dan.php $>$.

\section{Instructions}

Assignment \#34

Make a protest sign and protest.

\section{REPORTS}

Make a protest sign and publicly protest something that you deeply and sincerely feel needs to be changed. It could be the mistreatment of chickens at KFC or the lack of rights for children in our society. You can protest alone, with a group that you assemble or with a pre-existing protest group.

\section{DOCUMENTATION}

Have a picture taken of you with your protest sign while you are publicly protesting. Write a title that describes what and where you are protesting, for example "Protesting the mistreatment of chickens in front of the KFC in NE Portland, OR." 


\section{Figure 9}

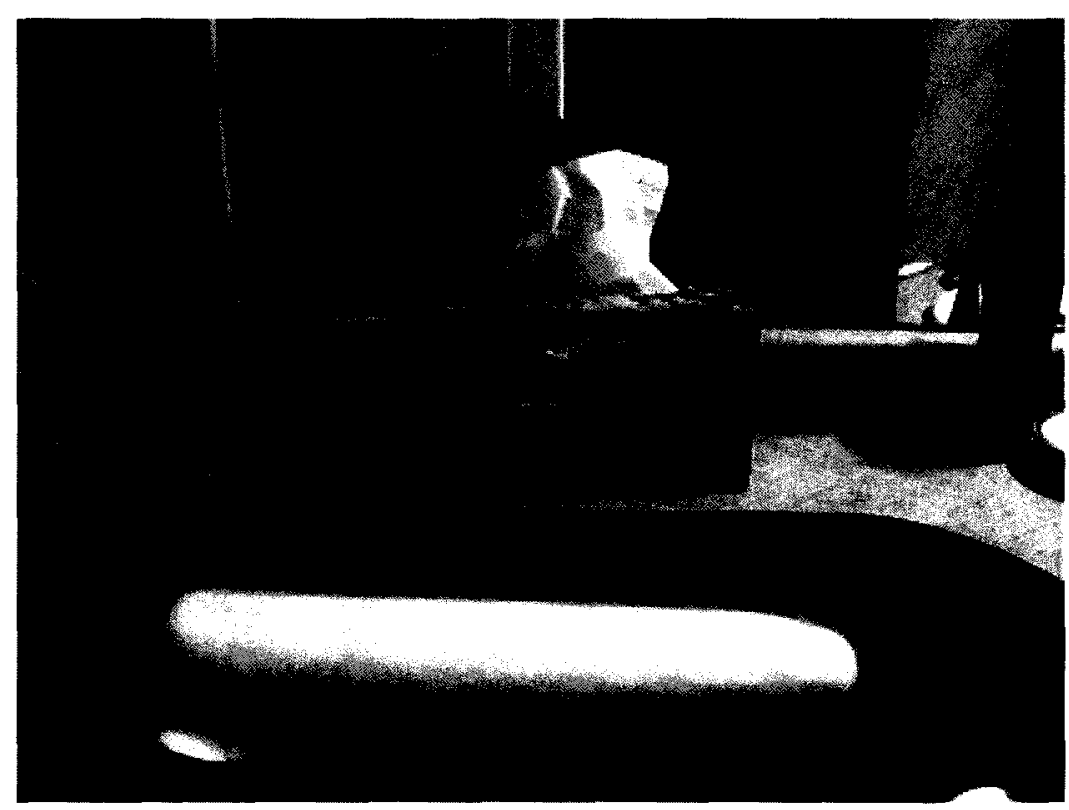

R.P. Frampton. Cut a bole into an object (North Delta, British Columbia CANADA) Report for Assignment 44, Learning To Love You More (web). 1 Dec. 2009. < http://www.learningtoloveyoumore.com/reports/44/frampton.php>.

\section{Instructions by R.P. Frampton}

Cut a hole in an everyday, functional object so that as people use it they can see how it works.

Take any object that people use and has some moving parts. Cut a hole in the side of it being careful not to ruin it. Put it back where it belongs so that your friends, visitors or passers-by can use it and see its internal workings. The object can be as simple or complex as you like but it should be something that we take for granted. Note: many objects are covered to keep dust out. You may want to take that into consideration before cutting open your DVD player but don't let it discourage you. There are solutions for everything. 


\section{Figure 10}

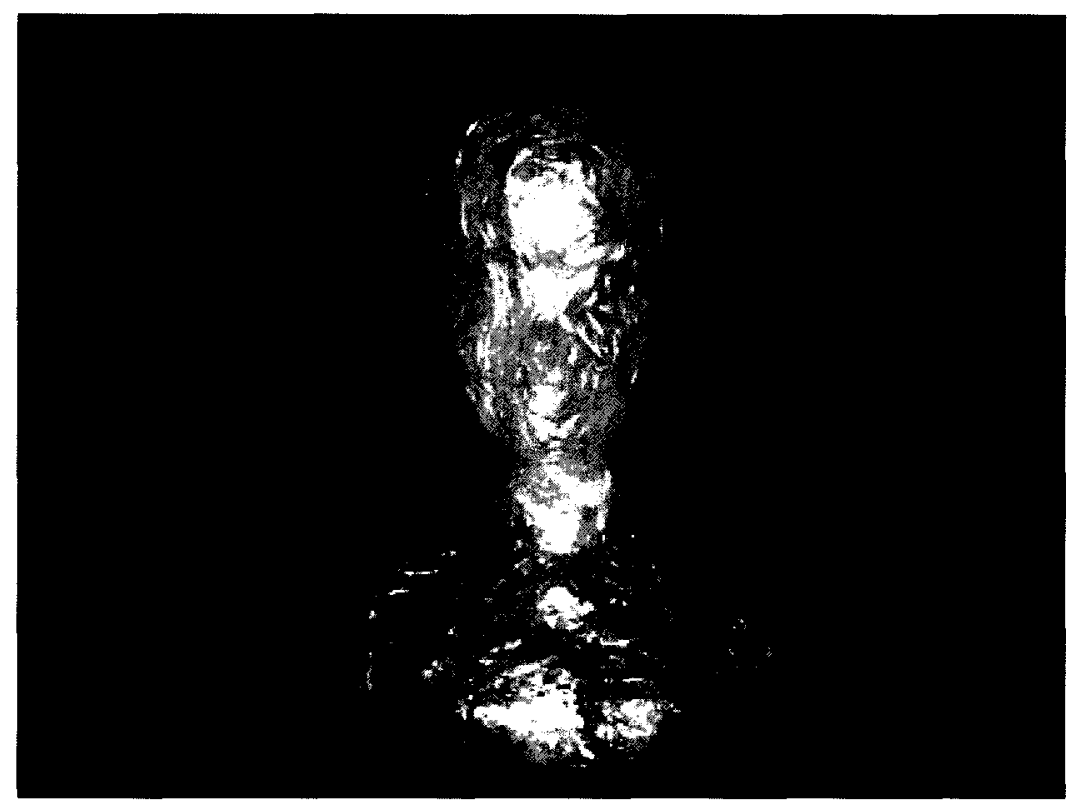

Mark Glasgow. Claire's hairdressing doll that she cut all of the hair off of (Donaghadee, IRELAND) Report for Assignment 5, Learning To Love You More (web). 1 Dec. 2009. < http://www.learningtoloveyoumore.com/reports/5/glasgow_mark.php>.

\section{Instructions}

Find someone that you don't know very well. Ask them to describe in great detail a significant object from their past. Write down the description. You can have them draw the object or you can draw it with their direction. Recreate the object three dimensionally as accurately as you can using only cardboard, paper and tape. Do not use colored paper, colored tissue paper or colored tape. Give it a title which includes the name of the person whose object you have recreated, such as "Nathaniel's Left Shoe."

Documentation: Take a picture of the object. 


\section{Figure 11}

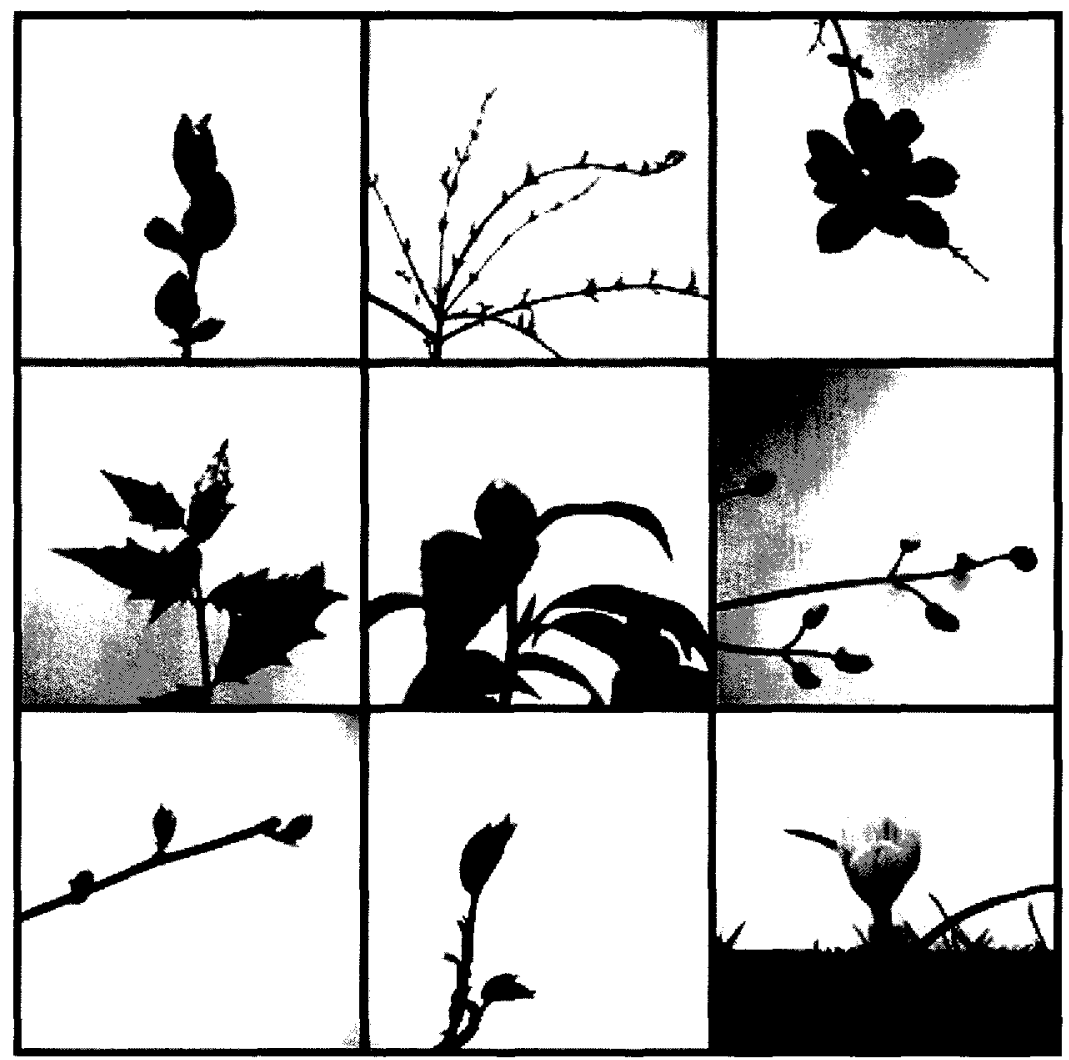

Trish Mau. Make a field guide of your yard (Vancouver, British Columbia CANADA) Report for Assignment 66, Learning To Love You More (web). 1 Dec. 2009. < http://www.learningtoloveyoumore.com/reports/66/mau_trish.php $>$.

\section{Instructions}

This assignment is for people who haven't spent much time with the land around where they live. So if you have planted a big, beautiful garden, that is terrific and you should go do another assignment. The rest of you are people who may not even really have a yard - maybe you live in an apartment and the yard is maintained by someone else, or maybe you just have a parking strip that seems to belong to the city. Maybe you live in a dorm and the "yard" is in the quad. Leave your home with a camera and big piece of white cardboard. Look around. Each time you see a new kind of living thing, put the white cardboard behind it and take a picture of it against this white background. This will be easiest if you have a friend who can hold the cardboard up. Take photographs of every single different growing thing that you see. Notice grasses, weeds, flowers, trees, insects, birds, cats, dogs. You don't have to identify what anything is, just take a photograph, as if you are a scientist on an island that no human has ever set foot on before.

Documentation: Make a series of 3-7 photographs. 
Figure 12

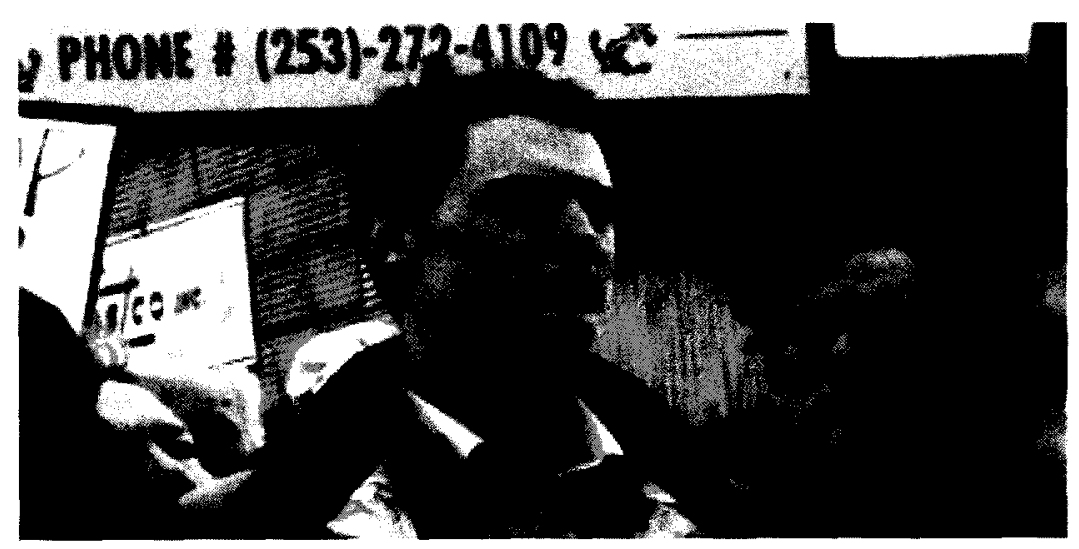

Tacoma Students for a Democratic Society. Protesting for a democratic society (Tacoma, Washington US A) Report for Assignment 34, Learning To Love You More (web). 1 Dec. 2009. < http://www.learningtoloveyoumore.com/reports/34/tacoma_students.php>. 


\section{Figure 13}

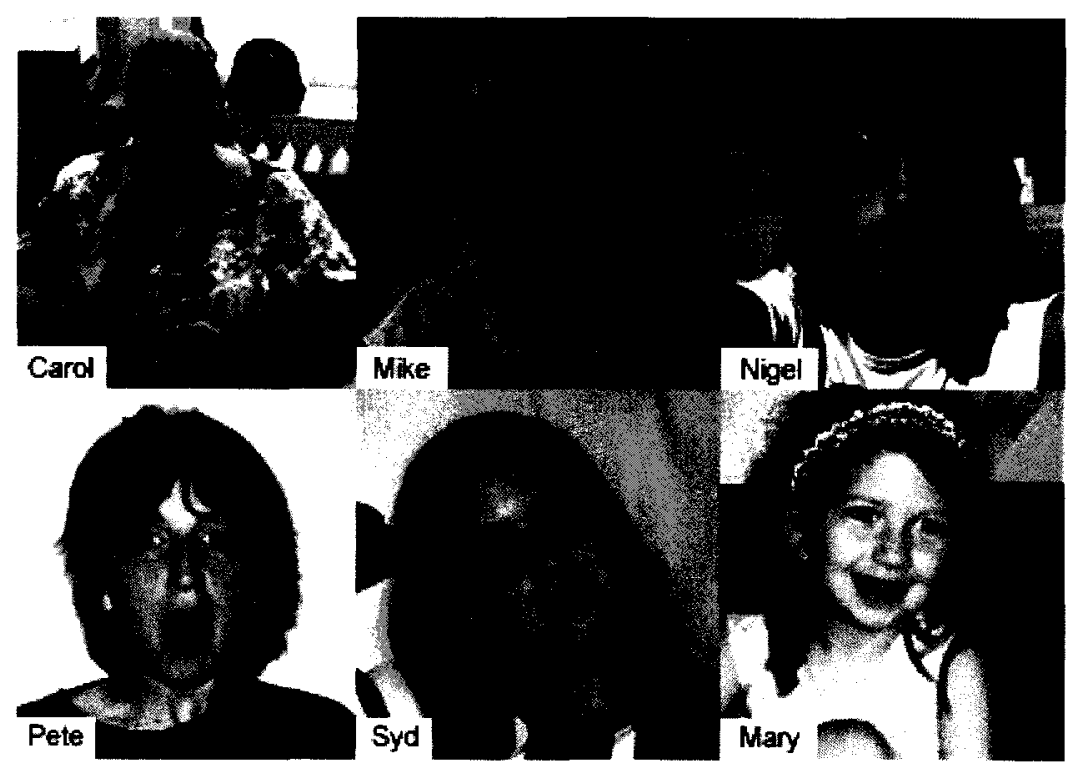

The Oliver Family. The Oliver Family Reports. Learning To Love You More (web). 1 Dec. 2009. < http://www.learningtoloveyoumore.com/oliver_family/index.php >. 


\section{Figure 14.1}

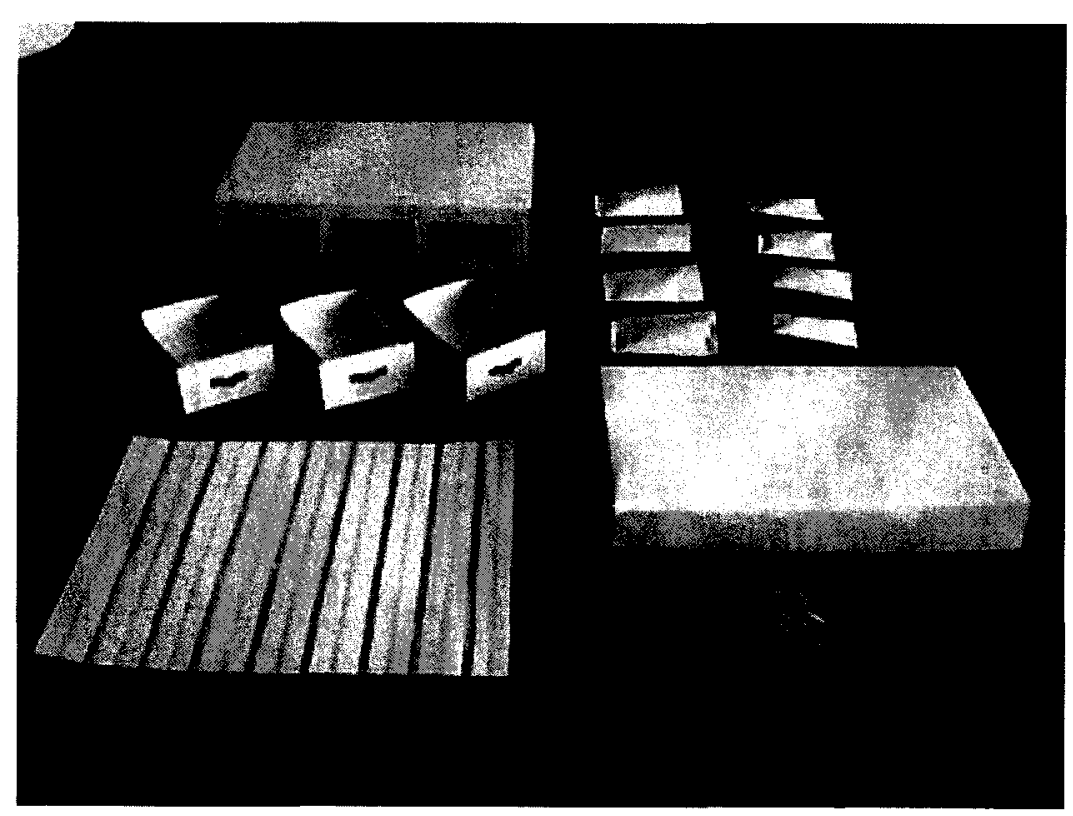

Figure 14.2

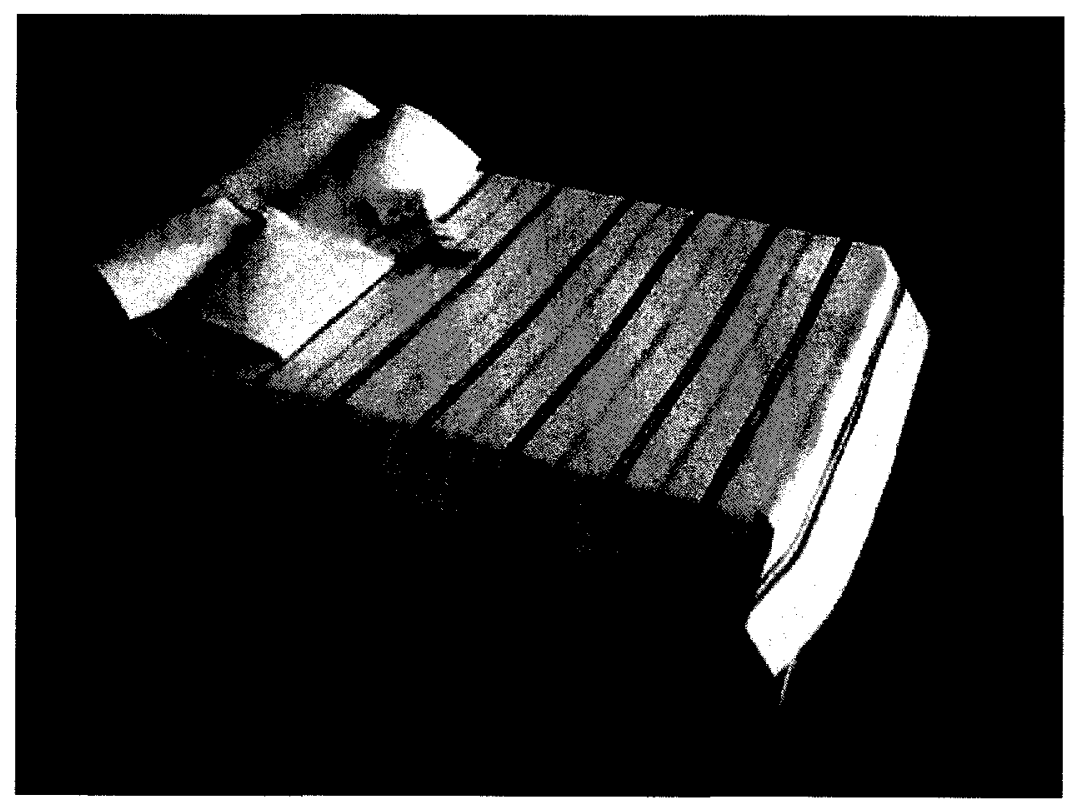

Carol Candeloro. Make a paper replica of your bed (Chicago, Illinois USA) Report for Assignment 16, Learning To Love You More (web). 1 Dec. 2009. < http://www.learningtoloveyoumore.com/reports/16/candeloro_carol.php>. 


\section{Figure 15}

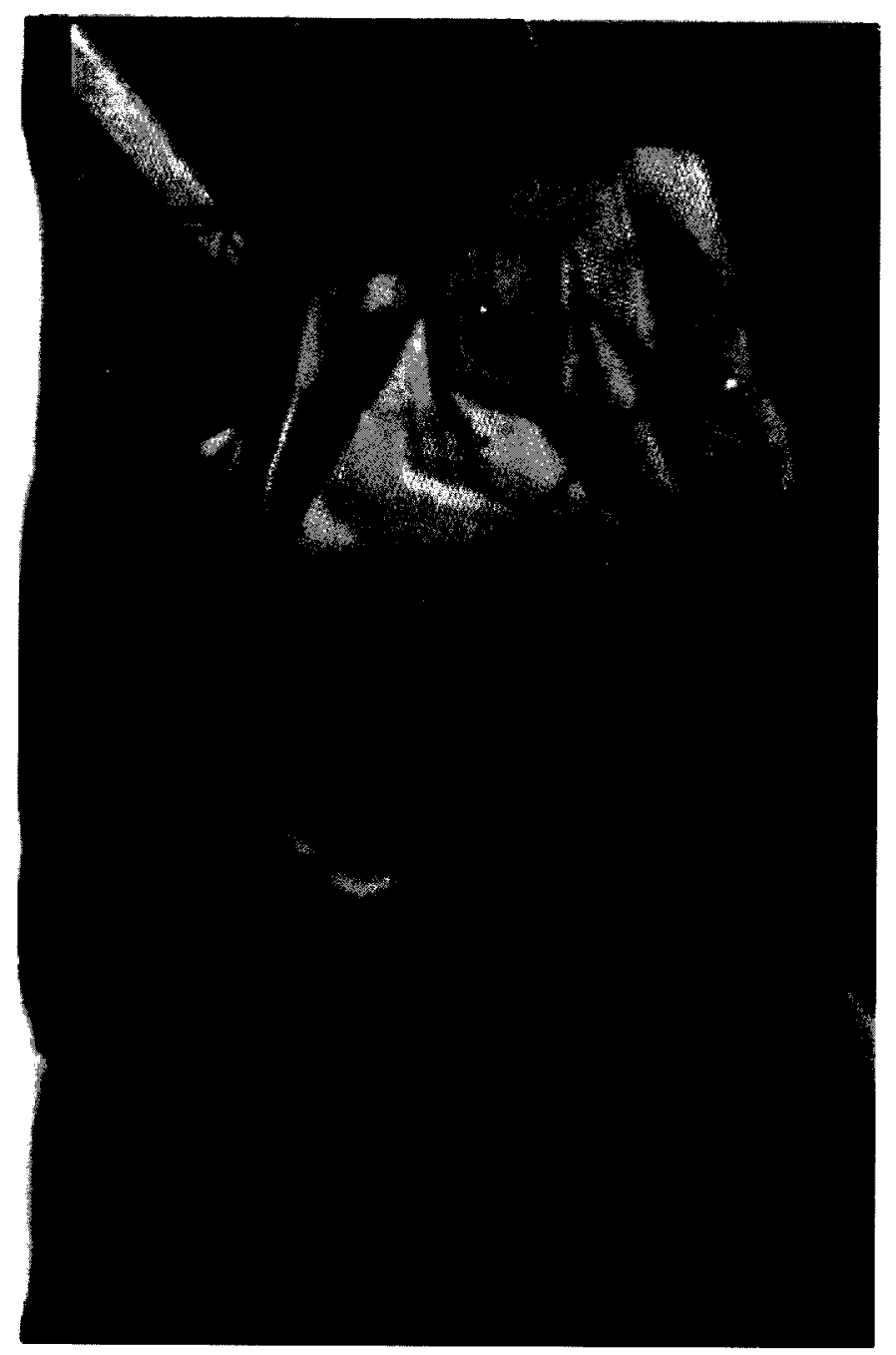

Jean Crotti or Suzanne Duchamp. Readymade Malbeureux (photograph) c. 1919 in The Complete Works of Marcel Ducbamp. Arturo Schwarz, ed. (New York: Delano Greenidge Editions, 2000), no. 367. 
Figure 16

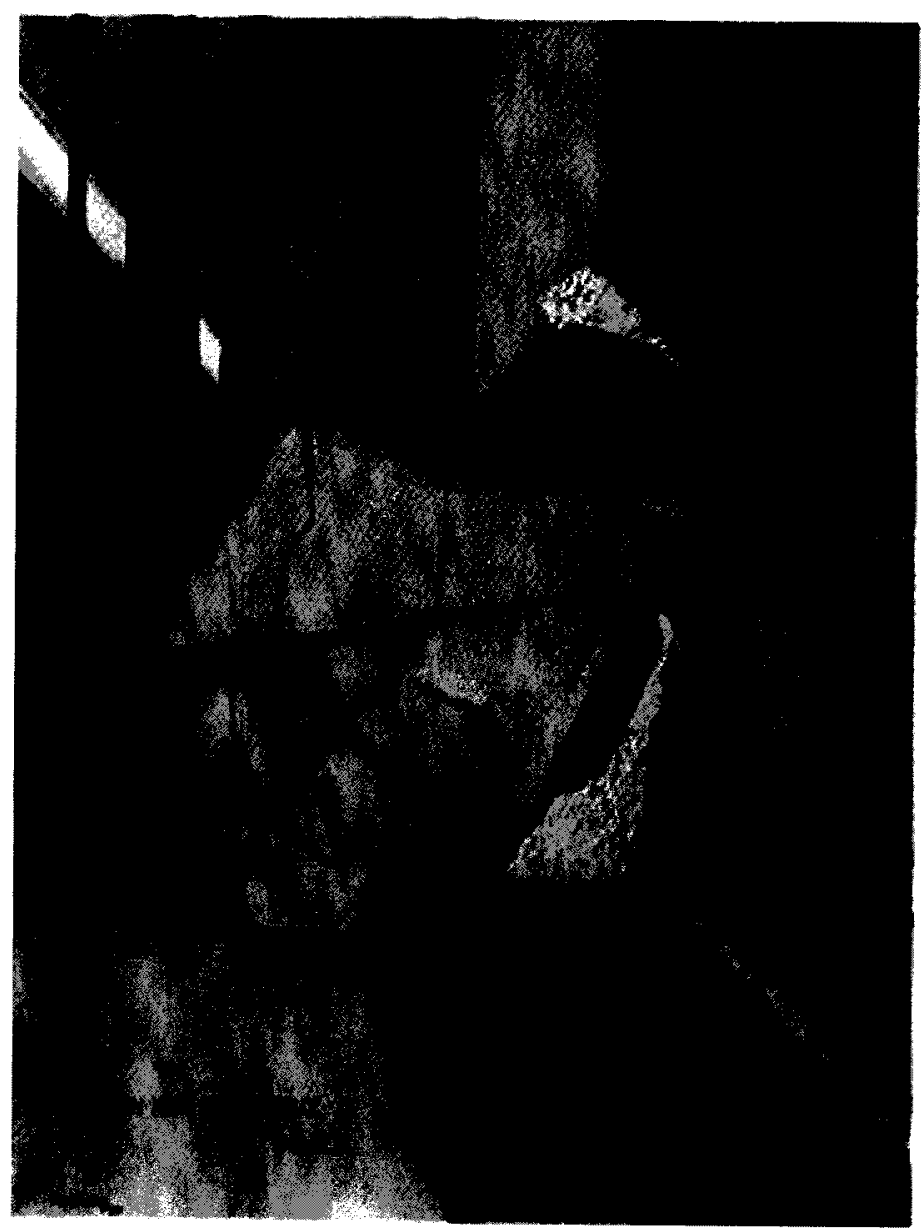

Suzanne Duchamp. Readymade Malheureux (painting) c. 1919 in The Complete Works of Marcel Duchamp. Arturo Schwarz, ed. (New York: Delano Greenidge Editions, 2000), no. 368. 
Figure 17
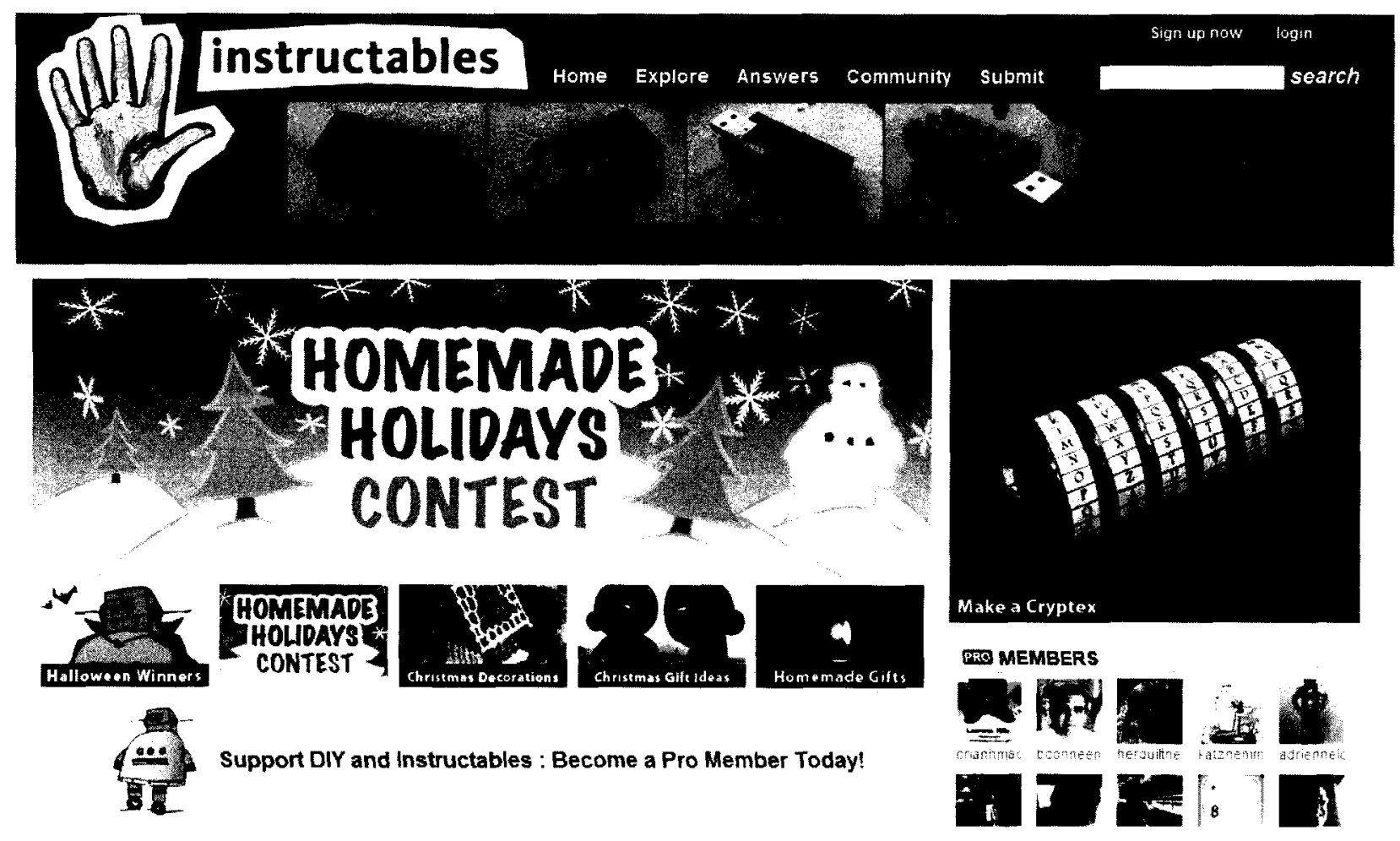

Screenshot. Homepage: Instructables.com (web). 1 Dec. 2009.

$<$ http://www.instructables.com $>$. 
Figure 18

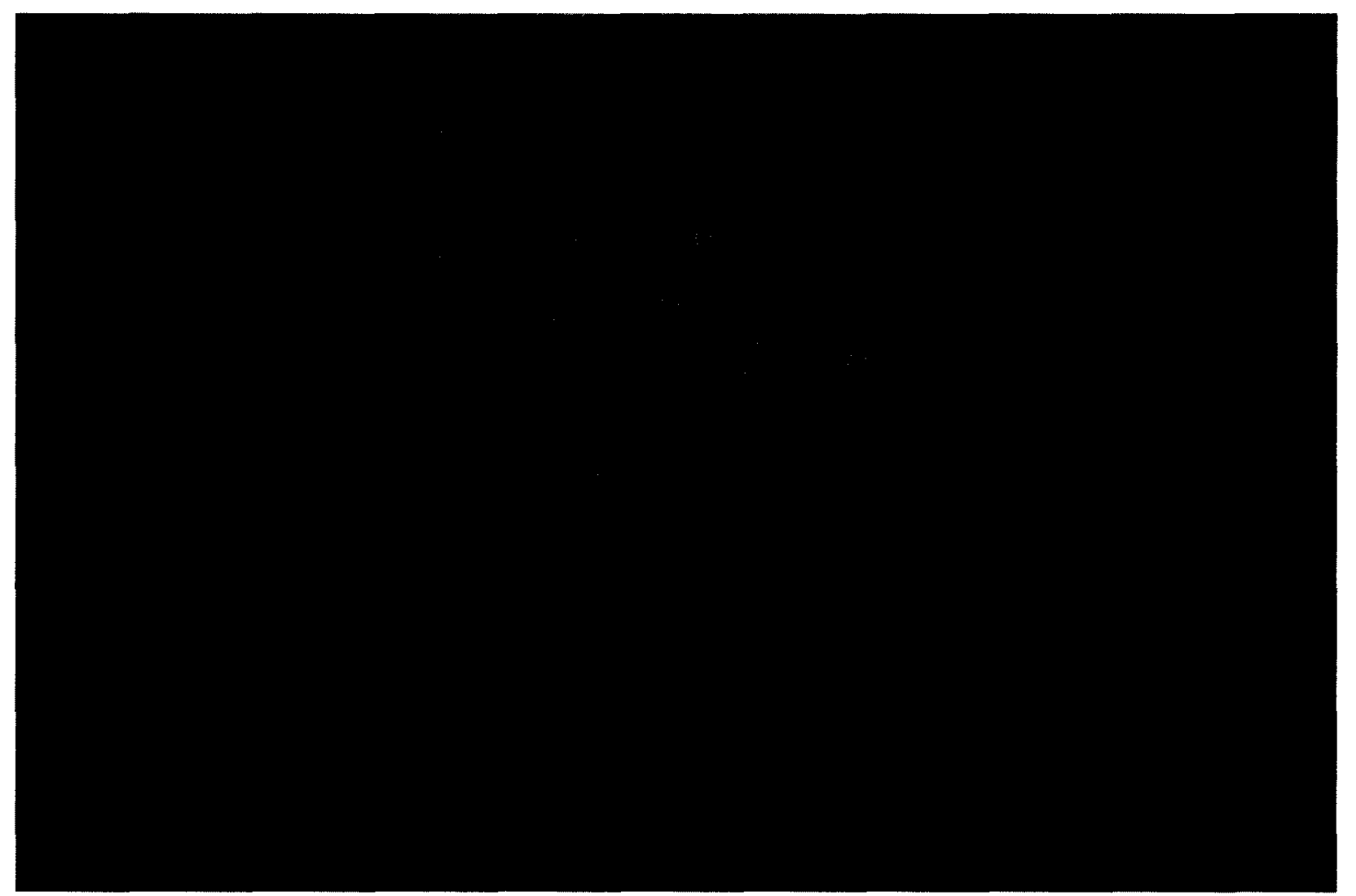

Yoko Ono. Shadow Piece (instruction painting) 1963, viewed in the $53^{\text {td }}$ Venice Biennale (Giardini Pavilion, Making Worlds / / Hacer Mundos, la Biennale di Venizia, June - November 2009), author's own photograph. 


\section{Figure 19}

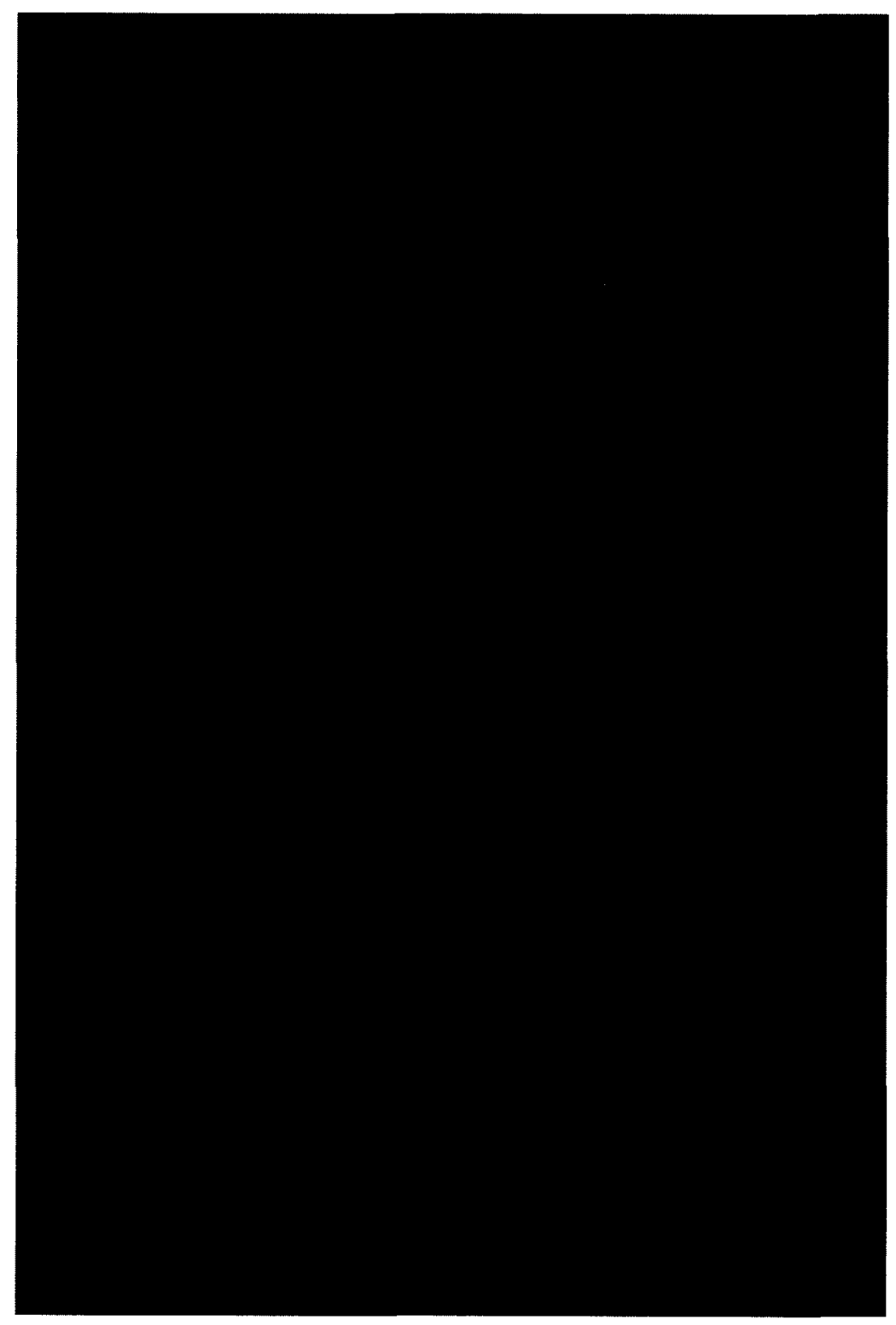

Yoko Ono. Walking Piece (instruction painting) 1963, viewed in the $53^{\text {rd }}$ Venice Biennale (Giardini Pavilion, Making Worlds // Hacer Mundos, la Biennale di Venizia, June - November 2009), author's own photograph. 
Figure 20

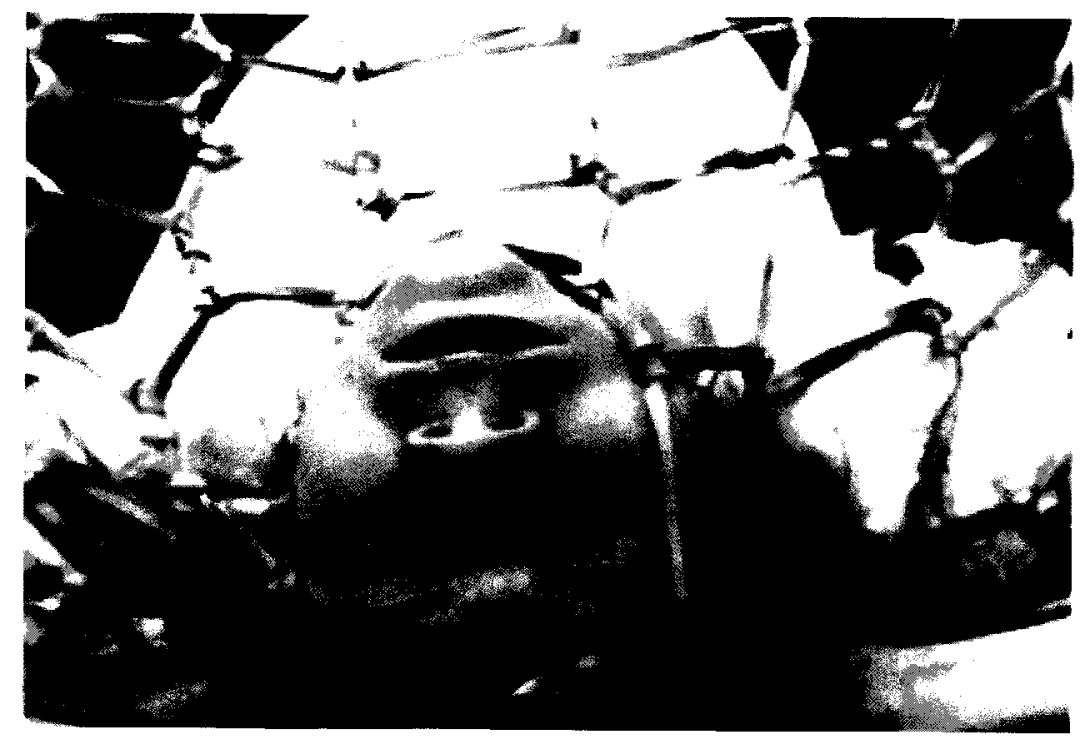

Lygia Clark. Lygia Clark using Rede de Elástico c.1973 (photograph). SFMOMA (web). 1 Dec. 2009. < http://blog.sfmoma.org/wp/wp-content/uploads/2008/11/clark2.jpg>. 
Figure 21

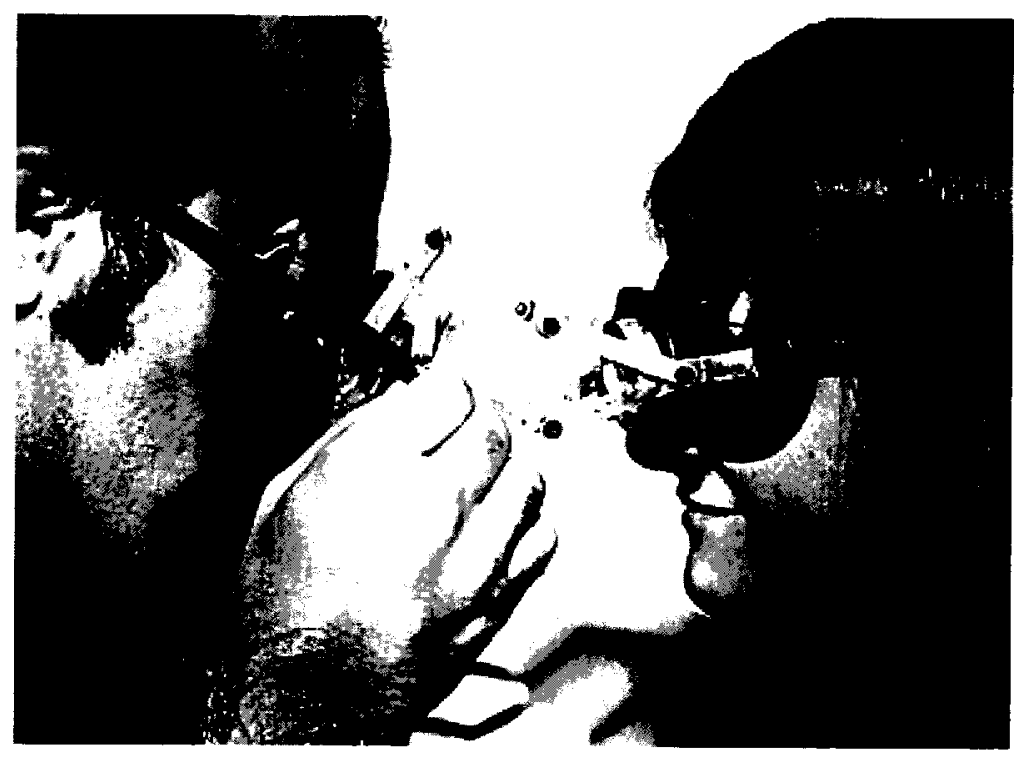

Lygia Clark. Mask with Mirrors (photograph). SFMOMA, (web). 1 Dec. 2009. < http://blog.sfmoma.org/wp/wp-content/uploads/2008/11/clark1.jpg >. 
Figure 22.1

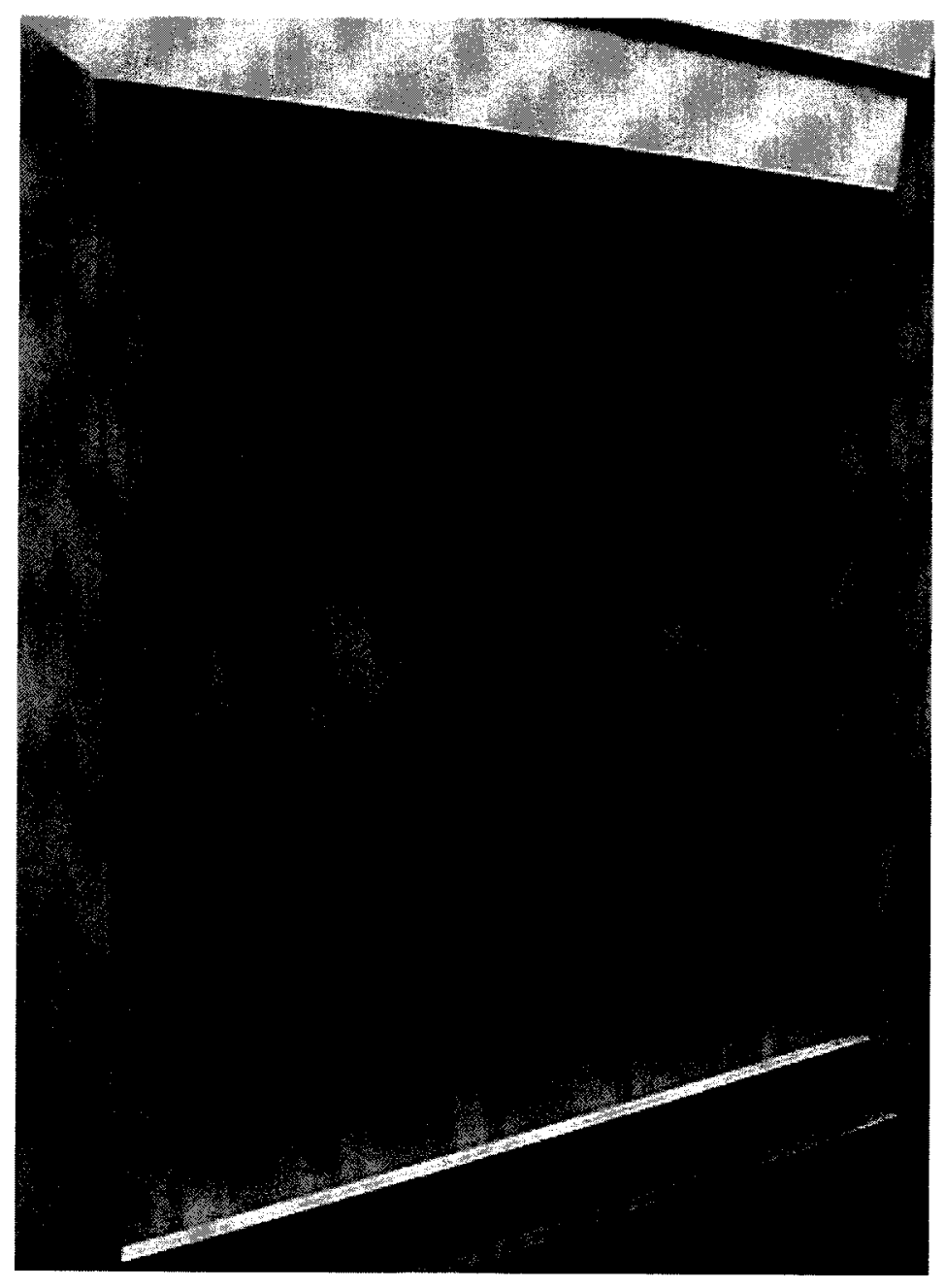

Roy Agam. Holy Light, viewed from the left (Agamograph) c. 1979. Saper Gallery, (web). 1 Dec. 2009. < http://www.sapergalleries.com/AgamHiddenImageL.jpg>. 
Figure 22.2

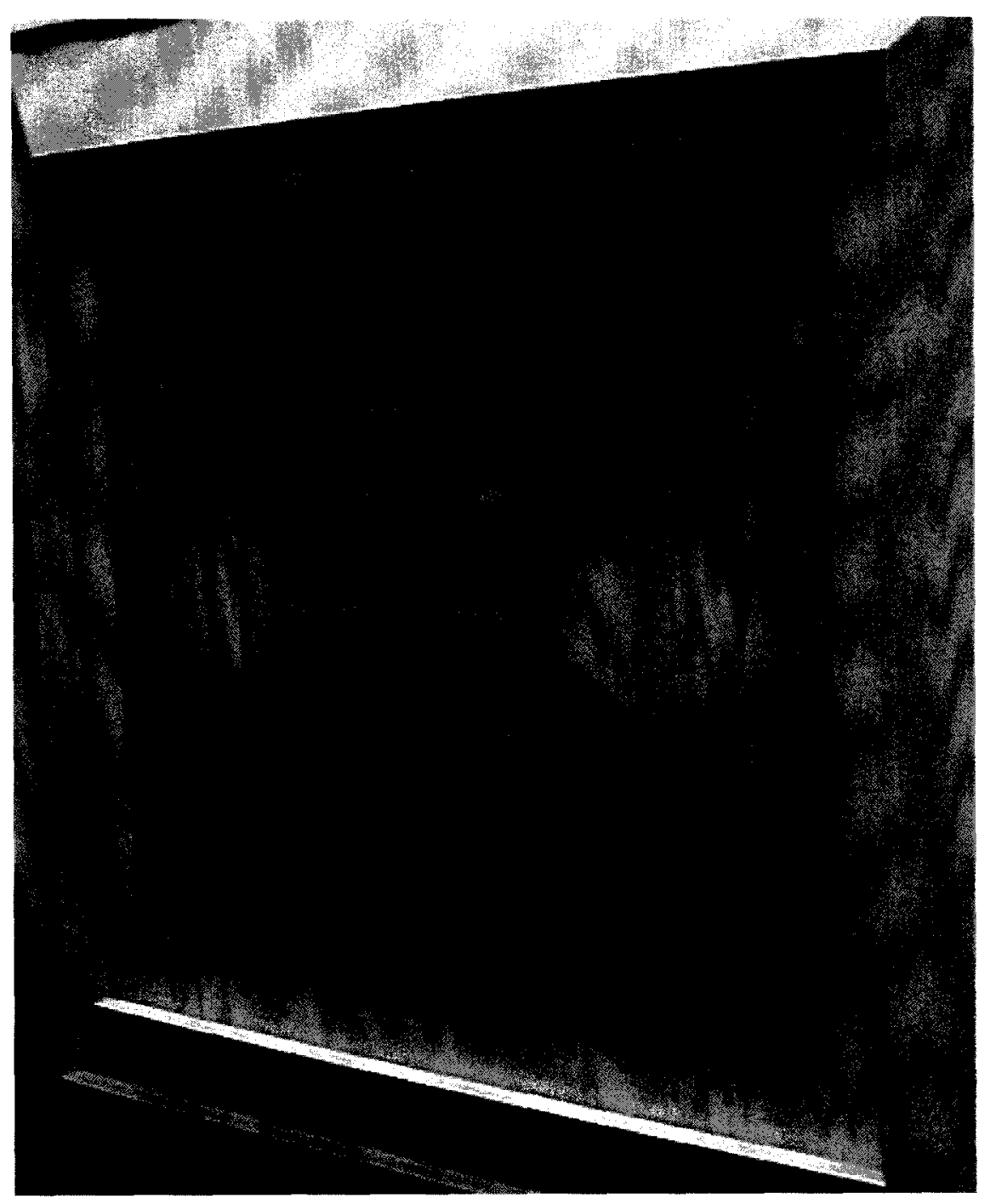

Roy Agam. Holy Light, viewed from the right (Agamograph) c. 1979. Saper Gallery, (web). 1 Dec. 2009. < http://www.sapergalleries.com/AgamHiddenImageR.jpg>. 
Figure 23

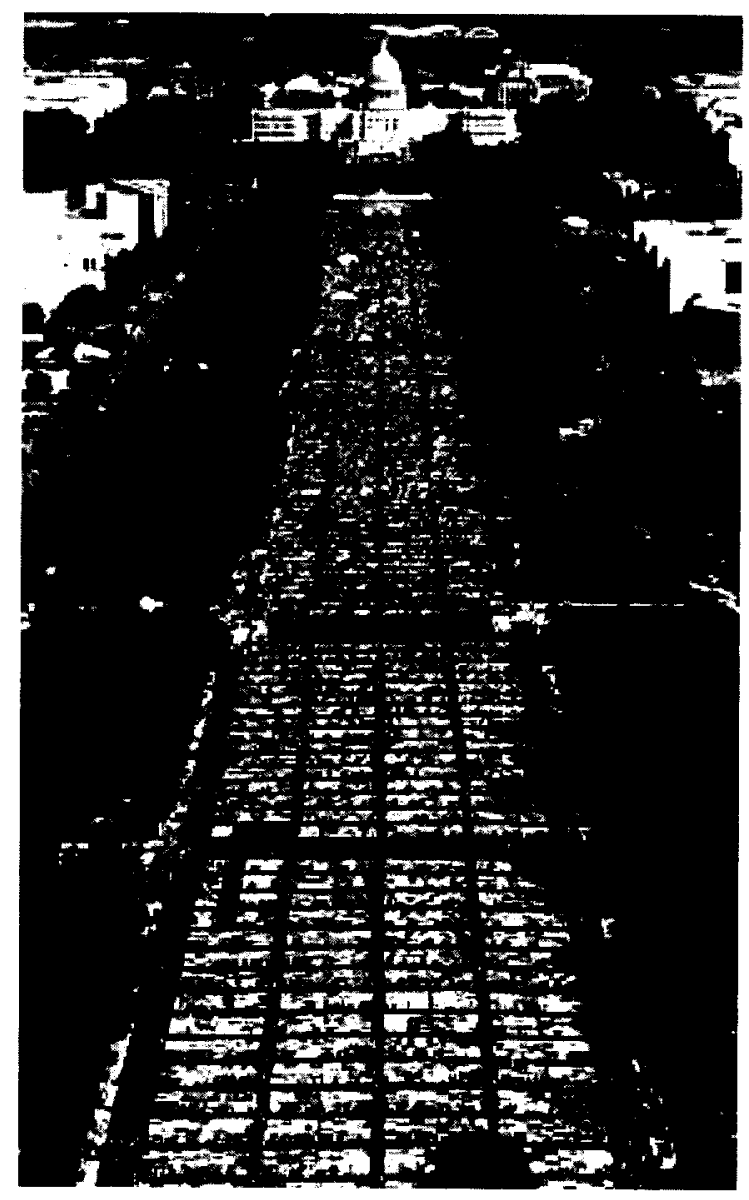

The 1996 display of the entire AIDS Memorial Quilt on the Mall in Washington, D.C. The NAMES Project Foundation. 1 Dec 2009 <http://www.aidsquilt.org/newsroom/images.htm>. 


\section{Bibliography}

Abrahams, Roger D. Everyday Life: A Poetics of Vernacular Practices. Philadelphia: University of Pennsylvania Press, 2005.

Alloway, Lawrence. Network: Art and the Complex Present. Ann Arbor: U.M.I., 1984.

Andrew, Caroline, et al. Accounting for Culture: Thinking Through Cultural Citizenship. Ottawa: University of Ottawa Press, 2005.

Arendt, Hannah. Crises of the Republic: Lying in Politics; Civil Disobedience; On Violence; Thoughts on Politics and Revolution. Fort Washington, PA: Harvest Books, 1972.

---. The Human Condition . 2nd ed. Chicago: University of Chicago Press, 1998.

Batchen, Geoffrey. "On the History of Photography: A Talk With Geoffrey Batchen" (Interview). Folio. Retrieved 23 May 2005, $<$ http://www.gc.cuny.edu/faculty/folio/fall2002/Batchen.htm>.

Barthes, Roland. Camera Lucida: Reflections on Photography. London: Flamingo, 1984.

Benjamin, Walter. The Work of Art in the Age of Its Technological Reproducibility, and Other Writings on Media. Cambridge: Belknap Press of Harvard University Press, 2008.

Benkler, Yochai. "The Wealth of Networks: How Social Production Transforms Markets and Freedom." The Wealth of Networks: Main Site.

$<$ http://www.jus.uio.no/sisu/the_wealth_of_networks.yochai_benkler/index.html.>.

Bhabha, Homi. The Location of Culture. New York: Routledge, 1994.

Bishop, Claire. "Antagonism and Relational Aesthetics". October Magazine 110, Fall 2004, pp. $51-$ 79.

Bishop, Claire. Participation. London :Cambridge, MA: Whitechapel MIT Press, 2006.

Bourriaud, Nicolas. Relational aesthetics. Collection Documents sur l'art. Dijon: Les Presses du réel, 2004.

Burnham, Jack. 'Systems Esthetics' in Antforum (September, 1968): 30 - 35.

Brunskill, R. W. Vernacular Architecture: An Illustrated Handbook. London: Faber, 2000.

Cabanne, Pierre. Dialogues With Marcel Duchamp. Cambridge, MA: Da Capo Press, 1987. 
Cabanne, Pierte. Dialogues With Marcel Duchamp. Cambridge, MA: Da Capo Press, 1987.

Certeau, Michel de. The Practice of Everyday Life. Berkeley: University of California Press, 2002.

CHArt (Organization). Computers and the History of Art. London: Mansell Publications, 1989.

Collingwood, R. G. The Principles of Art. Oxford: Clarendon Press, 1945.

d'Entreves, Maurizio Passerin. "Hannah Arendt." in the Stanford Encyclopaedia of Philosophy $<$ http://plato.stanford.edu/entries/arendt/\#WorAre>.

Dickie, George. Art and the Aesthetic: An Institutional Analysis. Ithaca: Cornell University Press, 1974.

Dissanayake, Ellen. Homo Aestheticus: Where Art Comes from and Why. Seattle: University of Washington Press, 1995.

Dutton, Denis. The Art Instinct. New York: Bloomsbury US, 2008.

Eco, Umberto. The Open Work. Cambridge: Harvard University Press, 1989.

Esche, Charles. Art and Social Change: A Critical Reader. London: Tate, 2008.

Fine, Gary Alan. Everyday Genius: Self-Taught Art and the Culture of Authenticity. Chicago: Chicago University Press, 2004.

Finkelpearl, Tom. Dialogues in Public Art. Cambridge, MA: MIT Press, 2001.

Fischer, Hervé. Digital Shock: Confronting the New Reality. Montreal: McGill-Queen's University Press, 2006.

Fletcher, Harrell, and Miranda July. Learning to Love You More. New York: Prestel Publishing, 2007.

Fletcher, Harrell, and Miranda July. Learning to Love You More. 2002-2009.

$<\mathrm{http}: / /$ www.learningtoloveyoumore.com $>$.

Foster, Hal. The Anti-aesthetic : Essays on Postmodern Culture. Port Townsend, Wash: Bay Press, 1983.

Frieling, Rudolf, Boris Grous, Robert Atkins, Lev Manovich, and San Francisco Museum of Modern Art. The Art of Participation, 1950 to Now. New York: Thames \& Hudson, 2008.

Greene, Rachel. Internet Art. New York: Thames and Hudson, 2004.

Gere, Charlie. 'Jack Burnham and the Work of Art in the Age of Real Time Systems', in Get Real. Morten Sondergaard ed. Roskilde: Informations Forlag \& The Museum of Contemporary Art in Roskilde, 2005. 
Hanisch, Carol. Frankly Feminist: A Collection of Writings From the "Hudson Valley Woman" 1991-1995. New York: TruthTeller, 1997.

Hanisch, Carol. "The Personal Is Political: the original feminist theory paper". March 1969. $<$ http://carolhanisch.org/CHwritings/PIP.html>

Heidegger, Martin. The Question Concerning Technology, and Other Essays. New York: Harper Perennial, 1982.

Higgins, Dick. Modernism Since Postmodernism: Essays on Intermedia. San Diego: Fiction Intl, 1997.

Rheingold, Howard. Way new collaboration. TED lecture, February 2008, $<$ http://www.ted.com/index.php/talks/view/id/216>.

Instructables.com. "Instructables - Make, How To, and DIY." < http://www.instructables.com>.

Ivey, Bill, and Stephen Tepper. Engaging Art: The Next Great Transformation of America's Cultural Life. New York: Routledge, 2007.

Jia, Weijia, and Wanlei Zhou. Distributed network systems. New York: Springer, 2005.

Kester, Grant H. Conversation Pieces: Community and Communication in Modern Art. Berkeley: University of California Press, 2004.

Klee, Paul. On Modern Art. Paul Findlay, trans. New York: Faber and Faber, 1966.

Kirkpatrick, Graeme. Critical Technology: A Social Theory of Personal Computing. Aldershot, Hants, England: Ashgate, 2004.

Krauss, Rosalind. L'Amour Fou: Photograpby \& Surrealism. New York: Aberville Press, 1985.

Krysa, Joasia, ed. Curating Immateriality: The Work of the Curator in the Age of Network Systems. Williamsburg, Brooklyn: Autonomedia, 2006.

Library and Archives. Proposals from Halifax (catalogue). National Gallery of Canada (Ottawa, 2000).

Lovink, Geert. Zero Comments: Blogging and Critical Internet Culture. New York: Routledge, 2007.

Lunenfeld, Peter. The Digital Dialectic: New Essays on New Media. Cambridge, MA: MIT Press, 2000.

Marioni, Tom. Beer, Art and Philosophy: The Act of Drinking Beer with Friends Is the Highest Form of Art, a memoir. San Francisco: Crown Point Press, 2003.

May, Christopher, ed. Key Thinkers for the Information Society. London: Routledge, 2003. 
McCollum, Alan. "Harrell Fletcher: Where I Lived, and What I Lived For" (interview). Domaine de Kerguéhennec, Centre d'art contemporain (Bignan, France, 2009)

<http://homepage.mac.com/allanmcnyc/harrellfletcher/mccollum_interview.html $>$.

McLuhan, Marshall. Understanding Media: The Extensions of Man. Cambridge, MA: The MIT Press, 1994.

Mieszkowski, Katharine. "The Friendster of photo sites". Salon.com, 2004 <http://dir.salon.com/tech/feature/2004/12/20/flickr/index.html>.

Mitchell, William J. The Reconfigured Eye: Visual Truth in the Post-Photographic Era. Cambridge, MA: MIT Press, 1992.

Morgan, Robert C., and School of Visual Arts (New York, N.Y.). The End of the Art World. New York: Allworth Press, 1998.

National Gallery of Canada. Caught in the Act: The Viewer as Performer. Ottawa: National Gallery of Canada, 2008.

Nelson, Dustin Luke. "InDigest InDialogue: Yuri Ono" (web interview). $<\mathrm{http}: / /$ www.indigestmag.com/ono1.htm $>$.

Nichols, Bill "The Work of Culture in the Age of Cybernetic Systems" in The New Media Reader. Noah Wardrip-Fruin \& Nik Montfort, eds. Cambridge, MA: MIT Press, 2003.

Obrist, Hans Ulrich and Bruce Altshuler. Do It. New York: Independent Curators, 1998.

Ono, Yoko. Grapefruit: A Book of Instructions. Reprint. New York: Simon and Schuster, 1970.

Ono, Yoko. "To the Wesleyan people" (lecture transcript). Wesleyan University, Connecticut, 1966. $<$ http://imaginepeace.com/news/archives/2526>.

Papandrea, Mary-Rose. "Citizen Journalism and the Reporter's Privilege". Boston College Law School Faculty Papers. <http://lsr.nellco.org/bc/bclsfp/papers/167/>.

Packer, Randall. Multimedia. New York: Norton, 2002.

Popper, Frank. Art, Action and Participation. London: Studio Vista, 1975.

Purves, Ted. What We Want Is Free: Generosity and Exchange in Recent Art. New York: State University of New York Press, 2004.

Sanchez, Osvaldo and George Yudice. Discerning the Heuristic Dimension of Public Art. University of Minnesota (Minesota, 1999). 1 Dec 2009 
$<$ http://artandcommitment.umn.edu/yudicesanchez.html $>$.

Schwarz, Arturo. The Complete Works of Marcel Duchamp. New York: Delano Greenidge Editions, 2000.

Sekula, Allan. Photograpby Against the Grain: Essays and Photo Works 1973-1983. Halifax, N.S: Press of the Nova Scotia College of Art and Design, 1984.

Shanken, Edward. Telematic Connections Timeline.

$<$ http://telematic.walkerart.org/timeline/timeline_shanken.html $>$.

Shanken, Edward. The House That Jack Built: Jack Burnbam's Concept of "Software" as a Metaphor for Art. Durham, NC: Duke University, 1998. < http://www.artexetra.com/House.html>.

Shirky, Clay. Here Comes Everybody: The Power of Organizing Witbout Organizations. New York: Penguin Press, 2008.

Siegel, Lee. Against the Machine: Being Human in the Age of the Electronic Mob. New York: Spiegel \& Grau, 2008.

"Specific Object: Live in Your Head: When Attitudes Become Form: Works, Concepts, Processes, Situations, Information" (pamphlet reprint).

$<$ http://www.specificobject.com/objects/info.cfm?inventory_id=11107>.

Stimson, Blake, and Gregory Sholette. Collectivism after Modernism: The Art of Social Imagination after 1945. Minneapolis: University of Minnesota Press, 2007.

Summers, David. Real Spaces: World Art History and the Rise of Western Modernism. Phaidon Press, 2003.

Sutton, Damian, Susan Brind, and Ray McKenzie. The State of the Real: Aesthetics in the Digital Age. New York: I. B. Tauris, 2007.

Wagner, Richard. The Art-Work of the Future. Reprint. Gloucestershire, UK: Dodo Press, 2008.

Weinberger, David. Small Pieces Loosely Joined: A Unified Theory of the Web. Cambridge, MA: Perseus, 2002. 